[Aus der Kgl. Universitäts-Augenklinik in Kiel. (Direktor: Prof. L. Heine.)]

\title{
Der Reflexcharakter der Adaptationsvorgänge, insbesondere der Dunkeladaptation, nnd deren Beziehungen zur topischen Diagnose und zur Hemeralopie.
}

\author{
Von \\ Dr. Carl Behr, \\ wissenschaftlichem Assistenten.
}

Mit Taf. VIII und IX, $1-4$ und 11 Figuren und 2 Kurven im Text.

Die Frage der Anpassungsfähigkeit der Netzhaut an grössere Intensitätsschwankungen des auf sie einwirkenden Reizlichtes ist neuerdings wieder häufiger Gegenstand physiologischer und auch klinischer Untersuchungen geworden.

Insbesondere sind in den letzten Jahren durch die grundlegenden Arbeiten Pipers vermittels einer neuen einwandsfreien Methode die physiologischen Verhältnisse der Empfindlichkeitszunahme der Augen während eines Dunkelaufenthaltes bedeutend klarer geworden. Mit dieser neuen Methode sind dann von klinischer Seite (Heinrichsdorff, Lohmann, Horn und in einer soeben erschienenen Arbeit von Stargardt) zahlreiche Untersuchungen an pathologischen Fällen angestellt, welche wertrolle neue Einzeltatsachen zutage gefördert haben, auffallenderweise aber unsere Vorstellungen über das Wesen der Adaptation im allgemeinen und über die Störungen derselben, über die Hemeralopie, im besonderen wohl kaum haben erweitern können.

Dieser bemerkenswerte Unterschied in der theoretischen Ausbeute der physiologischen und der klinischen Untersuchungsresultate über das Dämmerungssehen liegt meines Erachtens darin begründet, dass die klinischen Untersucher vorzugsweise Krankheiten der Netzhaut und der Aderhaut bearbeitet haben. Naturgemäss leiden in derartigen Fällen aber, im allgemeinen wenigstens, auch sämtliche andern visuellen F.unktionen des Auges. Nur unter besonderen Verhältnissen dürfte daher eine theoretische Verwertung der auf diese Weise gewonnenen Befunde möglich sein, insbesondere wenn man von dem 
Standpunkt der Duplizitätstheorie aus zwei voneinander scharf getrennte nervöse Sehapparate in der Retina annimmt und das "Dämmerungssehen" als eine isolierte Funktion des Stäbchenapparates ansieht.

Wollen wir uns Klarheit verschaffen über die Störungen des Dämmerungssehens an sich und ihre theoretische Bedentung, so diurfen wir daher nur jene pathologischen Fälle verwerten, in welchen die Funktionen des Zapfenapparates (Sehschärfe, Gesichtsfeld, Farbensinn usw.) normal sind, oder in denen sich umgekehrt bei normalem Därnmerungssehen eine Störung dieser andern Funktionen vorfindet. Bei rein retinalen bzw. chorioidealen Prozessen werden aber derartige Verhältnisse nur in sehr seltenen Fullen zu erwarten sein.

Eine gewisse Begrïndung für die Bevorzugung dieser retinalen Erkrankungen durch die genannten Autoren scheint mir darin zu liegen, dass der Vorgang der Adaptation und insbesondere gerade der Dunkeladaptation von physiologischer Seite in wesentlichen als ein retinaler Prozess angesehen wird, und dass eine Abhängigkeit von irgendwelchen höheren nervösen Zentren noch in keiner Weise klargestellt ist. So spricht z. B. Piper, ",on der wohl begründeten Annahme, dass die Einpfindlichkeitszunahme bei Dunkelaufenthalt sich im Endorgane selbst, also vermutlich in der Netzhant abspielt". Das Dämmerungssehen bzw. die Dunkeladaptation ist nun aber nicht allein von den Stäbchen selbst, sondern in höherem Grade noch von der Neubildung, bzw. dem Wiederersatz des Sehpurpurs abhäıgig, welcher in den Aussengliedern der Stäbchen, wahrscheinlich durch Vermittlung des Pigmentepithels vor sich geht. Diese sekretorische Tätigkeit in der Art einer Drüsenfunltion würde ohne sine ganz bestimmte Abhängigkeit von einem regulierendeu nervösen Zentrum nur schwer ein Analogon im Körper finden, insofern als - ich darf wohl sagen - ausnahmslos die sekretorischen Funktionen von einem solchen Zentrum im Gehirn bzw. Rückenmark oder vorn Sympathicus aus geleitet werden. Durch meine Untersuchungen hoffe ich nachweisen zu können, dass auch das Dämmerungssehen bzw. die Dunkeladaptation und damit wohl auch die Regeneration des Sehpurpurs unter einem regulierenden Einfluss eines höheren nervösen Zentrums steht.

Unsere Untersuchungen, und die sich aus ihnen ergebenden Folgerungen, stehen ganz auf dem Boden der Duplizitätstheorie, welche, wie schon erwähnt, eimen farbentiichtigen, auf Reize stärkerer Intensität anklingenden, in dem Zapfensystem lokalisierten, und einen zweiten farbenblinden, auf minimale 
Reflexcharakter d. Adaptationsworgänge, insbes. d. Dunkeladaptation usw. 203

Reize reagierenden, im Stäbchensystem lokalisierten visuellen Apparat annimmt. Die Tätigkeit des letzteren ist an den jeweiligen Gehalt an Sehpurpur gebunden.

Alle bekannten Tatsachen sind durch diese Theorie ungezwungen zu erklären. Finige neuere Untersuchungen haben weitere gewichtige Stützen für sie gefunden: Ein lichtschwaches Spektrum wird im Dunkeln farblos gesehen, steigert man dessen Helligkeit, so treten die Farben nach einem von der Dauer des vorhergegangenen Dunkelaufenthaltes abhängigen ,farblosen Intervall" über die Schwelle. Bei reiner fovealer Reizung (Zapfen!) treten die Farben sofort in ihrer vollen Sättigung vor das optische Bewusstsein (v. Kries), während sich in der Peripherie die Sättigung der Farbe langsam entsprechend der Zunahme ihrer absoluten Helligkeit aus dem farblosen Intervall entwickelt (Loeser). Durch v. Kries ist weiter festgestellt, dass die ausschliesslich aus Zapfen bestehende Fovea centralis für die beim Dämmerungssehen wirksamen minimalen Lichtreize völlig unempfindlich ist. Durch Boll und besonders durch Kühne wurde nachgewiesen, dass der in den Stäbchen isolierte Sehpurpur sich im Dunkeln anhäufe und durch Lichteinwirkung wieder zersetzt. Die Schnelligkeit und Intensität der Zersetzung wurde von ihnen abhängig von der Wellenlänge des einzelnen monochromatischen Lichtes gefunden. Neuerdings hat dieses Trendelenburg durch exakte, zahlenmässig zu verwertende Untersuchungen bestätigt. Die von ihm gefundene Kurve der Bleichungswerte der einzelnen Wellenlängen des Spektrums für den Sehpurpur zeigt dabei eine auffallende Übereinstimmung mit der Kurve ihrer Dämmerungswerte. Das Maximum findet sich in beiden Fällen bei einer Wellenlänge von $530 \mu \mu$ (grüngelb); demgegentiber liegt das Helligkeitsmaximum beim Tagessehen bei einer Wellenlänge von $600 \mu \mu$ (gelborange). In demselben Sinne sprechen die von Abelsdorff und Köttgen angestellten Untersuchungen über die Absorptionsgrösse des Sehpurpurs je nach den verschiedenen Wellenlängen des Spektrums. Nach ihnen wird das Maximum der Absorption durch die Strahlen mittlerer Wellenlänge erzielt. Von Himstedt und $\mathrm{Nagel}$ und später von Piper sind dann weitere bemerkenswerte Untersuchungen über die Alktionsströme der Netzhaut angestellt. Aus ihnen geht ebenfalls hervor, dass bei Reizung des helladaptierten Auges mittels verschiedenwelliger Lichter die langwelligen Strahlen $(580 \mu \mu)$ das Maximum der elektrischen Erregung aufweisen, während im dunkeladaptierten Auge wieder die Strahlen mittlerer Wellenlänge $(540 \mu \mu)$ den grössten Ausschlag hervorrufen. 
Gegenüber diesen schwerwiegenden Stïtzpunkten der Duplizitätstheorie verweisen die Gegner derselben (Hering, Hess) in erster Linie darauf, dass durch sie für eine und dieselbe Empfindung (Schwarzweiss) zwei verschiedene Organe vorhanden sind, was gegen ein Grunddogma der Sinnesphysiologie verstösst, nach welchem für die gleiche Empfindung auch der gleiche Vorgang in dem entsprechenden Sinnesorgan Voraussetzung ist.

Dieser Einwand würde meiner Ansicht nach von grosser Bedeutung sein, wenn nachgewiesen werden könnte, dass die in Betracht kommende Schwarz-Weissempfindung beim Tagessehen vollkommen der Helldunkelempfindung beim Dämmerungssehen entspricht. Dieser Beweis dürfte aber schwer zu erbringen sein, da vergleichende Untersuchungen in einem und demselben Zeitpunkt am gleichen Auge wegen der spezifischen Eigenart der Empfindlichkeitsentwicklung des Dämmerungsapparates nicht gut angestellt werden können. Ferner könnte der Einwand wohl begründet sein, wenn dieselbe SchwarzWeissempfindung nachgewiesenermassen etwa abwechselnd bald durch das eine, bald durch das andere System vermittelt würde. Eine gewisse Widerlegung dieses Einwandes diirfte aber meines Erachtens schon in der Verschiedenheit des Reizmaximums beider Systeme, je nach der Wellenlänge des einwirkenden Lichtes, liegen: Denn wären beide gleichzeitig oder abwechselnd nebeneinander in Tätigkeit, so müssten notgedrungen Schwankungen im Helligkeitsverhältnis eines optischen Eindruckes eintreten, welche aber, wie die tägliche Erfahrung lehrt, nicht beobachtet werden. Durch meine Untersuchungen hoffe ich nun einwandsfrei zejgen zu können, dass eine weitgehende zeitliche Unabhängigkeit in der Funktion zwischen beiden Systemen vorhanden ist, wie es bereits durch die Verschiedenartigkeit des physiologischen Ablaufs der Empfindlichkeitszunahme wahrscheinlich gemacht wird.

Wenn wir unroreingenommen die Frage der Anpassungsfähigkeit der Netzhaut an Schwankungen der auf sie einwirkenden Lichtreize untersuchen, so werden wir von vornherein zwischen einer Stäbohen- und einer Zapfenadaptation unterscheiden müssen. Auch darin hat die Doplizitätstheorie ihre Daseinsberechtigung erwiesen, indem nur durch sie die neueren Untersuchungen Pipers, Nagels und Anderer über die Dunkeladaptation als isolierte Tätigkeit der Stäbchen angeregt wurden. Die vielfach widersprechenden Untersuchungen älterer Autoren iiber die Adaptation haben dadurch zum Teil eine Widerlegung, zum Teil aber auch erst eine richtige Erklärung gefunden. 
A ubert hat das grosse Verdienst, als erster auf die Bedeutung der Anpassungsfähigkeit des Auges an Schwankungen der auf dasselbe einwirkenden Lichtmenge hingewiesen zu haben. Von ihm stammt das Wort Adaptation als Bezeichnung ,für die Accommodation des Auges für Lichtintensitäten", der "Einrichtung für verschiedene Helligkeiten". Aus seinen Untersuchungen, welche er bei Herabsetzung der Reizintensitäten anstellte, ergab sich, dass in den ersten Minuten des Dunkelaufenthaltes die Lichtempfindlichkeit des Auges sehr schnell, dann immer langsamer zunimmt. A ubert machte seine Untersuchungen mit einem durch einen galvanischen Strom zum Gliihen gebrachten Platindraht. Eine Abstufung der Helligkeit erzielte er durch Veränderung der bei der gleichen Stromstärke zum Glühen gebrachten Drahtlänge. Je grösser die Drahtlänge war, um so geringer war die entwickelte Lichtmenge. Durch Pipers Untersuchungen hat diese Aubertsche Regel nun scheinbar eine gewaltige Modifikation erfahren, insofern als Piper gerade einen umgekehrten Verlauf der Empfindlichkeitszunahme der Netzhaut bei Dunkelaufenthalt fand. Meines Erachtens ist dieser Widerspruch nur ein scheinbarer. Er ist begründet in der Prüfung der beiden verschiedenen Systeme der Netzhaut. Die von Aubert benutzte Reizquelle war immer überschwellig für den Zapfenapparat. Seine Befunde behalten daher ihre Bedeutung für die Adaptation dieses Systems ebenso wie seine Worte "dass die Empfindlichkeit für Licht im Anfang des Aufenthaltes im Finstern sehr schnell, allmählich aber immer langsamer zunimmt". Aubert konnte noch nicht den Unterschied zwischen den beiden prinzipiell voneinander zu trennenden Netzhautfunktionen des Tages- und des Dämmerungssehens machen. Seine Befunde finden von diesem Gesichtspunkte aus auch eine volle Bestätigung durch die neueren Untersuchungen über die Adaptationsfähigkeit des Zapfenapparates von Schaefer und Nagel. Auch diese Forscher stellen sich auf den Standpunkt, dass die A ubertsche Versuchsmethode „eher die Bedingungen für foveales Zapfensehen als für das reine Stäbchensehen verwirklicht".

Durch Charpentier und Treitel wurden die Resultate der Aubertschen Untersuchungen im allgemeinen bestätigt.

Piper hat, auf dem Boden der Duplizitätstheorie stehend, mit vollkommenen Methoden bewusst das isolierte Verhalten des Stäbchenapparates während des Dunkelaufenthaltes geprïft. Seine Methode ist relativ einfach und hat ausserdem den grossen Vorzug, dass sie zahlenmässige Vergleichswerte gibt. Bei der Einleitung in unsere eigenen 
Untersuchungen muss ich noch etwas näher auf dieselbe eingehen und verweise deswegen hier darauf.

Piper fand, dass die Empfindlichkeit des Auges für minimale Lichtreize nach vorausgegangener ausgiebiger Helladaptation in den ersten zehn Minuten des Dunkelaufenthalts nur relativ wenig, dann aber plötzlich sehr erheblich etwa bis zur dreissigsten Minute ansteigt. Von diesem Zeitpunkt an wird der Anstieg wiederum ein ungemein viel langsamerer. Durch $\mathrm{Nagel}$ ist festgestellt, dass auch nach einem 24 stindigen Dunkelaufenthalt eine weitere geringere, aber deutlich nachweisbare Steigerung der Emptindlichkeit vorhanden ist. Die von Piper aufgestellte Kurve des Verlaufs der Empfindlichkeitszunahme ist von allen Nachuntersuchern bestätigt worden, auch ich habe sie bei zahlreichen Untersuchungen an normalen Augen ausnahmslos vorgefunden. Das Charakteristische der Kurve liegt in den beiden Abknickungen nack Beendigung des primären langsamen bzw. bei Beginn des rapiden Anstiegs und nach Beendigung des letzteren. Die monokulare Empfindlichkeitszunahme nach Beendigung des steilen Anstiegs der Kurve beträgt normalerweise mehr als das 100 fache des Anfangswertes. Von Piper ist dann weiter nachgewiesen, dass die Daner des ersten langsamen Teils der Empfindlichkeitszunahme direkt abhängig ist von dem Zustand, in welchem die Netzhaut vor Beginn des Dunkelaufenthaltes stand. Je weniger intensiv die rorausgegangene Helladaptation war, um so niedriger waren die ersten Schwellenwerte und um so rascher begann der plötzliche Anstieg der Empfindlichkeit.

Auf diese Weise haben wir eine klare Vorstellung ron der Adaptationsfähigkeit und des Adaptationsverlaufs der Netzhaut bzw. der Stäbchen im Dunkeln erhalten.

Durch die Untersuchungen von Nagel und Schaefer sind wir nun auch in der Lage, uns über die speziellen Verhältnisse der Adaptationsfähigkeit der Zapfen an eine Verminderung der einwirkenden Lichtreize eine Vorstellung zu machen. Wie bereits erwïhnt, decken sich ihre durch eine wesentlich einwandsfreiere Methodik gewomnenen Befunde mit der Aubertschen „Adaptationsregel". Die Zapfenempfindlichkeit steigt sofort bei Beginn des Dunkelaufenthaltes und zwar sofort verhältnismässig rasch. Die Prüfungen während der ersten 30 Sekunden des Dunkelaufenthaltes sind aus naheliegenden Gründen (Nachbilder, relativ lange Dauer der Einstellung usw.) nur sehr schwer durchzuführen. Mit der längeren Dauer des Dunkelaufenthaltes werden die Resultate genauer. Vom Ende der ersten 
halben Minute bis zur sechsten Minute wurde eine Empfindlichkeitszunahme um das 16 fache des Anfangswertes (der 30 Sekunden nach Beginn des Dunkelaufenthaltes festgestellt war) nachgewiesen, also eine mit Berücksichtigung des Ausserachtlassens der Empfindlichkeitszunahme während der ersten halben Minute, welche aller Wahrscheinlichkeit nach sehr erheblich ist, relativ bedentende Abnahme des Schwellenwertes der Zapfenerregung.

Die isolierte Untersuchung des Zapfenapparates nach der sechsten Minute lässt sich wegen des sich immer mehr geltend machenden Anstiegs der Empfindlichkeit der Stäbchen nicht mehr ganz einwandsfrei durchführen. Eine Ergänzung und Bestätigung fanden die A ubert-Nagel-Schaeferschen Befunde durch die Untersuchungen Loesers über den Einfluss der Dunkeladaptation auf die spezifische Farbenschwelle. Aus ihnen geht hervor, dass die Farbenempfindlichkeit (als isolierte Funktion des Zapfenapparates) in den ersten Sekunden des Dunkelaufenthaltes um ein beträchtliches zunimmt. Erst nach einigen Minuten leitet als Ausdruck für den Beginn der Tätigkeit des Stäbchenapparates eine farblose Lichtempfindung die richtige Farbenempfindung ein. Die Zunahme der Farbenempfindlichkeit erreicht nach 8-12 Minuten Dunkelaufenthaltes ihr Maximum, nimmt dann langsam wieder $a b$, um nach 40 Minuten in einen definitiven Zustand überzugehen. Es ist sehr zu bemerken, dass das Maximum des Empfindlichkeitsanstieges und der ihm folgende Abfall gerade in den Augenblick hineinfällt, in welchem für den Stäbchenapparat der steile Anstieg beginnt, anderseits ebenso, dass der definitive Zustand des Zapfenapparates mit der Beendigung dieses Anstieges einsetzt.

Für die Adaptation des Stäbchenapparates hat Piper noch zwei weitere Gesetze gefunden, die demselben, wie Piper annimmt, eine gewisse Sonderstellung zu geben scheinen. Von ihm ist nachgewiesen, dass die binokular festgestellte Reizschwelle für minimale Reize nach ausgiebiger Dunkeladaptation ungefähr doppelt so niedrig wie die unter gleichen Bedingungen ermittelte monokulare Reizschwelle war. Dieses von ihm „die binokulare Reizaddition" genannte Gesetz, welches den beim Tagessehen bekannten Tatsachen vollkommen zu widersprechen scheint, versuchte Lohmann dadurch zu erklären, dass er auf die Möglichkeit des Bestehens einer latenten Störung des Muskelgleichgewichtes der Augen hinwies. Bei dem Fortfall des korrigierenden Faktors des fovealen binokularen Einfachsehens könnte auf einem Auge die in bezug auf die Dunkeladaptationsfähigkeit hochwertigere parazentrale Partie zur Einstellung gelangen und 
so einen höheren binokularen Wert vortäuschen. Ich habe diese Pipersche Regel bei meinen Untersuchungen in einer etwas modifzierten Weise nachgeprüf, um den von Lohmann erhobenen Einwand ausschalten zu können. $\mathrm{Da}$ die Empfindlichkeitsunterschiede benachbarter Teile der Netzhautperipherie nach maximaler Dunkeladaptation viel geringer sind als die, welche zwischen den zentralen bzw. perizentralen und den parazentralen Partien bestehen, so habe ich an dem weiter unten noch genauer zu schilderuden, von mir benutzten Dunkeladaptationsperimeter die monokulare und binokulare Reizschwelle zweier ungefälur korrespondierender peripherer Netzhantstellen bestimmt und verglichen. Wenn ich dabei auch nicht eine Steigerung der Empfindlichkeit un das Doppelte bei binokularer gegenüber der monokularen Untersuchung feststellen konnte wie Piper, so waren die Differenzen in vielen Fällen immerhin so grosse, dass ich das Gesetz der binokularen Reizaddition bei der Dunkeladaptation im allgemeinen bestätigen kann. Der Einwurf Lohmanns dürte demnach nur für vereinzelte Ausnahmefälle Gültigkeit haben. In dem nach Abschluss dieser Arbeit erschienenen Aufsatz von Stargardt finden sich ebenfalls Beobachtungen, welche dieses Pipersche Gesetz bestätigen.

Anderseits hat Piper nachgewiesen, dass dic Reizschwelle bei der Dunkeladaptation abhängig ist von der benutaten Flächengrösse des Reizobjektes, insofern als der Reizwert eines Objektes deutlich und nicht unerheblich zu- oder abnimmt mit der Flächengrösse seines Netzhautbildes. Ganz im Gegensatz zu den dem Tagessehen dienenden Elementen der Netzhaut, welche lediglich durch Änderung der Lichtintensität, „dagegen so gut wie gar nicht durch Änderung der Flächengrösse des Objektes alteriert wird". Vom klinischen Standpunkt aus glaube ich, dass dieser letzte Satz eine gewisse Einschränkung erfahren dürfte. Unter pathologischen Verhältnissen, z. B. bei peripheren, am Optikus angreifenden Schädlichkeiten finden wir es nicht selten, dass sich das Gesichtsfeld mit zunehmender Grösse des Perimeterobjektes erweitert. In demselben Sinne zeigen die Verhältnisse der relativen Hemianopsien eine ganz bestimmte Abhängigkeit der Empfindlichkeit des Zapfenapparates von der Grösse der benutzten Untersuchungsobjekte. Nicht selten sehen wir einen absoluten Ausfall der Wahrnehmung eines kleinen Perimeterobjektes, während doppelt oder mehrfach so grosse mehr oder weniger deutlich in den betreffenden Gesichtsfeldhälften erkannt werden. Anderseits dürte auch die Abhängigkeit der Weite des normalen Farben- 
gesichtsfeldes von der Flächengrösse der benutzten Untersuchungsobjekte gegen die Pipersche Auffassung sprechen. Je grösser die Perimeterobjekte sind, um so grösser wird auch das Gesichtsfeld für Farben.

Eine vergleichende Beurteilung des Einflusses der Flächengrösse der Reizobjekte auf die Empfindlichkeit beim Zapfen- und beim Stäbchenapparat ist $\mathrm{m}$. E. schon aus dem Grunde nicht einwandsfrei, weil die benutzten Reizgrössen einen sehr verschiedenen Schwellenwert in beiden Fällen haben. Die bei der Piperschen Regel in Betracht kommenden Reize sind minimal, liegen eben über der Schwelle und sind in bezug auf ihre Intensität auf das feinste abstufbar, während bei der Untersuchung des Zapfenapparates immer bedeutend überschwellige Reize benutzt werden, deren vergleichende Intensitätsbestimmung und Abstufbarkeit sehr ungenau ist.

Ich glaube daher, dass die Folgerung, welche Piper aus diesem Gesetz zieht, „dass die lichtperzipierenden Elemente des Hell- und Dunkelauges auf verschiedene Art miteinander bzw. mit den höheren Teilen der Sebbahn verknüpft sind, derart, dass im einen Ealle durch Addition der benachbarte Elemente treffenden Einzelreize eine Verstärkung der Helligkeitsempfindung in die Wege geleitet werden kann, dass dieses aber im andern Falle kaum oder gar nicht erfolgt", schwerlich berechtigt sein dürfte. Allerdings spricht Piper hier auch nur von einer Vermutung.

M. E. beruben nun aber beide Gesetze, das der Addition der binokularen Eindrücke und das der Abhängigkeit des Reizwertes von der Winkelgrösse des Reizobjektes im Stadium der maximalen Dunkeladaptation auf einem und demselben physiologischen Vorgang der Summierung der einzelnen von jedem Netzhautpunkt zentral geleiteten Reize, wobei es gleichgültig ist, ob sich in einem Auge die gereizte Fläche vergrössert, oder ob die Vergrösserung derselben dadurch erzielt wird, dass in andern Auge gleichzeitig eine Reizung stattfindet.

Ein prinzipieller Unterschied zwischen der Zapfenund der Stabchenfunktion in bezug a uf diese beiden Piperschen Gesetze dürfte aus den oben angeführten Gründen wohl nicht vorhanden sein.

Nach dem angeführten physiologischen Tatsachenmaterial liegt demnach schon eine wohlbegründete Wahrscheinlichkeit vor, dass die Tätigkeit der Stäbchen und der Zapfen zeitlich voneinander getrennt ist: Der Zapfenapparat vermittelt die Lichtempfindungen vorzugsw eise wenn nicht ausschliesslich im Zustand einer Helladaptation, 
der Stäbchenapparat im Zustand einer vorgeschrittenen Dunkeladaptation. Es scheinen also je nach den äusseren Belichtungsrerlältnissen nur immer die durch einen der beiden funktionell so verschiedenen Apparate zentral geleiteten Reize als Wahrnehmungen vor unser optisches Bewusstsein zu treten.

Ein schwerwiegender Beweis für diese Annahme durfte mit dem Nachweis erbracht werden kömnen, dass bei einer hochgradigen Funktionsbeeinträchtigung des einen Apparates keine nachweisbare Störung in der Funition des andern und hauptsächlich keine Änderung der Qualität der betreffenden optischen Wahrnehmung besteht, insbesondere dass bei einem fast vollkommenen Ausfall der Stäbchenfunktion keine Störung im Tagessehen rorbanden ist. Aus naheliegenden Gründen ist, wie bereits erwähnt, ein derartiger isolierter Ausfall eines Systems bei retinalen Prozessen nar ausnahmsweise zu erwarten, Aussichtsvoller erschienen mir für die Beantwortung dieser und der verschiedenen andern oben angeführten noch offenen Fragen Untersuchungen des Dämmerungssehens bei Läsionen der optischen Leitungsbalm zu sein, ron der es bekannt ist, dass die verschiedenartigen Leitungsfasern in verschiedenartiger Weise auf eine und dieselbe einwirkende Schädlichkeit reagieren kömen.

Ich habe daher zunächst einmal systematisch alle jene Fälle untersucht, in denen aus irgendeinem Grund eine Läsion der optischen Leitungsbahn an irgendeiner Stelle anzunehmen war. Dabei konnte ich nun in der Tat nachweisen, dass der Stäbchen- und der Zapfenapparat in ganz verschiedener Weise durch einen pathologischen Prozess geschädigt werden kann. Ja, es kann sogar die Funktion des einen Apparates völlig oder nahezu völlig normal sein, während die des andern hochgradig herabgesetzt oder so gut wie anfgehoben ist. Diese Fälle habe ich in der vorliegenden Arbeit zur Beantwortung der verschiedenen noch offenen Fragen verwertet, dat nur sie einwandsfreie Schlussfolgerungen gestatten. In jedem der betreffenden Fälle war die Erkrankung der optischen Leitungsbahn klinisch durch das eine oder andere Symptom überdies gesichert.

Ausserdem erscheinen mir gerade diese Fälle besonders geeignet, einen Beitrag zur Klärung des Begriffis der Adaptationsstörungen im allgemeinen, der He meralopie, liefern zu liönnen. A us den erwähnten physiologischen Untersuchungen über die Stäbchen- und Zapfenadaptation geht hervor, dass bei einer plötzlichen Herabsetzung der Helligkeit zunächst die Empfindlichkeit des Zapfenapparates schnell ansteigt. Da nun die bekannten hemeralopischen Beschwerden gerade 
Refiexcharakter d. Adaptationsworgänge, insbes. d. Dunkeladaptation usw. 211 unter derartigen Verhältnissen vou plötzlichen Änderungen der Lichtintensität manifest werden, dürfte es meines Erachtens schon von vornherein wahrscheinlich sein, dass für die Hemeralopie in erster Linie Störungen der Zapfenfunktion in Betracht kommen. Ein wirklicher Beweis wird aber erst dann erbracht sein, wenn wir bei einem Ausfall der Stäbchenfunktion keine hemeralopischen Beschwerden vorfinden.

Anordnung der Untersuchungen.

Um zahlenmässig verwertbare Resultate zu erhalten, habe ich meine Untersuchungen an dem Piperschen "Adaptometer" angestellt.

In einem lärgeren Kasten befinden sich drei voneinander durch Aubertsche Diaphragmen getrennte Abteilungen. Hinter jeder dieser Blenden ist eine Milchglasscheibe angebracht. In die hinterste Abteilung wird die Lichtquelle (50kerzige Glühlampe) eingefügt. Das dritte Diaphragma schliesst auf der entgegengesetzten Seite, dem zu Untersuchenden gegenüber, den Kasten ab. Diese Blende dient also lediglich zur Einstellung der gewünschten Grösse des Untersuchungsobjektes, während die beiden andern die Lichtmenge, welche auf die zu beobachtende Milchglasscheibe fällt, variieren. An einer Skala, welche die Grösse der Seite der quadratischen Blendenöffnung angibt, kann abgelesen werden, bei welcher minimalen Blendenöffnung noch eine Lichtempfindung eintritt. Jedem Skalenteil entspricht ein bestimmtel Lichtwert. Beim Zugrundelegen einer willkülichen Einheit kamn daher leicht eine Tabelle berechnet werden, aus welcher wiederum die reziproken Werte der Empfindlichkeit der émzelnen Blendenweiten sich ergeben. Über nähere Einzelheiten des Apparates und der Berechnung muss ich auf das Original Pipers verweisen.

Ich konnte mich nun nach der Grundidee meiner Untersuchungen nicht darauf beschränken, lediglich die Dunkeladaptation des parabzw. perifovealen Bezirkes der Netzhaut allein zu untersuchen, sondern musste ron vornherein darauf ausgehen, auch die der Peripherie in derselben Weise festzustellen. So konnte ich dann auch unter einzelnen äquivalenten Teilen einer Netzhaut oder beider Angen nähere Vergleiche über ibre Funktion während der Dunkeladaptation anstellen. $Z u$ dem $Z$ weck standen mir zwei Wege offen: entweder liess ich den Adaptometer auf einem Perimeterbogen verschieblich anbringen, und ich untersuchte die Adaptation bestimmter Netzhautstellen bei ruhendem, geradeaus gerichteten Blick, oder aber ich liess den Adaptometer unbeweglich und stellte nur durch entsprechende Ände- 
rung der Blickrichtung die zur Untersuchung gewïnschte excentrische Netzhantstelle ein.

Ich bin dem letzteren Wege gefolgt und habe mir an dem Adaptometer einen Perimeterbogen von $1 / 2 \mathrm{~m}$ Radius anbringen lassen. Der Kopf des zu Untersuchenden kommt in den Mittelpunkt des Bogens. Dieser ist nun so angebracht, dass or sich um die Längsachse des Adaptometers dreht, und zwar liegt der Drehungsmittelpunkt genau in der Mitte der vorderen zur Beobachtung dienenden Milchglasscheibe. Der' Bogen selbst ist breiter als der Durchmesser der Milchglasscheibe bzw. der maximalen vorderen Blendenöffnung und hat an der Stelle der Blende eine runde Öffnung, welche den zur Beobachtung dienenden Teil der Milchglasscheibe freilässt. Wendet nun der Patient sein Auge auf einen bestimmten Punkt des Bogens, so wird durch den ron der Milchglasscheibe ausgehenden Lichtreiz gerade derjenige Teil der Netzhant getroffen, welcher nach der der Blickwendung entgegengesetzten Seite in derselben Excentrizität wie der fixierte Punkt, vom Mittelpunkt der Milchglasscheibe aus gerechnet, gelegen ist. Übertragen wir die Werte auf ein Gesichtsfeldschema, so haben wir sie jedesmal in genau derselben Excentrizität wie der gewanderte Fixierpunkt, aber auf der entgegengesetzten Seite in der Verlängerung desselben Durchmessers einzutragen. Als Fixationsobjekt habe ich eine in einer lichtdicht nach aussen verschlossenen, nur vorn dureh eine kleine runde Öfnung unterbrochenen Kapsel angebrachte kleine Glühbirne benutzt, wie sie auch Stargardt verwendet hat; die Öfnung ist innen durch ein rubinrotes, in die Kapsel eingefügtes Glas verschlossen, dessen Dämmerungswert bekanntlich sehr gering ist. Die Abstufung der Helligkeit des Glühlämpchens geschieht, abgesehen davon, dass nacheinander mehrere rote Gläser oder Milchglasscheiben in die Kapsel eingefügt werden können, durch Regulierung der zufliessenden Strommenge mittels eines dazwischen geschalteten Rheostaten.

Man stellt den Fixationspunkt auf eine minimale eben noch wahrnehmbare Helligkeit bei Beginn des Dunkelaufenthaltes ein. Bei intelligenten und zuverlässigen Patienten kann man auch auf dieses Fixationsmittel verzichten, indem man den Zeigefinger des betreffenden Patienten an die zu fixierende Stelle des Perimeterbogens legt und den Patienten auffordert, seinen Finger anzusehen. Es ist aber zweckmässig, durch intermittierenden Druck auf den Finger die Aufmerksamkeit auf diesen Punkt zu fesseln und das Lagegefühl durch andere ebensogut zu lokalisierende und in den Raum 
zu projizierende sensible Eindrücke zu unterstützen. Im allgemeinen sind auch die Patienten schon vorher durch die Untersuchungen am Försterschen Perimeter mit dem Untersuchungsprinzip vertraut geworden, so dass eine kurze Instruktion vor Beginn der Dunkeladaptation genuigt, um sie auch mit dieser Modifikation ausreichend bekannt zu machen.

Von Bedeutung ist, dass der Adaptometer sich auf einem in bezug auf seine Höhe zu regulierenden Untersatz befindet, damit die Beobachtungsfläche der vorderen Blende immer in Augenhöhe gebracht werden kann und so die Vorbedingung einer genaueren Gesichtsfelduntersuchung erfüllt wird.

Bei dieser vergleichenden Untersuchung der Dunkeladaptation ist noch auf einen Punkt hinzuweisen. Will man die einzelnen Netzhautbezirke eines oder beider Augen auf die Funktion ihres Stäbchenapparates hin vergleichen, so kommt man zu keinen einwandsfreien Werten, wenn man die Untersuchung während des rapiden Anstiegs der Empfindlichkeit macht. Jede Einstellung erfordert gewisse Zeit, während welcher die Empfindlichkeit weiter schnell ansteigt. Wir müssen daher die Beendigung dieses schnellen Anstiegs abwarten und die Untersuchung im Zustand der zweiten minimalen und daher für den zahlenmässigen Vergleich nicht in Betracht kommenden Empfindlichkeitssteigerung vornehmen. Ein weiterer Vorzug der Wahl dieses Zeitpunkts liegt in der gewaltigen Höhe des erreichten normalen Empfindlichkeitswertes, insofern als eventuell gefundene grosse Differenzen (von mehr als 1000 Einheiten z. B.) viel eindeutigere und zuverlässigere Resultate geben, als geringere Differenzen während des Empfindlichkeitsanstiegs mit seinen normalerweise niedrigeren Werten.

Vorversuche: Vor Beginn unserer Untersuchungen an pathologischen Fällen war die Frage zu entscheiden, ob der erreichte Empfindlichkeitswert in der Netzhautperipherie nach ausgiebiger Dunkeladaptation an allen Stellen ungefähr gleich ist, und ob nicht physiologische Differenzen zwischen einzelnen Teilen bestehen. Nach v. Kries ist die Zunahme der Empfindlichkeit durch Dunkeladaptation in Netzhautzentrum ron einem relativ geringen Betrag, mit wachsender Excentrizität nimmt sie dann bis zu $4^{0}$ jederseits rapid, darauf nur noch langsam zu, um schliesslich wieder etwas abzunehmen. Nach den Versuchen von Breuer und Pertz liegt das Maximum der $\mathrm{Zu}$. nahme bei etwa 10 bis $20^{\circ}$. Aus diesen Untersuchungen geht schon hervor, dass die perizentral gefundenen Werte der Dunkeladaptation 
im Hinblick auf das Pipersche Gesetz der Abhängigkeit des Schwellenwertes von der Objektgrösse geringer sein müssen als die peripher gefundenen.

Ich habe nun für meinen Adaptometer - in allen Untersuchungen ist die maximale Blendenweite am vorderen Aubertschen Diaphragma zur Anwendung gekommen - zunächst an einer grösseren Reibe von Normalen die nach ausreichender Dunkeladaptation erreichten Werte der Empfindlichkeit der verschiedenen excentrischen Fetzhautstellen festgestellt und gefunden, dass die zentralen Werte die geringsten sind, dass die Empfindlichkeit schnell und gleichmässig auf beiden Seiten ansteigt, und dass zwei gleichweit excentrisch gelegene Stellen auf der nasalen und temporalen Seite denselben oder fast denselben Schwellenwert aufwiesen. Die bei einigen Cntersuchmingen roxkommenden Differenzen wechseln in bezug auf die Seiten und betreffen immer nur 2 oder 3 Skalenteilchen, ein Umstand, der vollkommen ungezwungen durch eine verschieden starke Anspannung der Aufmerksamkeit erklärt werden kann. Derartig minimale Differenzen haben für unsere pathologischen Fälle gar keine Bedentung, da wir hier, wie wir sehen werden, viel gewaltigere Unterschiede vor uns haben. Bei dem Vergleich der Dunkeladaptation der verschiedenen Netzhautstellen des vertikalen Meridians hat man sehr auf die Blendenwirkung der Lider zu achten. Am zweckmässigsten hebt der Untersucher leicht das Oberlid des Patienten. Auch hier finden sich dieselben Verhältnisse. Jenseits von 50 bzw. $60^{\circ}$ sinkt dex Schwellenwert wieder etwas und erreicht hier ungefähr den perizentralen Wert. Ebenso ist die Empfindlichkeitssteigerung nach $3 / 4$ stündiger Dunkeladaptation unter normalen Ver. hältnissen auf beiden Augen von völlig gleichem Werte. Einen Teil dieser physiologischen Untersuchungen hat auf meine Veranlassung Herr Dr. Burck vorgenommen. Durch sie ist also die objektive Grundlage für meine vergleichenden Untersuchungen der Dunkeladaptation verschiedener Netzhautstellen eines oder beider Augen unter pathologischen Verhältnissen gegeben.

\section{Klinische Untersuchungen.}

Je nach den verschiedenen Abschnitten der optischen Leitungs* bahn (Nervus opticus, Chiasma, Tractus opticus, intracerebraler Teil der Sehbahn) fasse ich hierunter jetzt die Fälle zusammen und erörtere im Anschluss daran jedesmal die bemerkenswerten Ergebnisse derselben. 
Refexcharakter d. Adaptationsvorgänge, insbes. d. Dunkeladaptation usw. 215

\section{Optikusstammaffektionen.}

Die Empfindlichkeitssteigerung der Stäbchenfunktion nach $3{ }_{1}^{2}$ stündigem Dunkelaufenthalt zeigt, wie Piper nachgewiesen hat, relativ grosse individuelle Schwankungen, so dass die untere Grenze für eine normale Funktion schwer anzugeben ist. Nach den bis jetzt vorliegenden Erfahrungen an Gesunden dürfte als sehr tief angenommene untere Grenze der normalen monokularen Empfindlichkeitssteigerung eine Blendenweite von 96 am Piperschen Adaptometer anzusehen sein, welcher etwa 1500 Empfindlichkeitseinheiten nach der Piperschen Berechnung entsprechen. Die binokulare Empfindlichkeit ist annähernd doppelt so gross. Um ganz sicher zu gehen, habe ich nur jene Fälle herausgegriffen, welche eine hochgradige Differenz gegenüber diesem Werte aufwiesen, oder in denen zwischen beiden Augen ein grösserer Unterschied bestand.

In allen mitgeteilten Fällen war eine ophthalmoskopisch sichtbare Veränderung am Optikus als objektiver Beweis für das Vorhandensein einer anatomischen Läsion des Nerven vorhanden.

1. J. S., 45 Jahre, Arbeiter. Tabes dorsalis.

Vor $3-4$ Jahren vorübergehendes Doppeltsehen, seit nugefähr 3 Jahren "rheumatische" Schmerzen in beiden Beinen, L. $>$ R., von ausgesprochenem lancinierenden Charakter, seit 2 Jahren Gürtelgefühl und Unsicherheit des Ganges besonders im Dunkeln. Seit einigen Wochen Incontinentia urinae. Im 22. Lebensjahr Lues. Sonst gesund. Frau und 2 Kinder sind gesund. 1 Abort. 1 Kind tot an Hirnhautentzündung.

Achsen von 2 (D).

Se.: R. $=6 / 15$, mit $+4,0 \mathrm{~S}={ }^{B} / 7$.

L. $=\left.6\right|_{20}$, mit $+5,0 \mathrm{~S}={ }_{10}$ (Astigmatismus mit schrägen

Pupillen: Anisokorie, rechts weiter als links, R. Pupille entrundet. Beiderseits reflektorische Pupillenstarre.

Ophthalmosk.: R. völlig normal.

L. der Optikus ist etwas grau verfärbt im Vergleich mit dem der rechten Seite.

Gesichtsfeld: Für weisse und farbige Objekte $(5 \mathrm{qem})$ normal beiderseits.

Neurologischer Befund: Patellar-Achillesreflexe fehlen beiderseits, ebenso Triceps- und Radiusreflexe. Grobe Kraft ist $\mathrm{R}$. $=\mathrm{L}$, und entsprechend. Ataxie der oberen und unteren Extremitäten. Dentliches Rombergsehes Phänomen. Sensibilität: Spitz und stumpf; kalt und warm wird am linken Unterschenkel nicht unterschieden, ebenso spitz und stumpf vorn in der Gegend der 3. bis 5. Rippe.

Serumdiagnose auf Lues positiv. (Prof. Klingmüller.)

Keine hemeralopischen Beschwerden. 
Dunkeladaptation:

Schwellenwert sofort

binokular 67 , rechts 67 , links 60

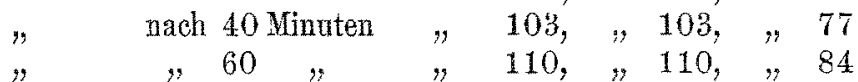

In den von Piper berechneten Einheiten ausgedrückt beträgt nach 60 Minuten Dunkelanfenthalts die Empfindlichkeit R. $3755 \mathrm{E}$

L. $1038 E$.

Trotz der relativ gleichen und normalen Sebsehärfe (in Anbetracht der vorliegenden Refraktionsanomalie) und des normalen Gesichtsfeldes findet sich ein grosser Unterschied in der Stäbchenfunktion beider Augen. Erst durch diese Differenz wird der sonst wohl kaum als pathologisel anzusprechende Farbuntersehied beider Optici mit grosser Wahrscheinlichkeit im Sinne einer beginnenden schweren anatomischen Veränderung zu erklären sein.

2. W. F., 5̌ Jahre, Schlosser. Tabes dorsalis incipiens.

Kommt wegen einer Brifle. War immer gesund. Lues negiert. Incontinentia urinae.

Visus: Beiderseits $={ }^{6} / 7$, mit $+2,25$. Nieden I von $40-28 \mathrm{~cm}$.

Pupillen: $\mathrm{R} .=\mathrm{L}, 2,5 \mathrm{~mm}$, reagieren prompt.

Ophthalmosk.: Beiderseits graue atrophisehe Verfärbung der Optici, Grenzen und Gefässe ohne Befund.

Gesichtsfeld: Beiderseits normal.

Keine hemeralopischen Beschwerden.

Neurologiseher Befund: Normal, abgesehen von einem ausgesprochenen Romberg.

Dunkeladaptation:

Schwellenwert sofort binokular 22 perizentral

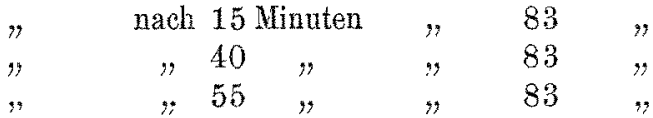

In Empfindlielkeitseirheiten 1001 (gegenüber dem normalen binokrilaren Minimum von 3000).

Binokular seitlich: Blick nach R. $20^{\circ} 91$
L. $20^{\circ} 90$.

3. Th, 58 Jalre. Tabes dorsalis.

Früher angeblich gesund; niemals Lues. Ehe kinderlos, keine Aborte. Seit längerer Zeit Klagen über Kopfdruck, laneinierende Schmerzen in den Beinen. Keine Blasen-Mastdarmstörungen. Keine Parästhesien. In den letzten 6 Wochen Abnahme des Gedächtnisses angeblich nach Überanstrengung.

Visus: Beiderseits $=b_{i}(E)$.

Augenbewegungen abgesehen von einem geringen Nystagmus in den Endstellungen frei.

Pupillen: Beiderseits miotiseh (2 mm) mit leichter Anisokorie.

Lichtreaktion fehlt beiderseits vollkommen.

Konvergenzreaktion ist beiderseits prompt. 
Reflexcharakter d. Adaptationsvorgänge, insbes. d. Dunkeladaptation usw. 217

Ophthalmoskop.: R. ist der temporale Papillenrand grau besonders in der unteren Hälfte verfärbt, die nasale Hälfte ist noch deutlich gerötet.

L. besteht ebenfalls eine Verfärbung der temporalen Hälfte, jedoch nicht so ausgesprochen wie $R$. Grenzen, Gefässe und Peripherie sind normal.

Gesichtsfeld: L, normal.

R. für Weiss ( $5 q \mathrm{~mm}$ ) völlig normal, für Farben mittlere konzentrische Einschränkung (5 qmm).

Dunkeladaptation sofort 27 monokular und binokular nach 45 Minuten $60 \quad " \quad \quad \quad \quad \quad=42 \mathrm{EE}$.

Status nervosus:

Patellarreflexe fehlen beiderseits, ubbrige Reflexe ohne Befund.

Ataxie im linken Bein. Hypalgesie des linken Beines.

Romberg angedeutet.

4. W. M, 64 Jahre, Steuermann. Apoplexie. Neuritische Sehnervenatrophie.

Vor 4 Jaliren Abnahme des Sehvermögens auf dem rechten Ange, seit einem Jahr auch auf dem linken Ange. Vor 11 Wochen apoplektiformer Insult mit prodromalen starken Kopfschmerzen, darauf linksseitige Extremitätenparese. Lues negiert. Mässiges Potatorium konzediert.

Visus: Beiderseits $6 / 7^{\circ}$

Pupillen: R. weiter als L. Reaktion prompt.

Ophthalmosk.: Beiderseits grauweisse Verfürbung der Optici, die Grenzen der Papillen sind unscharf, die Venen stärker geschlängelt. Gefässe sonst ohne Befund.

Gesichtsfeld: $R$. die nasale Hälfte ist zum grössten Teil ausgefallen, nur im oberen Quadranten ist noch ein Rest neben der vertikalen Trennungslinie vorhanden. Um $F$ gehen die Grenzen nach unten und seitlich auf der nasalen Hälfte bis etwa $15^{\circ}$. Der temporale obere Quadrant ist normal, der untere in seiner unteren Hälfte beeinträchtigt.

L. besteht eine geringe konzentrische Einengung, welche anf der nasalen Hälfte stärker ausgesprochen ist.

Dunkeladaptation nach ${ }^{3 / 4}$ stündigem Dunkelaufenthalt:

binokular 76, L. $76(79,1 E E)$, R. $62(64 E E)$.

Die Peripheriewerte sind:

R. temporal schräg oben $\left(30^{\circ}\right.$ und $\left.50^{\circ}\right) 65$ horizontal $40^{\circ} \quad 65$

schräg temporal unten 65 , ebenso gerade nach oben.

L. temporal sehräg oben 67 , gerade nach oben und unten 60 , schräg unten 60

nasal schräg oben und unten 60 .

5. Christine H., 19 Jahre. Juvenile Tabes dorsalis.

Von 9 Geschwistern sind 7 im ersten Lebensjahr gestorben. Seit ihrer Kindheit besteht Ineontinentia urinae besonders beim Husten. Seit längerer Zeit Parästhesien in beiden Beinen, blitzartige Schmerzen in den Unterschenkeln, Unsicherheit in den Beinen beim Gehen. Kein Gürtel-

т. Graefe's Archir für Ophthalmologie. LXXV. ?. 
gefühl. Zeitweise Kopfsehmerzen mit anselliessendem Erbrechen ohne Flimmererseleinungen vor den Augen. Seit 8 Tagen vorïbergehend Doppeltsehen.

Visus: L. $S=6 / 7$, R. F. Z. in $4 \mathrm{~m}$.

Pupillen: Links weiter als rechts $(3: 2 \mathrm{~mm})$, leicht entrundet. Reaktion auf Licht völlig aufgehoben, auf Konvergenz prompt.

Ophthalmosk.: Optici beiderseits weisslichgrau verfärbt, bei normalen Grenzen und Gefässen.

Gesichtsfeld: R. nur noch ein kleiner zentraler Rest erhalten, in dessen mittleren Teilen noch rot und blau erkannt wird.

L. schräg von oben aussen und unten innen eingeengt. Die Rotempindung ( $5 \mathrm{qmm}$ ) ist nach allen Seiten über $10^{\circ}$ um $F$ hinaus erhalten, für grössere Rotobjekte entsprechend weiter.

Augenbewegungen abgesehen von einem Strabismus divergens frei.

Neurolog. Befund: L. Paramammillardrüse. Fehlen der Patellar- und Achillesreflexe beiderseits. Übrige Sehnen- und Hautreflexe lebhaft. Keine Ataxie. Romberg angedeutet. Hitzigsehe Zone unter der linken Mammilla, über der linken Ścapula, an den Aussenseiten beider Untersehenkel.

Serumdiagnose positiv für Lues. (Prof. Klingmüller.)

Lumbalpunktion: Druck normal. Keine Vermehrung der Eiweisskörper. Geringe Lymphocytose.

Patientin machte eine energische Sehmierkur durch. Während der Zustand des linken Anges unverändert blieb, verfiel das rechte immer weiter, bis schliesslich totale Amaurose eintrat. Im Anschluss an die Schmierkur machte Patientin noch eine Zittmannkur durch. Unter derselben verselhwanden die Kopfschmerzen völlig, die Incontinentia urinae besserte sich, das Gesichtsfeld des linken Auges erweiterte sich etwas. Die Sehschärfe blieb normal. Der rechte Optikus wurde nach einem Jahr porzellanweiss, der linke hatte seine grauweisse Farbe nicht verändert.

Die Untersuchung der Dunkeladaptation ergab in diesem Zustand (also bei normaler zentraler Selsschärfe, unregelmässiger mittlerer konzentrischer Gesichtsfeldverengerung) nach einem Dunkelaufenthalt von 50 Minuten einen Schwellenwert von 65 bis $66=145$ bis $210 E E$. Dieselben Werte fanden sich auch in den übrigen funktionstüehtigen Teilen des Gesichtsfeldes.

Irgendwelche hemeralopischen Beschwerden waren weder von der Patientin während der langen Zeit der Beobachtung angegeben, noch dureh unsere Untersuehungsmethoden nachweisbar gewesen.

Der Adaptationsbefund blieb immer der gleiche.

6. R. H., 52 Jahre, Polizeiwachtmeister. Lues cerebro-spinalis.

Kommt zwecks Brillenverordnung.

Visus: R. ${ }^{6} / 10$ (Cataracta incipiens), L. mit $-1,75 D=6 / 5$.

Pupillen: miotisch, R. = I., beiderseits lichtstarr, schwache Konvergenzreaktion. (Unvollkommene totale Starre.)

Ophthalmosk.: Optici beiderseits temporal and unten grau verfärbt, sonst $0 . B$.

Gesichtsfeld: In beiden nasalen und oberen Hülften leichte unregel- 
mässige periphere Einengung. Die Farbuntersuchung (rot) mit absteigenden Objektgrössen ${ }^{1}$ ) ergibt stellenweise ein Zusammenfallen der Grenzen und eine leichte Einengung im ganzen, siehe Schema.
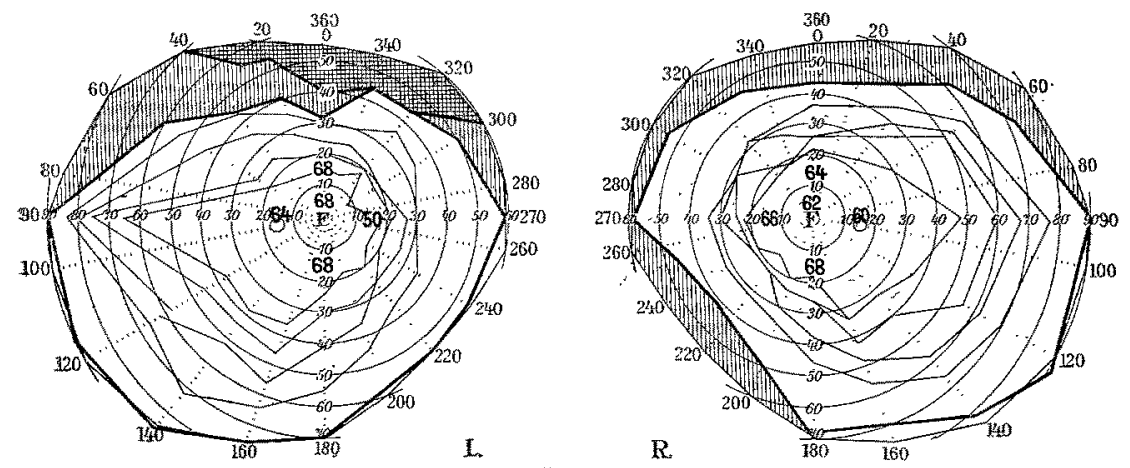

Fig. 1.

Dunkeladaptation: binokular:

sofort $\quad 30$

nach 10 Minuten 64

$" 20 \quad " 65$

$" 30 \quad " \quad 68-69$

$" 45 \quad \# \quad 68-69$

(Empindichkeitswerte 625)

auch bei monokularer Prüfung

und $20^{\circ}$ seitlich beiderseits.

Neurologiseher Befund: Grobe Kraft R. = L. entsprechend, Patellarreflexe gesteigert R. $>$ L. Achillesrefl. beiderseits sehr schwach. Hypästhetische Zone tuber dem linken Pectoralis und der linken Scapula, sonst o. B.

Serumdiagnose positiv für Lues. (Prof. Klingmüller.)

1) Anmerkung. Ich babe die Methode der Gesichtsfelduntersuchung mittels mehrerer verschieden grosser Farbobjekte (5, 10, 20 und 40 qum Objektfläche) hintereinander in zahireichen ähnlichen Fällen angewendet, in denen der ophthalmoskopische Befund zweifelhaft pathologisch war und in denen die Gesichtsfelduntersuchung mit nur einer einzigen Objektgrösse für Weiss und Farben normale Grenzen ergeben hatte. In manchen Fällen konnte ich mittels dieser Methode Störungen der optischen Leitung nachweisen, die mir sonst entgangen wären.

Normalerweise sind bekanntlich die peripheren Grenzen für die versehiedenen Objektgrössen der Farben auch von entsprechender verschieden grosser Ausdehnung. Die Grenzlinien für die einzelnen Objektgrössen laufen fast immer parallel zueinander, so dass der $Z$ wischenraum zwischen ihnen (bei den oben genannten Objektgrössen ungefähr $6-10^{9}$ ) annähernd der gleiche bleibt. Liegt nun irgendein anatomischer Prozess vor, welcher den Optikusquerschnitt in seinen peripheren Teilen in Mitleidenschaft zieht, so ändert sich der Abstand der verschiedenen Grenzen. Die Grenzlinien werden unruhiger, zeigen Einknickungen and rücken, was besonders wichtig ist, aneinander, bis sie schliesslich zusammenfallen, so dass für kürzere oder längere Strecken die Grenzen für zwei oder mehrere verschieden grosse Objekte dieselben sind. Eine ausführlichere Mitteilung behalte ich mir vor. 
Patient machte eine Schmierkur durch. Während der Beobachtung nahm die Verfärbung des linken Optikus noch zu, die Dunkeladaptation blieb unverändert.

Irgendwelche hemeralopische Beschwerden waren nicht vorhanden and auch dureh eine darauf gerichtete Untersuchung nicht nachweisbar.

In dem vorstehenden Gesichtsfeldschema sind ausser den Weissgrenzen die Grenzen für verschieden grosse rote Objekte eingetragen. Die Zahlen entsprechen dem Solwwellenwert der betreffenden Gesichtsfeldpartien nach $\int_{4}$ stündigem Dunkelaufenthalt.

7. W. W, 34 Jahre, Werftarbeiter. Lues aerebri.

Seit längerer Zeit Abnahme des Visus beiderseits. Seit drei Wochen Doppeltsehen und leichte Incontinentia urinae. Abnahme des Gedächtnisses. Proptosis beiderseits. Strabismus convergens. Gleichnamige Doppelbilder beim Blick geradeaus, deren Abstand nach beiden Seiten abnimmt.

Pupillen: R. leicht entrundet, total starr,

L. nnvollkommene totale Starre (Konvergenzreaktion ist noch in geringem Grade vorhanden).

Oplthalmosk.: Papillen graw, besonders temporal, sonst o. B.

Visus: Beiderseits is $(+1,0 D)$.

Accommodation o. B.

Gesichtsfeld: Leicht konzentriseh eingeengt für Weiss und Farben.

Dunkeladaptation: Beiderseits zentral und peripher 67-68 (Empfindlichkeitswerte $331-625$ ) nach 50 Min.

Stat. nervosus: Grobe Kraft $\mathrm{R}_{*}=$ L. Patell.-Refl: Rechts schwach mit Jendróssik, links fehlend. Achilles-Ref. fehlen beiderseits. Sensibilität o. B., abgesehen von einer Hypalgesie im ganzen Gesicht. Cornealrefl. beiderseits vorhanden. Sonstiger Befund normal.

Serumdiagnose positiv für Lues. (Prof. Klingmüller.)

Patient machte eine Schmierkar durch, während welcher keine Änderung der verschiedenen Symptome eintrat. Irgendwelche hemeralopische Beschwerden waren auch hier nicht vorhanden.

8. M. B., 45 Jahre, Postschaffner. Multiple Sklerose.

Klagt über Schmerzen in den Augen beỉm längeren Lesen. Seit einem Jahr besteht ein schwarzer Fleck vor seinem linken Auge, der das. Sehen aber nicht beeinirachtigt. Seit einem haben Jahr schnell voribergehende Schwindelanfälle, ab und zu leichte Kopfschmerzen, zeitweise Erschwerung der Sprache (das Aussprechen selbst leichter Worte fallt ihm dann schwer). Ebensolange leichte Schwäche im linken Bein. Kein Zwangslachen. Abnahme der Potenz seit einem halben Jahr. Für Lues sprieht nichts. Visus: Beiderseits ${ }^{4} / 5$ bis ${ }^{6} / 4(+0,5 D)$. Acommodation entsprechend. Augenbewegungen: Nystagmus in den Endstellungen. Andentung von Graefeschen Phänomen. Pupillen o. B.

Ophthalmosk: Optici beiderseits in toto granweisslich verfärbt. Grenzen unscharf. Gefässe o. B.

Gesichtsfeld: Fur Weiss (5 qmm) normal.

Die Untersuchung mit abstejgenden Reizgrössen (Rot) (s. o.) ergibt be- 
sonders links nasal eine leichte Einschachtelung der Grenzen mit unregelmässigen Knickungen. Für Rot 5 qmm normale Grenzen beiderseits.

Dunkeladaptation sofort: 50 , nach 10 Minuten binokular $63, \quad$ rechts 63 , links 56

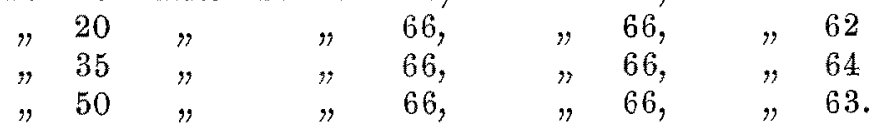

Die Empfindlichkeitswerte nach 50 Minuten Dunkelaufenthaltes betragen: rechts 210 , links 81,2 .

Stat. nervosus: Herabsetzung der groben Kraft der linken Hüftheber. Sehnenreflexe beiderseits lebhaft. Linker Arm zeigt deutlichen Intentionstremor. Sensibilität normal. Der linke untere Bauchdeckenreflex ist stark herabgesetzt. Sprache skandierend. Leichter Tremor manuum.

Patient wurde in die Klinik aufgenommen. Unter absoluter Bettrube besserten sich zunächst die nervösen Symptome bis auf den Optikusbefund, die Störung der Dunkeladaptation und die Parese des linken Beins.

Lumbalpunktion: Druck 240-250 (respir. Schwankungen), geringe Vermehrung des Eiweissgehaltes, Pleocytose (5-6 Lymphocyten in Gesichtsfeld).

Serumdiagnose negativ. (Prof. Klingmüller.)

Nebenhöhlen 0 . B.

Patient klagte niemals über hemeralopische Beschwerden.

Die Störung der Dunkeladaptation versehwand schliesslich obenfalls. Der nach $3 /{ }_{1}$ stündigem Dunkelaufenthalt erreichte Endwert entsprach durchans dem Normalen $(102$ B. W. $=2303 E E$.

9. Z. R., 34 Jahre, Versicherungsinspektor. Multiple Sklerose.

Sehvermögen früher gut. Seit einigen Wochen ständig Kopfschmerzen, Schwindel und starke Mïdigkeit. Seit einer Woche Abnahme der Sehkraft rechts, ebensolange Verschlechterung des Gedächtnisses. Sonst immer gesund. Für Lues keine Anhaltspunkte.

Bei seiner Aufnahme in die Klinik fand sich eine doppelseitige Nellritis optici, die rechts stärker ausgesprochen war als links, Herabsetzung der Sehschärfe rechts auf F.-Z, in $1 \mathrm{~m}$, Visus L. $={ }^{6} / 7$, normales Verhalten der Pupillen, im Gesichtsfeld rechts ein zentrales Skotom, Nystagmus horizontalis in den Endstellungen auch beim Blick nach oben. Die neurologische Untersuchung ergab lebhafte Selnenreflexe, Andeutung von Fussklonus, Fehlen der Bauchdeckenreflexe. Die Untersuchung der Nebenhöhlen ergab normale Verhältnisse. Die Serumdiagnose auf Lues war negativ. (Prof. Klingmüller.)

Trotz des Fehlens von Lues in der Anamnese und trotz der negativen Serumdiagnose wurde eine mildere Schmierkur verordnet. Während der weiteren klinischen Beobachtung traten Klagen über vorübergehenđes Doppeltsehen auf, das durch Prüfung auf Doppelbilder jedoch nicht genauer festgestellt werden konnte. Die Sehsehärfe des rechten Auges besserte sich langsam, das zentrale Skotom verschwand, die Neuritis optici ging zurück. Eine Untersuchung vier Monate später ergab eine Steigerung der Sehnen- 
reflexe bei normalem Verhalten der groben Kraft, beiderseits Andeutung von Fussklonus, Fehlen des linken unteren und starke Herabsetzung des rechten unteren Bauchdeckenreflexes, Tremor manuum. Die Sehschärfe war R. $\left.{ }^{3}\right|_{10}$, L. ${ }^{6} / \tau$, beiderseits blieb der Nystagmus bestehen, auf dem rechten Auge entwickelte sich eine temporale Abblassung, links verwaschene Grenzent und leichte grane Verfärbung dez temporalen Hälfte. Gesichtsfeld norma!.

Eine Untersuchung ein Jahr später ergab ophthalmoskopiseh dieselben Veränderungen. Zu den übrigen nervösen Symptomen hatte sich dann noch eine deutlich skandierende und verwaschene Sprache und Intentionstremor in beiden Armen hinzugesellt. Die Sehschärfe betrug damals R. ${ }_{20}$ L. $60^{\circ}$ Die Untersuchung der Dunkeladaptation ergab eine hochgradige Herabsetzung der Fmpfindlichkeit. Nach ${ }_{1}$ stindigem Dunkelanfenthalt betrug der Schwellenwert: R. $61(51,8 E E)$, L. $64(106,3 E E)$.

Irgendwelche hemeralopische Bescliwerden bestanden nicht.

Weitere drei Monate später war die Sehschärfe wieder auf ihren fruheren Stand gestiegen. R. $6 / 10, \mathrm{~L}, /_{7}$.

Die Zunahme der Netzhautempfindlichkeit durch Dunkelaufenthalt war ebenfalls ganz bedentend grösser geworden. Nach $3 /{ }_{4}$ stïndigem Dunkelaufenthalt betrug der perizentrale Schwellenwert:

$$
\begin{aligned}
& \text { R. } 92 \quad(1422 E E), \\
& \text { L. } 106 \quad(2890 E E) \text {. }
\end{aligned}
$$

Die Peripheriewerte waren beiderseits ungefähr die gleichen, nur fand sich in beiden nasalen Gesichtsfeldhälften eine relative Herabsetzung gegenaber den gleich excentrischen Partien der temporalen Hälften (Tractusaffektion?):

L. $20^{\circ}$ temporal $112(4329 E E)$, R. $20^{\circ}$ temporal $94(1555 E E)$,

L. $20^{\circ}$ nasal $104(2571 E E), \quad$ R. $20^{\circ}$ nasal $90(1309 E E)$.

Demgegenïber war beiderseits zwischen $20^{\circ}$ oben und $20^{\circ}$ unter kein Unterschied vorhanden:
L. $20^{\circ}$ oben 110 ,
L. $20^{\circ}$ unten 112 ,
R. $20^{\circ}$ oben 92 ,
R. $20^{\circ}$ unten 92 .

10. P. S., 62 Jahre, Händler. Arteriosklerotische Sehnervenatrophie beiderseits.

Seit zwei Jahren Versehlechterung des Sehens. Sonst gesund.

Visus: R.: H. B. in $1 \mathrm{~m}, \mathrm{~L}_{\text {. }}=5 / 7$.

Ophthalmosk.: Rechts Papille fast porzellanweiss, Grenzen seharf, $A r^{*-}$ terien eng, zeigen Kaliberunregelmässigkeiten.

Links Papille besonders temporal grau verfärbt, Arterien eng, Grenzen seharf.

Gesichtsfeld: Links für Weiss normal, für Farben (5 qmm) leicht eingeengt, rechts temporaler Rest. prompt.

Rechte Pupille reagiert direkt auf Licht nur wenig ausgiebig, indirekt

Sonstigel" Befund, insbesondere der neurologische Befund und die Serumdiagnose negativ. 
Reflexcharakter d. Adaptationsrorgänge, insbes. d. Dunkeladaptation usw. 223

Dunkeladaptation bei mittlerer vorderer Blende links:

$$
\text { sofort } 62 \text {, }
$$

nach 10 Minuten 85,

$\begin{array}{lll}30 \quad " & 93, \\ & 60 \quad & 95 .\end{array}$

In Anbetracht der bei der Untersuchung verwendeten mittleren Blende ist das Endresultat als normal anzusprechen.

11. M. Gr., 64 Jahre, Sehiffszimmermann. Atrophia n. optici beiderseits, e causa ignota. Seit 20 Jahren schlechtes Sehen. Seit einem Jahr wegen multipler Hanteancroide in chirurgiseher Behandlung. Sonst gesund. Kommt zwecks Invalidisierung.

Visus: R. mit $+1,0 D=6 / 15$, L. mit $+1,0 D=6 / 20$.

Beiderseits Abblassung der Papillen mit engen Arterien und leicht unscharfen Grenzen.

Gesichtsfeld: Beiderseits unregelmässig konzentrische Einschränkujg; R. $>$ L., besonders für Farben.

Pupillarreaktion auf Licht träge, auf Konvergenz gut.

Sonstiger Befund abgesehen von den Hauteancroiden und deren operativen Residuen normal.

Serumdiagnose negativ.

Dunkeladaptation nach ${ }^{3}{ }_{4}$ stündigem Dunkelaufenthalt binokular 62 , ebenso monokular rechts und links $(64 E E)$.

Keine hemeralopischen Beschwerden.

12. A. L., 63 Jahre, Witwe. Lues cerebri. Staungspapille und Neuritis optici.

Vor 8 Tagen plötzlich Abnalime der Sehschärfe des linken Auges, seitdem auch vor dem rechten Auge wechselnd auftretende Nebel. Voraufgegangen waren heftige Kopfschmerzen, die sich in der letzten Zeit aber wieder gebessert haben. Von 10 Kindern sind 8 frül gestorben, kein Abort. Sonst immer gesund.

Visus: R. $6 / 10$ mit $+2,0 \mathrm{D}$

L. F.Z. in $1 \mathrm{~m}$.

Pupillen: R. = L. L. Reaktion auf Licht direkt nur spurweise, indirekt prompt. R. prompte Reaktion.

Augenbewegangen frei.

Ophthalmosk: L. Stauungspapille ( $3 \mathrm{D}$ Prominenz), unterhalb der Papille kleine Blutung, Venen stark gefullt und geschlängelt. R. Neuritis optici, keine messbare Niveaudifferenz.

Gesichtsfeld: L. mittlere Konzentrische Einengung. Relatives zentrales Skotom für kleine weisse Objekte und absolutes für Farben. R. mittiere Einengung der peripheren Grenzen oben und unten.

Die Allgemeinuntersuchung ergibt normale Verhältnisse.

Lumbalpunktion: Druck $250 \mathrm{~mm}$. Keine Pleocytose. Keine Vermehrung der Globuline und Albumine.

Serumdiagnose positiv für Laes. (Prof. Klingmüller.)

Unter einer energischen Sclimierkur nahm die Prominenz der Stauungspapille langsam $a b$, die Farbe der Papille wurde dabei etwas blasser. Die 
Sehschärfe betrug nach 14 Tagen R. $/ 15$ mit $+2,0$ D. L. F.- Z. in $3 \mathrm{~mm}$.

Die Untersuchung der Dunkeladaptation ergab nach 1 stündigem Dunkelaufenthalt einen binokularen Schwellenwert ron $84=625 E E$, einen monokularen von R. $84=625 E E$ und L. $54=17 \mathrm{EE}$.

Nach weiteren drei Wochen war auf dem L. Auge das zentrale Skotom fur Weiss rerschwunden und nur noch durch 5 qmm Farbobjekte nachweisbar. Die Ausdehnung lesselben betrug jetzt ungefahr $10^{\circ}$ nach allen Seiten. Die peripheren Grenzen erweiterten sich beiderseits. Die Prominenz der Papille war geringer geworden.

Visus: R. $={ }^{6} / 5$ mit $+2,0 D . \quad L .=6 / 50$ mit $+3,0 D$.

Die Dunkeladaptationsprifung nach $3 / 4$ stündigem Dunkelaufenthalt ergab
R. 93
1. 64
binokular 93

nach $\left.\right|_{4}$ stündigem Dunkelaufenthait
R. 100
$\mathrm{I}, 67$
binokular 100 .

Während der ganzen Zeit der klinischen Beobachtung waren nicht die geringsten hemeralopischen Erscheinungen beobachtet worden.

13. J. Str., 42 Jahre, Kutscher. Diabetes. Zentrales Skotom beiderseits.

Vor 3 Wochen innerhalb einiger Tage Verschlechterung des Sehens auf beiden Augen. Schon ror 1 Jahr war das Sehen während 8 Tagen so schlecht, dass Patient keine Zeitung lesen konnte. Wird wegen Diabetes mellitus auf der medizinischen Klinik behandelt. Kein Potus. Kein Nikotinmissbrauch.

Visus: Beiderseits ${ }^{6} / 35$ Gl. b. n.

Anisokorie. Pupillarreaktion prompt auf Licht und Konvergenz.

Ophthalmosk.: Beiderseits temporale atrophische Verfärbung. Grenzen

und Gefâsse ohne Befund. Macula beiderseits frei.

Gesichtsfeld: Relatives zentrales Skotom beiderseits.

Dunkeladaptation monokular beiderseits: Sofort 4.0

nach 20 Minuten 63

$\begin{array}{lrrrr}" & 35 & , & 83 & \\ " & 45 & " & 90 & \\ " & 60 & & 104 . \quad \text { Empfindlichkeitswert } 2571 .\end{array}$

14. P., Fischer, 60 Jahre alt. Intoxikationsamblyopie.

Seit 1 Jahr Abnahme der Sehschärfe. Sonst immer gesund. Keine Lnes. Starker Raucher, mässiger Potus.

Visus: Beiderseits o/20 Gl. b. n.

Pupillen reagieren prompt auf Licht und Konvergenz.

Augenbewegungen frei.

Ophthalmosk.: Beiderseits ausgesprochene temporale Abblassung de: Optici bei normalen Grenzen und Gefässen.

Gesichtsfeld: Relatives zentrales Skotom für grün und rot ( $5 \mathrm{qmm}$ ) zwischen Fixierpunkt (diesen nasal etwas übergreifend) und blindem Fleck.

Nenrologische Untersuchung ergibt normale Verhältnisse. 
Reflexcharakter d. Adaptationsvorgänge, insbes. d. Dunkeladaptation usw. 225

Serumdiagnose auf Lues negativ. In Urin kein Zueker.

Adaptation binokular nach $3 / 4$ stündigem Aufenthalt im Dunkeln 111 Schwellenwert $=4025$ Empfindlichkeitseinheiten.

15. A. S., 15 Jabre, Dienstmädchen. Sehnervenatrophie nach Staungspapille bei chronischem Hydrocephalus.

Seit früher Kindheit (ungefähr 5. Lebensjahr) sieht Patientin beiderseits schlecht. War angeblich niemals ernstlich krank.

Pupillen: Links etwas enger als rechts, L. schlechte direkte, prompte indirekte Reaktion auf Licht. $R$. Lichtreaktion und beiderseits Konvergenzreaktion normal.

Visus: R. ${ }^{6 / 15}-6 / 10(+1,5 D)$. L. E.-Z. $1 / 2-1 \mathrm{~m}$. stellung.

Angenbewegungen frei. Das linke Auge steht in leichter Divergenz-

Gesichtsfeld: R. mittlere konzentrische Einengung für Weiss, für Farben nur gering, so dass sich die peripheren Weiss- und Farbgrenzen genähert haben. L. hochgradige konzentrische Einengung. Farb- und Weissgrenzen fallen fast zusammen.

Ophthalmosk.: Papillen beiderseits fast ganz weiss, Grenzen verwaschen. Gefässe stark geschlängelt. L. kleine chorioretinitische Herde zentral.

Neurologisch ohne Befund.

Serumdiagnose negativ.

Lumbalpunktion: Druck $320 \mathrm{~mm}$.

Flüssigkeit klar. Keine Globuline, keine Albumine. Geringe Vermehrung der Lymphocyten.

Dunkeladaptation nach ${ }^{5} / 4$ stündigem Dunkelaufenthalt.

$$
\begin{aligned}
& \text { R. } 124=(>8764 E E) . \\
& \text { L. } 116=(5991 E E) .
\end{aligned}
$$

16. A. P., 21 Jahre, Tischler. Turmschädel.

R. Optikus granweiss, besonders unten, Grenzen leicht verwaschen.

L. Optikus etwas weniger blass, sonst wie $R$.

Strabismus concomitans divergens.

Visus: R. ${ }_{\mid 20}$ mit $+7,0 D$.

L. ${ }^{6 / 15}$ mit $+8,0 D$.

Gesichtsfeld beiderseits leicht konzentrisch eingeengt.

Pupillen reagieren prompt.

Dunkeladaptation: Sofort binokular 37, links 37, rechts 24

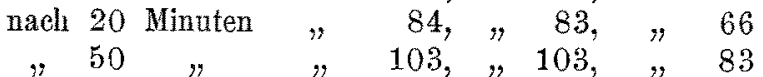

$(2422 E E)(1001 E E)$.

17. $\mathrm{Ph}$. A, Arbeiter, 42 Jahre. Einseitige Optikusatrophie nach Schädelbasisfraktur.

Früher gesund mit beiderseits gleich gutem Sehvermögen. Am 9. XII. 09 stürzte er $\left.13^{1}\right|_{2} \mathrm{~m}$ tief in einen Schacht hinunter, war 2 Tage olne Besinnung. Konnte dann in den folgenden Tagen seine Glieder nicht bewegen; dieses besserte sich jedoch langsam, so dass er nach 14 Tagen aufstehen konnte. Bis dahin trug er auch einen Kopfrerband. 
Gleich nach dem Unfall soll das rechte Auge blutunterlanfen gewesen sein; ungefähr 3 Wochen später bemerkte Patient, dass er mit diesem Auge schlechter sehen konnte als früher. Das Sehen hat sich almählich etwas gebessert.

Status praes: : Ro Enophthalmus, (Am Exophthalmometer R. $10 \mathrm{~mm}$, L. $12 \mathrm{~mm}$.) Narbe in den Supercilien aussen. Das Jochbein scheint leicht nach linten und nuten gepresst zu sein.

Der r. Bulbus steht etwas tiefer, ist leicht in seiner Beweglichkeit beschränkt (besonders beim Blick nach oben).

Pupillen: Anisokorie, rechts weiter als links. Direkte Lichtreaktion rechts etwas träge, indirekte und Konvergenzreaktion prompt. L. normal.

Ophthalmosk.: R. Optikus in toto blass-atrophisch, Gefässe und Grenzen sind nicht verändert. L. normal.

Visus: $\mathrm{R}_{0}=3 \%_{50} . \quad \mathrm{L}_{\mathrm{0}}=6 / 6$ beiderseits Emmetropie).

Dunkeladaptation: Sofort binokular 65 , rechts 65 , links 65 nach 10 Minuten $" 90, " 67, " 90$ " $50 \quad " \quad$ "110, \#102, "110.

Bei einer Nachprüfung an einem sehr trüben Tage war der Schwellenwert nach 50 Minuten beiderseits 125.

Gesichtsfeld: $R$. relatives zentrales Skotom fur Farben. Mittelgradige Einschränkung der peripheren Grenzen für Weiss, stärker für Farben; Ausfall der Farbempfindung im unteren nasalen Quadranten. L. normal.

Die jetzt folgenden Fälle betreften retinale Prozesse.

18. A. L, 19 Jahre, Knecht. Retinitis pigmentosa.

Eltern sind nieht verwandt. In der Familie kein Augenleiden. Während der Schulzeit schon schlechtes Sehvermögen, Pat. kann sich aber nicht erinnern, dass er damals auch des Abends besonders schlecht sehen konnte. Erst seit 3 bis 4 Jahren ist angeblich eine stärkere Abnahme des Sehvermögens im Dunkeln bemerkt worden, im Anschluss daran auch eine stärkere Abnahme des Selens an Tage.

Status praes.:

Visus: R. ${ }^{2} / 50^{\circ}$ L. 1/50. Durch Gläser keine Besserung.

Angenbewegungen: Mässiger Strabismus divergens, sonst ohne Befund.

Ophthalmosk.: Beiderseits ausgedehnte "Knochenkorperchen"-Pigmentflecke in der Peripherie, bis nahe an den Optikus heran, links mehr als rechts.

L. Optikus graugelb verfärbt, Grenzen nicht ganz seharf, Retinalgefässe stark verengt.

$R$. ähnlicher Befund, nur' etwas weniger stark ausgesprochen.

Gesichtsfeld: Hochgradige konzentrisehe Einengung mit Inversion der Farbgrenzen.

Dunkeladaptation: Beiderseits monokular und binoknlar 113

$=4667 \mathrm{EE}$. (Befund mehrfach geprüft.)

Serumdiagnose negativ. (Prof. Klingmüller.)

Hochgradige und typische hemeralopische Beschwerden. 
Reflexcharakter d. Adaptationsvorgänge, insbes, d. Dunkeladaptation usw. 227

19. Frau W. E., 36 Jahre. Retinitis pigmentosa.

Serumdiagnose: negativ.

Visus: R. mit $-4,5 D, S=6 \%$

L. mit eyl. $+3,0 . D, S=6 / 35$.

Ophthalmosk.: Rechte Papille normal, ringförmig in der Peripherie mässig viel Knochenkörperchen.

Linke Papille verwaschen, gelblich verfärbt, ausgedehnte typische Retinitis pigmentosa.

Gesichtsfeld: Rechts absolutes Ringskotom. Inversion der Farben zentral, Grenzen derselben: rot ungefähr $5^{0}$, blà $2-3^{0} \mathrm{um} F$.

Links Grenzen für Weiss nur leicht eingeengt. Blangrenze hochgradig und etwas unregelmässig konzentrisch eingeengt $\left(5-15^{0} \mathrm{um} F\right)$. Rot leicht konzentriseh eingeengt.

Dunkeladaptation: sofort binokular $48, \quad$ R. $48, \quad$ L. 22 , nach $\left.3\right|_{4}$ Stunden binokular $\quad 97, \quad, \quad 97, \quad, \quad 57$, in Empindlichkeitseinheiten $\quad, 1784, \quad$, 26. Ausgesprochene ond typische hemeralopische Besehwerden.

Epikrise: Trotz ausgesprochenen Störungen des farbentüchtigen Zapfenapparates, die sich durch die Inversion der Farbgrenzen und die beträchtliche Einschränkung für Blau ergeben, ist die Stäbchenfunktion in den gleichen Gesichtsfeldbezirken vollkommen normal auf dem rechten Auge. Die bestehenden hemeralopischen Beschwerden können daher unmöglich auf eine Herabsetzung der Dunkeladaptationsfähigkeit i. e. der Stäbchenfunktion zurückgeführt werden, wie es der Fall 17 in durchaus einwandsfreier Weise ebenfalls zeigt.

In den folgenden Fälen hat auch die Dunkeladaptation nun mehr oder weniger hochgradig gelitten.

20. J. M., 18 Jahre, Arbeiter. Seit Kindheit schlechtes Sehen beiderseits. Das Sehen verschlechtert sich noch bedeutend mehr des Abends und im Dunkeln, so dass Pat. sich jetzt kaum allein zurechtfinden kann.

Visus: R. mit $-4,\left.0 D{ }^{6}\right|_{20}$ fast, L. mit $-4,\left.0 D{ }^{5}\right|_{20}$

Pupillen reagieren prompt.

Ophthalmosk: Optici beiderseits graugelb verfärbt. Typische Retinitis pigmentosa.

Dunkeladaptation nach ${ }_{1 / 2}$ Stunde binokular Sehwellenwert $68=625 \mathrm{EE}$.

Gesichtsfeld: Grosses absolutes Ringskotom beiderseits. Grenzen zentral für Weiss $5-8^{0}$ um $F$ für Farben.

21. F. A., 45 Jahre, Arbeiter. Retinitis pigmentosa sine pigmento.

Seit längeren Jahren fortschreitende Verschlechterung des Sehens, besonders im Dunkeln.

Visus: Beiderseits $6 / 10^{*}$

Ophthalmosk.: Beiderseits graugelbe Verfärbung der Optici mit mässiger Verengerung der Gefässe. Fundus tabulatus. In der Peripherie finden 


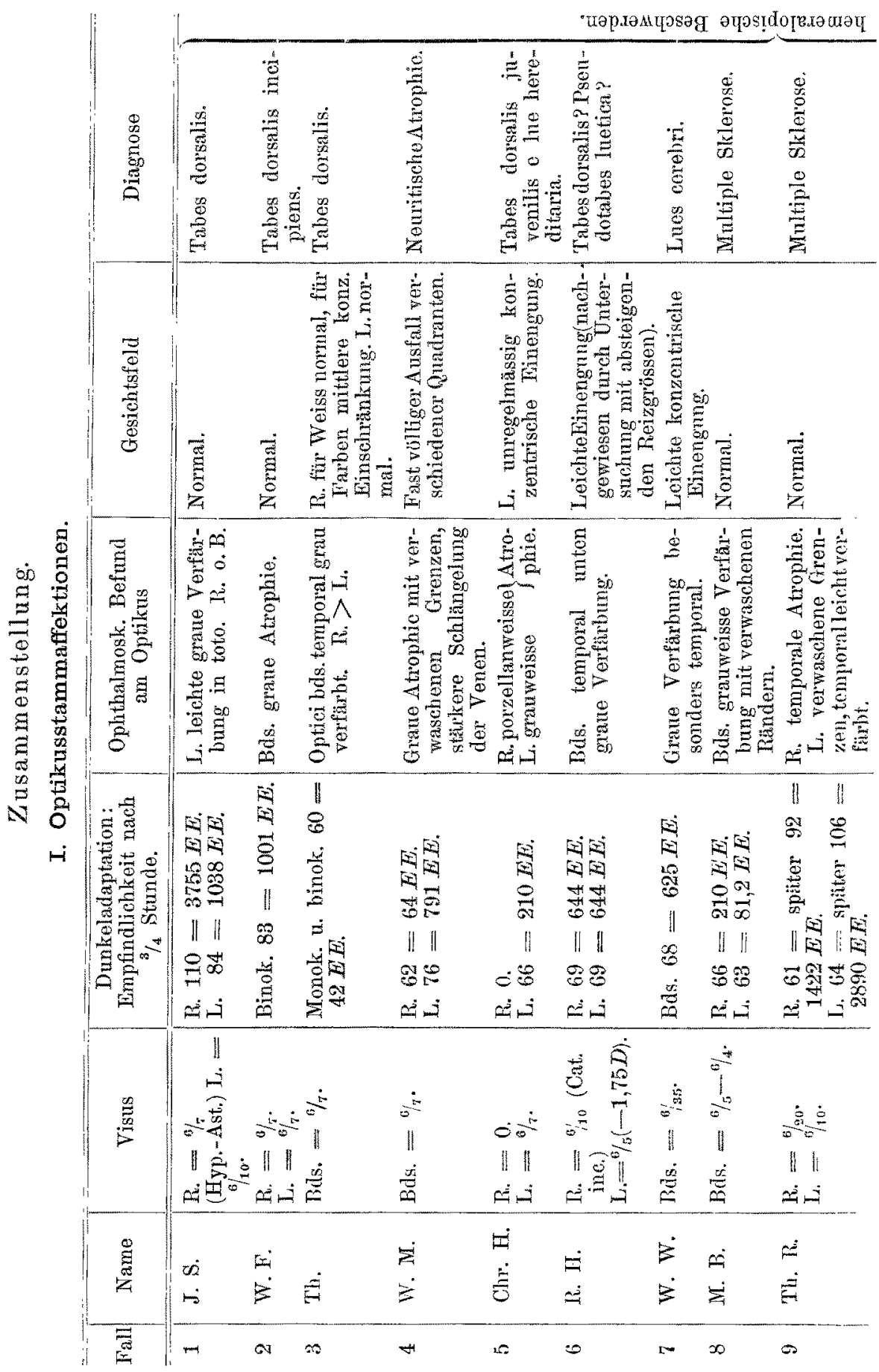


Reflexcharakter d. Adaptationsvorgänge, insbes. d. Dunkeladaptation usw. 229

\begin{tabular}{|c|c|c|c|c|c|c|c|c|c|c|c|c|}
\hline \multicolumn{8}{|c|}{ 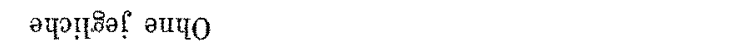 } & \multicolumn{5}{|c|}{ 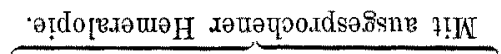 } \\
\hline 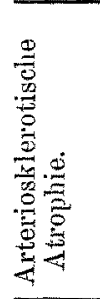 & 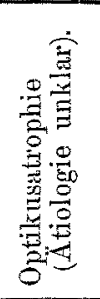 & 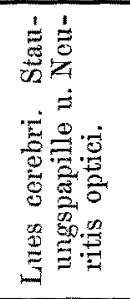 & 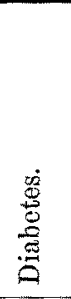 & 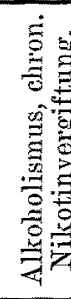 & 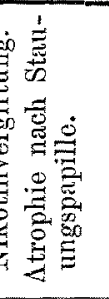 & 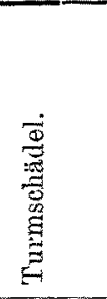 & 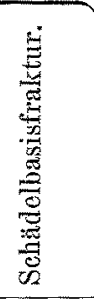 & 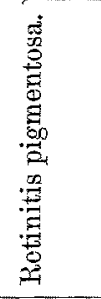 & 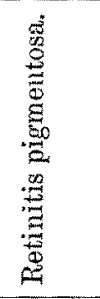 & 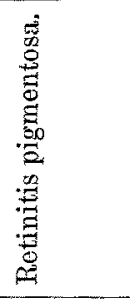 & 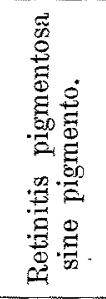 & 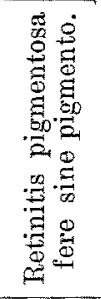 \\
\hline 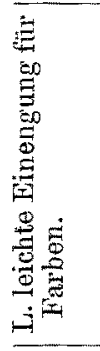 & 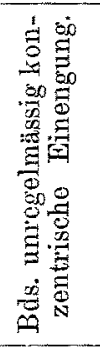 & 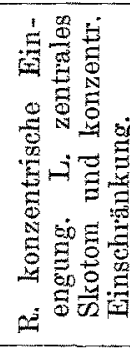 & 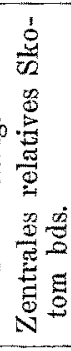 & 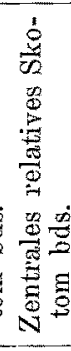 & 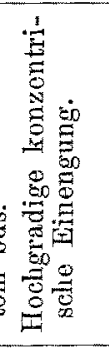 & 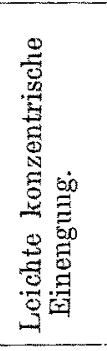 & 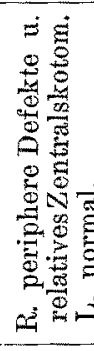 & 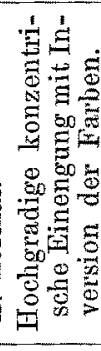 & 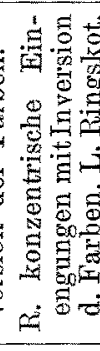 & 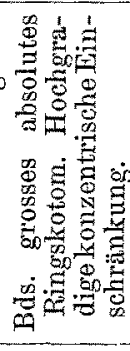 & 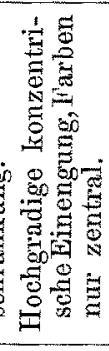 & 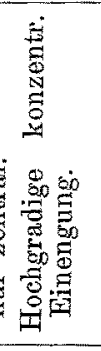 \\
\hline 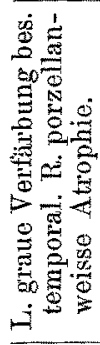 & 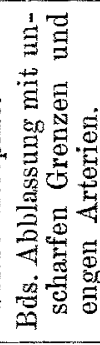 & 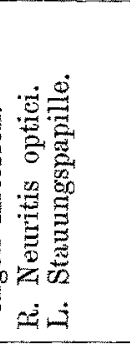 & 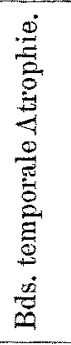 & 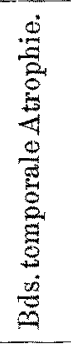 & 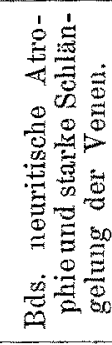 & 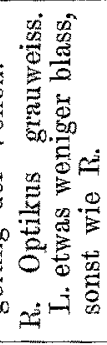 & 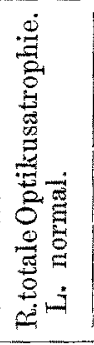 & 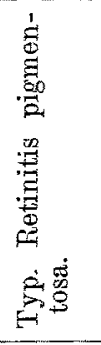 & 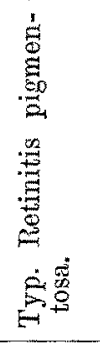 & 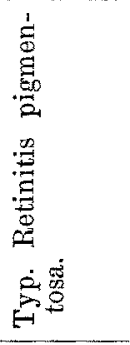 & 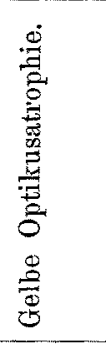 & 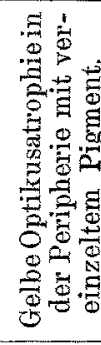 \\
\hline . & $\begin{array}{l}0 \\
01 \\
-10 \\
11 \\
8 \\
0 \\
0 \\
0\end{array}$ & 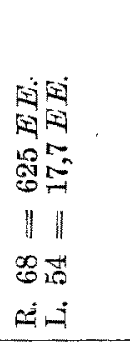 & $\begin{array}{l}60 \\
5 \\
5 \\
61 \\
11 \\
0\end{array}$ & 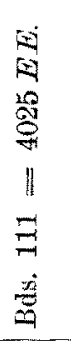 & 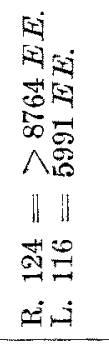 & 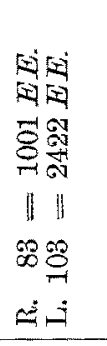 & 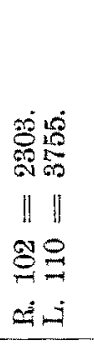 & 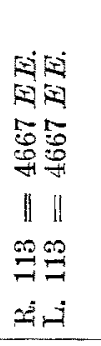 & 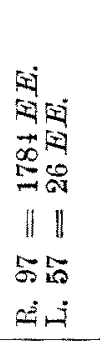 & 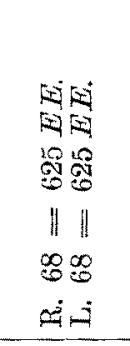 & 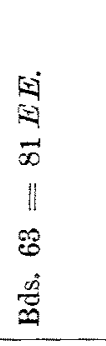 & 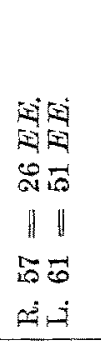 \\
\hline$\dot{s}$ & 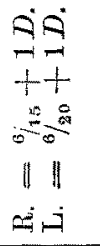 & 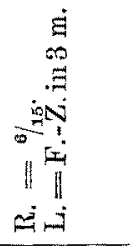 & 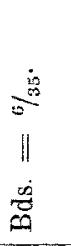 & $\begin{array}{c}\dot{\vec{\theta}} \\
\frac{\theta}{\theta} \\
\|\end{array}$ & 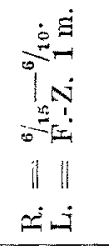 & 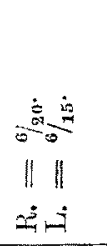 & 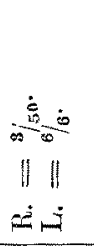 & 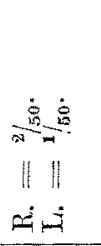 & 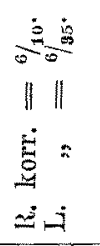 & 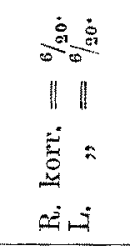 & $\begin{array}{l}\dot{\dot{\theta}} \dot{\theta} \\
\|\| \\
\| \dot{1}\end{array}$ & 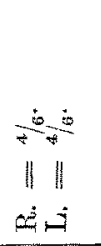 \\
\hline & $\dot{\vec{B}}$ & i & $\dot{\vec{i}}$ & 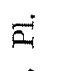 & $\dot{x}$ & 2 & 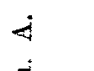 & - & = & i & $\dot{4}$ & $E$ \\
\hline & $\dot{z}$ & $\dot{4}$ & $\dot{s}$ & $\dot{\nexists}$ & $\dot{4}$ & $\dot{4}$ & $\overrightarrow{\nexists z}$ & 4 & 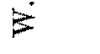 & $\dot{s}$ & $E$ & $\ddot{H}$ \\
\hline & & & $\rightarrow$ & $\Xi$ & $\stackrel{20}{2}$ & & 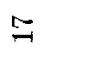 & & & 尽 & $\vec{\sigma}$ & 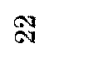 \\
\hline
\end{tabular}


sich nur ganz vereinzelt kleine Pigmentleckehen. Bei einem Aufenthalt in der Klinik vor zwei Jahren waren diese noch nicht vorhanden. sonst $0 . \mathrm{B}$.

Pupillen: R. = L., Liohtreaktion ist rechts etwas schlechter als links,

Gesichtsfeld: Ziemlich hochgradige konzentrische Einengung für Weiss, der Farbensinn ist nur noch zentral erhalten.

Typische Hemeralopie.

Dunkeladaptation: sofort binokular 52, R. 44, L. 52

nach 30 Minuten $61,, 61,, 61$

"60 "63, "63, "63=81EE.

22. H. E. Retinitis igmentosa fere sine pigmento.

Abnahme des Visus im Dunkeln seit dem siebenten Lebensjalnr.

Visus: Beiderseits ${ }^{4} / 6$.

Ophthalmosk: Beiderseits sind die Optici graugelb verfärbt, die Grenzen verwaschen, die Gefässe eng, die Peripherie ist überall leicht gekörnt, ganz vereinzelt findet sich Pigment.

Gesichtsfeld: Hochgradige konzentrische Einengung. Farben nur zentral exkannt, Rot besser als Blau.

Dunkeladaptation nach 50 Minuten binokular 61, R. 57, L. 61 $=$ R. 26, L. $51 E E$.

Von Horn sind ebenfalls Fälle von typischer Retinitis pigmentosa mitgeteilt, in denen die Dunkeladaptation (und damit die Stäbchenfunktion) sowohl in ihrem Empfindlichkeitsanstieg wie in dem erreichten Empfindlichkeitsmaximum vollkommen normal war. Leider fehlen in seinen Mitteilungen nähere Angaben über die Funktionstuichtigkeit des Zapfenapparates (Gesichtsfeld, Sehschärfe). - Dass durch den der Retinitis pigmentosa zugrunde liegenden anatomischen Prozess auch die Stäbchenfunktion in bezug auf die Dunkeladaptation mehr oder weniger empfindlich geschädigt werden kann, beweisen die letzten von mir mitgeteilten Fälle, wie sio in ähnlicher Form auch von Lohmann und Stargardt beschrieben sind.

Irgendwelche feste Beziehungen zwischen der Schädigung des Zapfenapparates und der Schädigung des Stäbchenapparates bestehen nicht. Aus meinen Fällen ist ersichtlich, dass die Zapfentätigkeit (Sehschärfe bzw. Gesichtsfeld) hochgradig gestört sein kann, während die Stäbchenfunktion keine Herabsetzung aufweist (Fall 18 und 19), anderseits kann umgekehrt bei relativ normaler Sehschärfe eine ganz bedeutende Beeinträchtigung der Dunkeladaptation bestehen.

Wenn wir unter Hemeralopie nach der üblichen Auffassung eine Störung der sofortigen Anpassungsfähigkeit der Netzhaut an eine plötzliche Verminderung des einwirkenden Reizlichtes verstehen, so geht aus meinen Fällen und denen Horns hervor, dass diese Störung 
nicht auf eine Beeinträchtigung der Funktion der Stäbchen zurückzuführen ist. Ihre Anpassungsfähigkeit kann bei typischer Retinitis pigmentosa (mit ausgesprochener Hemeralopie) entsprechend ihrem Verhalten unter physiologischen Verhältnissen durchaus normal sein.

Wenn demgegenüber die Zapfenfunktion in bezug anf die Sehschärfe normale Verhältnisse aufweisen kann, so zeigen uns doch anderseits die typischen Störungen des Farbensinns im Gesichtsfeld und besonders das Verschwinden der Farbempfindung bei herabgesetzter Beleuchtung, dass eine Störung der Zapfenfunktion in jedem Fall zu den typischen Symptomen gehört. Wir werden daher nicht fehlgehen, wenn wir auf Grund der eben genannten bekannten und der mitgeteilten neuen Beobachtungen die Hemeralopie auf eine Schädigung lediglich der Zapfentätigkeit zurückführen.

Aus dem verschiedenen Verhalten der Stäbchenfunktion dürfen wir dann wohl auch weiter den Schluss ziehen, dass der zugrunde liegende anatomische Prozess kein einheitlicher ist, wie es ja auch die Verschiedenheit des ophthalmoskopischen Bildes bei sonstigem gleichem Befund wahrscheinlich macht.

Aus meiner Zusammenstellung ergibt sich weiter, dass der Stäbchenund Zapfenapparat durch einen anatomischen Prozess im Nerv. opticus in ganz verschiedener Weise funktionell beeinträchtigt wird. Auf der einen Seite sehen wir eine hochgradige Herabsetzung, wenn nicht gar ein völliges Erlöschen der Stäbchenfunktion beim Dämmerungssehen, während die Zapfenfunktion in den gleichen Netzhautbezirken nicht die geringste Beeinträchtigung aufweist (die Sehschärfe ist normal, ebenso der zentrale und parazentrale Farbensinn: Fall 1 bis 6 und Fall 8, in den Fällen 1, 2, 3 und 8 zeigt dabei auch das periphere Gesichtsfeld nicht die geringsten Störungen). Ist auch die Zapfenfunktion in mehr oder weniger starkem Grade beeinträchtigt und die Sehschärfe auf ${ }^{6} /{ }_{15},{ }^{6} / 20$ und mehr herabgesetzt, so braucht darum die Störung der Stäbchenfunktion keineswegs in entsprechender Weise erheblicher zu sein (Fall 5, 7 und 11).

A uf der andern Seite kann die Zapfenfunktion eine hochgradige Störung aufweisen, ohne dass die Stäbchentätigkeit im Dämmerungssehen die geringste Störung zeigt (Fall 15, 17, 18).

Die isolierte Funktionsstörung des Stäbchenapparates bei absolut oder relativ normaler Funktion des Zapfensystems finden wir nach den obigen Untersuchungen vorzugsweise bei einfach degenerativen, entzündlich degenerativen und rein entzündlichen Prozessen am Optikus (tabische, luetische und neuritische Atrophie). 
Eine besondere Stellung nimmt die Erkrankung des Optikus bei multipler Sklerose ein. In beiden mitgeteilten Fällen fand sich, gewissermassen im akuten Stadinm, eine hochgradige Herabsetzung der Stäbchenfunktion gegenüber keiner oder nur einer leichteren Beeinträchtigung der Zapfenfunktion. In beiden Fällen stellte sich aber nach dem Abklingen der Exacerbation die Stäbchenfunktion in überraschender Weise wieder her.

In ganz anderer Weise werden demgegenüber die beiden visuellen Apparate durch diejenigen Prozesse beeinflusst, welche vorzugsweise mechanisch durch Druck schädigen. Die Stäbchenfasern scheinen in diesen Fällen eine grössere Widerstandsfähigkeit bzw. ein bei weitem ausgiebigeres Vermögen, sich zu regenerieren, zu besitzen als die Zapfenfasern (Fall 15, 17).

Eine besondere Stellung kommt dann den axialen degenerativ entziindlichen Optikusaffektionen zu (Alkohol, Nikotin, Diabetes), insofern als bei ihnen eine Störung der Stäbchenfunktion nicht zu bestehen braucht, wie die Fälle 13 und 14 zeigen. In ihnen finden wir trotz einer relativ erheblichen Herabsetzung der Sehschärfe eine vollkommen normale Dunkeladaptation. Die Erklärung dafür diurfte in diesen Fällen eine prinzipiell andere sein als in den vorher erwähnten. Der für das zentrale Sehen in Betracht kommende Teil des optischen Apparates, welcher hier isoliert gestört ist, hat in bezug auf die Funktion des Dämmerungssehens nur eine untergeordnete Bedeutung, so dass ein relativer Ausfall dieses Teiles keine nachweisbare Störung der Stäbchenfunktion nach Massgabe unserer Untersuchungsmethode bedingt. Damit soll aber nicht ausgeschlossen werden, dass durch feinere Methoden in den funktionell beeinträchtigten Gesichtsfeldpartien auch eine Störung des Dämmerungssehens nachgewiesen werden könnte.

Als weiteres Ergebnis der obigen Untersuchungen ist das Feblen jeglicher hemeralopischer Beschwerden bei Störungen des Dämmerungssehens zu nennen. In keinem Fall, selbst nicht in denen mit den höchstgradigen Hemmungen oder möglicherweise mit einem totalen Ausfall der Stäbchenfunktion, waren die von $\mathrm{K}$ rienes als konstant genannten Symptome der Hemeralopie neben den bekannten subjektiven Beschwerden yorhanden (Herabsetzung des zentralen quantitativen Farbensinnes, besonders des Blausinnes, bei Tageslicht; Verschwinden des Blau por Rot bei herabgesetzter Beleuchtung; Einengung der Farbengrenzen, besonders der Blaugrenzen, bei Tageslicht, abnorme Pupillenweite im Dunkeln usw.). Demgegenuiber lehren 
die Fälle 18 und 19, dass trotz einer normalen Stäbchenfunktion eine typische und hochgradige Hemeralopie vorhanden sein kann.

Auch aus der Gegenüberstellung dieser beiden Beobachtungen dürfte sich meines Erachtens mit einer gewissen Notwendigkeit der Schluss ergeben, dass der unter dem Namen der Hemeralopie oder Torpor retinae bekannte Symptomkomplex an sich nichts mit einer Erkrankung des Stäbchenapparates zu tun hat, wie wir bereits oben ausgeführt haben. In einigen Fällen der ersteren Art wurde zwar angegeben, dass die betr. Patienten im Dunkein schlecht lesen konnten. Diese Angabe einer angedenteten Hemeralopie zeigt schon durch sich selbst, dass sie auf eine Störung der Zapfenfunktion der Fovea centralis zu beziehen ist. Sie ist in ihrer Art auch eine Stuitze für die Anschauung, dass die Hemeralopie vielmehr auf eine Störung der Zapfenadaptation zu beziehen ist. Die Anpassung an plötzliche stärkere Schwankungen der Helligkeit, insbesondere an eine plötzliche Herabsetzung der Helligkeit, war bei allen meinen Patienten der Fälle 1 bis 17 in keiner Weise von der normaler Menschen zu unterscheiden.

Durch meine Untersuchungen ist dann weiter festgestellt, dass zwischen der Stäbchenfunktion und der Pupillarreaktion keine Beziehungen bestehen. Die Stäbchentätigkeit kann höchstgradig beeinträchtigt sein, ohne dass die Pupillarreaktion weniger prompt und weniger ausgiebig ist. Eine nennenswerte pupillomotorische Valenz dürfte demnach dem Stäbchenapparat nicht zukommen.

Wenn wir uns nun zum Schluss noch fragen, in welcher Form sich der Ausfall der Stäbchenfunktion beim Tagessehen äussert, so sehen wir, dass eine Beeinflussung der optischen Eindrücke in diesem Fall nicht nachweisbar ist. Die Patienten geben sämtlich auf das bestimmteste an, dass sie genau so sehen wie früher. Insbesondere zeigen die Fälle, in welchen eine grössere Differenz in der Funktionstüchtigkeit der Stäbchen zwischen beiden Augen besteht, dass die optischen Eindrücke jedes einzelnen Auges bei abwechselnder Beobachtung während des Tagessehens nicht die geringsten qualitativen Differenzen aufweisen.

Mit grosser Wahrscheinlichkeit darf demnach mit Berücksichtigung der physiologischen Eigentümlichkeiten der Stäbchentätigkeit angenommen werden, dass der Stäbchenapparat während der visuellen Tätigkeit am Tage so gut wie gar nicht in Tätigkeit tritt.

Von Lohmann sind Fälle von chronischer Intoxikationsamblyopie r. Graefe's Archiv für Ophthalmologie. LXXV. 2. 
veröffentlicht, welche ebenso wie meine. Fälle keine Störungen der Dunkeladaptation aufwiesen, ferner von Horn drei Fälle von Stauungspapille, welche bei normaler Funktion des Zapfenapparates einen normalen Ablauf der Empfindlichkeitszunahme der Stäbchen während des Dunkelaufenthaltes zeigten. Sie sprechen ebenfalls im Sinne meiner Fälle und der aus jhnen sich ergebenden Schlüsse. Fon beiden Autoren und neuerdings auch von Stargardt ist eine Störung der Dunkeladaptation bei tabischer Optikusatrophie beobachtet, jedoch war in diesen Fällen eine mehr oder weniger hochgradige Herabsetzung der zentralen Sehschärfe als Zeichen einer schon weit vorgeschrittenen Leitungsbehinderung sämtlicher zentral leitender Optikusfasern vorhanden.

Durch vergleichende Untersuchungen der zentralen Empfindlichkeit der Netzhaut von Hemeralopen und Normalen nach Dunkelaufenthait hat $\mathrm{Hess}$ festgestellt, dass dieselbe deutlich geringer als in normalen Augen ist. Er kommt zu dem mit meinen Befunden durchaus übereinstimmenden Schluss, dass die Sehpurpurregeneration und damit auch die Stäbchenfunktion mit der Hemeralopie nichts au tun hat.

\section{Zusammenfassung.}

In manchen Fällen von entzündlichen und degenerativ entzündlichen Optikusprozessen kann als ein Frühymptom eine hochgradige Störung der Dunkeladaptation (Stäbchenfunktion) bestehen, bevor irgendeine Beeinträchtigung der Sehschärfe und des Farbensinns (Zapfenfunktion) nachweisbar ist. Dagegen kann in den mehr durch Druckschädigung zu stande kommenden Leitungshemmungen im Optikus die Stäbchenfunktion länger erhalten geblieben bzw. sich sehr viel vollkommener wieder restituiert haben als die $Z$ apfenfuntion.

Trotz einer höchstgradigen Funktionsstörung der Elemente des Dämmerungssehens können jegliche hemeralopische Beschwerden fehlen, anderseits kann bei einer a usgesprochenen Hemeralopie die Dunkeladaptation sensu strictiori sowohl in bezug auf ihren Ablauf wie auf ihren erreichten Endwert rollkommen normal sein.

Trotz hochgradiger Störung der Dunkeladaptation (und damit der Stäbchenfunktion) kann die Lichtreaktion der Pupille vollkommen normal sein. 
Bei multipler Sklerose kann eine hochgradige Beeinträchtigung der Dunkeladaptation bzw. der Stäbchenfunktion neben einer leichten, ophthalmoskopisch nachweisbaren Veränderung der Papille als einziges Symptom eines frischen Herdes im Optikus bestehen. Mit dem Abklingen der akuten Erscheinungen kann sie sich dann trotz fortschreitender Atrophie der Papillen und event. auch Abnahme der Sehschärfe wieder völlig restituieren.

\section{Chiasmaerkrankungen.}

1. E. B., 60 Jahre, ohne Beruf. Meningitis chron.

Neuropathiseh schwer belastet. Im 14. Jahr Nervenfieber. Im 30. Jahr Gelirnhantentzündung, damals $1 \frac{1}{2}$ Jahr bettlägerig. Seitdem andanernd quälender Kopfdruek und starke Kopfschmerzen, besonders beim Husten, Niesen und heftigen Bewegungen exacerbierend. Zeitweise sind sie unerträglich. Beim Bücken jetzt seit einiger Zeit Flimmern vor den Augen, ebensolange zunehmende Sehwere in den Augenlidern.

Status praes.: Beiderseits Ptosis paralytica, die Lider decken jedoch die beiden Corneae nieht völlig.

Visus: R. mit cyl. $+1,0 \mathrm{D}$ A. hor. $S=\left.{ }^{6}\right|_{10}-6 / 7$.

L. $+1,5 D$ comb. cyl. $-1,0 D$ A. senkr. $S=6 / 2-6 / 10$.

Pupillen: Rechts $=$ links, $2,5 \mathrm{~mm}$, reagieren prompt auf Licht und Konvergenz.

Augenbewegungen frei.

Ophthalmosk.: Auf beiden temporalen Papillenhälften findet sich eine ganz geringe weissgrau-rötliche Verfärbung; sonst ohne Befund.
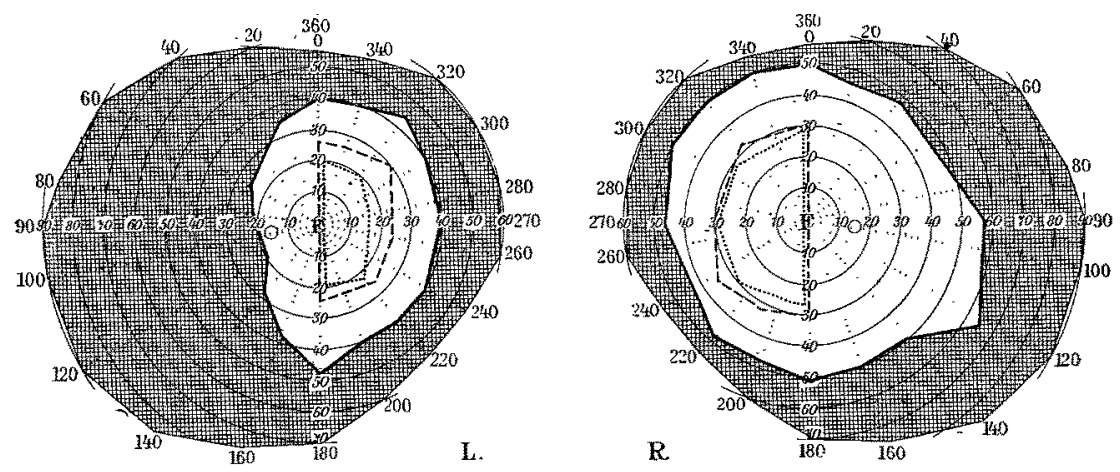

Fig. 2.

Gesichtsfeld: Bitemporale Hemiachromatopsie (5 qmm). Die Trennungslinie geht durch den Fixierpunkt. Die Weissgrenzen $(5 \mathrm{qmm})$ der temporalen Hälften zeigen eine hochgradige Einengung L. $>$ R. Die Farben- und Weissgrenzen der nasalen Hälften sind leicht konzentrisch eingeengt $\mathrm{L} .>\mathrm{R}$. Untersuchung anf hemianopische Pupillenstarre ergibt auf dem linken 
Ange eine dentliche Starre, wenn das Licht von links ins Ange fälti. (Untersuchung mittels der an anderer Stelle von mir mitgeteilten Methode.)

Dunkeladaptation (nach $3 / 4$ stïndigem Dunkelaufenthalt am Dunkelperimeter):

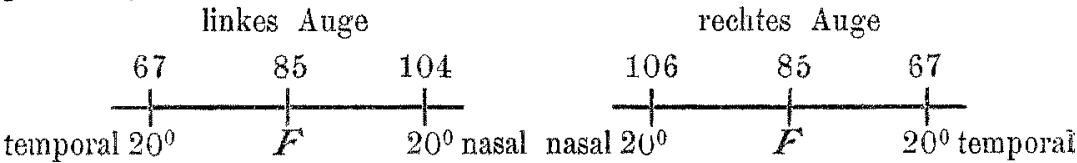

In Empfindlichkeitseinheiten:

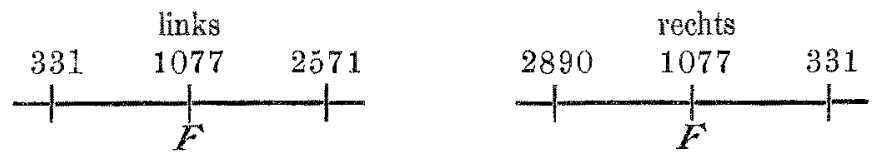

Die Allomeinuntersuchung: (Med. Klinik) ergab: Kleines adiposes Fräulein. Aligemeine Arteriosklerose. Bhutdrucksteigerung (200 mm Riva Rocei). Neurologisch ohne Befund. Urin frei.

Serumdiagnose auf Lues negativ (mehrfach wiederbolt). (Prof. Klingmüller.)

Eine Nachmtersuchung drei Monate später ergab beiderseits eine ausgesprochene partielle Atrophie der Optici.

L. Optikus: Temporal grauweiss mit einem ganz leichten rötlichen Schimmer, nasal noch deutlich rötlieh, aber mit grauem Unterton.

R. Optikus: Temporal im mittleren Sektor grauweiss verfärbt, sonst aberall rötlich (vielleielt etwas in toto abgeblasst). Grenzen und Gefầsse beiderseits ohne Befund.

Gesiehtsfeld: Bitemporale Hemiachromatopsie.

L. uberschreitet die Weissgrenze temporal die vertikale Trennungslinie um einige wenige Grade $(5)$. $R$. geht die Weissgrenze temporal noch bis $20^{\circ}$ in der horizontalen. In den nasalen Hälften links hochgradige, rechts mittlere konzentrisehe Einengung für Weiss und für Farben.
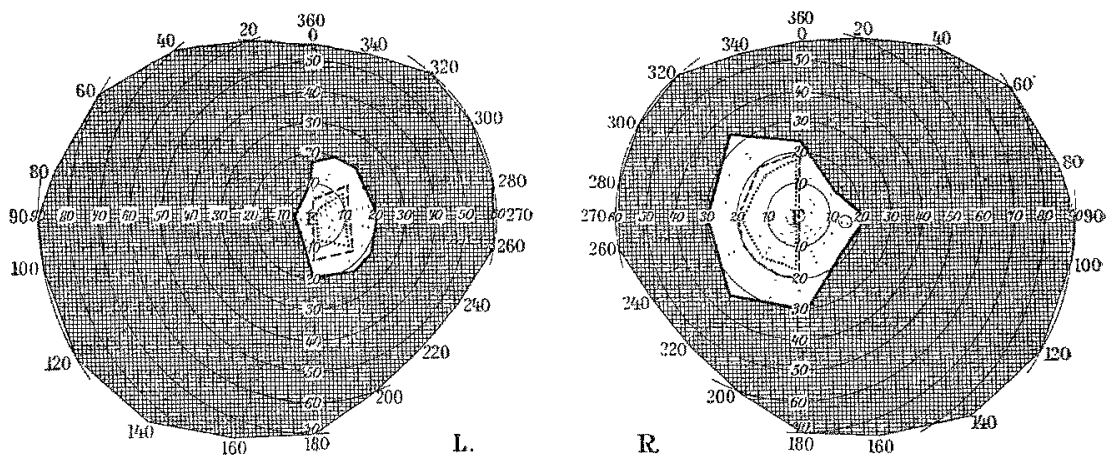

Fig. 3.

Pupillarreaktion bei fovealer Belichtung prompt. 
Dunkeladaptation nach $3 / 4$ stündigem Dunkelaufenthalt:

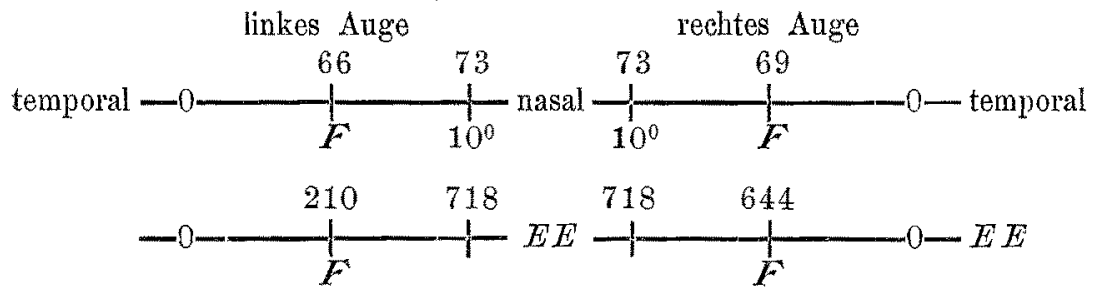

Visus: R. $\%$ mit Korrektion

L. $\left.{ }^{6}\right|_{50} ", "$

Patientin wurde in die "medizinische Klinik zwecks Vornahme einer Lumbalpunktion anfgenommen. (Prof. Wandel) Dieselbe ergab: Druck $205 \mathrm{~mm}$, im Zentrifugat finden sich sehr wenig Formelemente (Lymphocyten). Eiweissgehalt $1 / \%_{00}$. Nach der Punktion füllte sich die Patientin subjektiv wohler und freier im Kopf. Im Sehen ebenfalls angeblich Besserung.

Untersuchrong 8 Tage später: Visus: R. mit $+1,0 D S=6 / 15$

Ophthalmosk.: Wie frtiher; ebenso Gesichtsfeld.

L. mit $-1,0 D S=\left.6\right|_{35}$ (langsam).

Dunkeladaptation nach 1 stïndigem Dunkelaufenthalt:
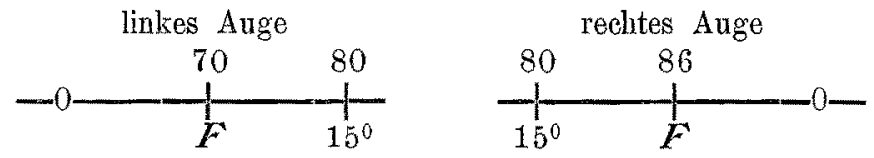

in Empfindlichkeitseinheiten:
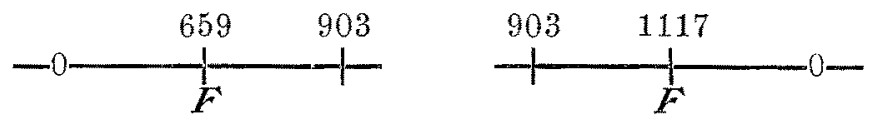

Epikrise: Dreissig Jahre nach Überstehen einer Gehimhautentzïndung stellte sich eine unter unsern Augen zunehmende doppelseitige Optikusatrophie und eine doppelseitige Ptosis ein. Als Sitz der Erkrankung wurde durch die Gesichtsfelduntersuchung das Chiasma, und zwar die Gegend zwischen vorderem und hinterem Winkel, besonders auf der linken Seite festgestellt. Dass es sich im vorliegenden Falle nicht um das Hinzutreten einer neuen Erkrankung, sondern um ein Aufflammen des alten Leidens handelt, macht der Umstand wahrscheinlich, dass die Patientin in der Zwischenzeit niemals ganz beschwerdefrei war. Als Ursache der Erkrankung ist demnach mit grösster Wahrscheinlichkeit ein chronischer meningitischer Prozess anzusehen, dafür spricht der Befund der Lumbalpunktion und die Lokalisation am Chiasma und in der Fossa interpeduncularis. Eme Lues ist mit grosser Wahrscheinlichkeit auszuschliessen, da keine An- 
haltspunkte für eine solche in der Anamnese und dem Allgemeinbefund vorhanden sind. Die bestehende Arteriosklerose därfte wohl in keinem direkten Zusammenhang mit dem cerebralen Leiden stehen.

Es war in diesem Fall auch an einen exacerbierenden chronischen Hydrocephalus internus zu denken, der durch Ausdehnung des Recessus des III. Ventrikels die Chiasmamitte geschädigt haben konnte. Die Entscheidung der Frage war in bezug auf die einzuschlagende Therapie von Bedeutung, insofern als dann zur Erhaltung des Sehvermögens eine Palliativtrepanation in Frage gekommen wäre. Die Besserung, die sowohl subjektiv wie objektiv nach der Lumbalpunktion eintrat, schien in gewissem Sinne für diese Ansicht zu sprechen. Dex klinische Befund sprach aber mit so schwerwiegenden Gründen dagegen, dass wir die Diagnose Hydrocephalus fallen lassen mussten. Denn wenn die Chiasmaaffektion in erster Linie durch Druckschädigung infolge Ausdehnung des Recessus des III. Ventrikels verursacht wäre, dann war die Beeinträchtigung der ungekreuzten Fasern beiderseits am äusseren Chiasmawinkel nicht erklärt, anderseits gehört eine isolierte doppelseitige Oculomotoriuslähmung, welche ausserdem allein die die Levatores palpebrarum versorgenden Aste betraf, durchaus nicht zum Bilde eines Hydrocephalus. Ausserdem fehlte eine Staungspapille. Mit der Annahme einer entzïndlichen Affektion stimmt auch die hochgradige Beeinträchtigung der Dunkeladaptation in den noch erhalten gebliebenen Teilen der nasalen Gesichtsfeldhälften überein, welche, wie aus den vorhergehenden Ausfuhrungen sich ergab, vorzugsweise bei entzündlichen, weniger bei einfach komprimierenden Prozessen einzutreten pflegt.

Dass durch eine Lumbalpunktion ein chronischer meningitischer Prozess subjektiv und auch objektiv zeitweise gebessert werden kann, ist eine bekannte klinische Erfahrung.

2. H. 'Th., 61 Jahre, Schneider.

Sah angeblich stets nur mit Brille gut. Seit einem Jahr Abnahme đes Visus beiderseits. Ist seit 6 Wochen schon wegen Sehnervenerkrankung in augenärztlicher Behandlung. Im vorigen Jahr zweimal an Gürtelrose erkrankt. Sonst immer gesund. Ab und zu Kopfschmerzen. Sonst keinerlei cerebrale Beschwerden. Keine Lues, kein Poitus. Keine Polydipsie oler Wachstumsstörungen.

Status praes. Pupillen: Links weiter als rechts $(2,5: 2,0 \mathrm{~mm})$. Reaktion auf Licht bei fovealer Belichtung deutlich beiderseits vorhanden, Aussehlag der Verengerung ist jedoch selır gering. Konvergenzreaktion ist beiderseits prompt.

Augenbewegungen frei. 
Reflexcharakter d. Adaptationsvorgänge, insbes. d. Dunkeladaptation usw. 239

Visus: Beiderseits mit $+3,0 \mathrm{DS}=6 / 15$.

Ophthalmosk.: $\mathrm{R}$. ausgesprochen atrophische Verfärbung der temporalen Papillenhälfte, nasal noch deutlich rote Färbung.

L. temporale Atrophie, nasal noch rötlich, aber weniger als R. Grenzen, Gefässe beiderseits ohne Befund.

Gesichtsfeld: Bitemporale Hemianopsie. Absolut fuir Farben und kleinere weisse Objekte (Trennungslinie geht durch $F$ ). Bewegungen grosser weisser Objekte $(40 \mathrm{qmm})$ werden beiderseits in einem nach der Peripherie zu zackig begrenzten Bezirk in der Form einer mittleren konzentrischen Einschränkung um $F$ als ,Flimmern" erkannt. Der" Übergang von dem absoluten in diesen relativen Defekt ist ein allmählicher, so dass die Angaben der Grenzen wechseln. In den nasalen Hälften sind die Farb- und Weissgrenzen durchaus normal.

Halbseitige Pupillarreaktion; Nur vereinzelt erfolgt bei seitlicher Belichtung eine geringe Pupillenverengerung, diese findet sich nur bei Belichtung von der Nasenseite aus beiderseits (Binoknlarlupe).

Wilbrandscher Prismenversuch: Es erfolgt keine Einstellung, wenn die Basis des Prisma nasenwärts, dagegen eine prompte Einstellung, wenn die Basis schläfenwärts gerichtet ist (monokular gepruift beiderseits). aufenthalt:

Dunkeladaptation am Dunkelperimeter nach ${ }^{3}$ stïndigem Dunkel-

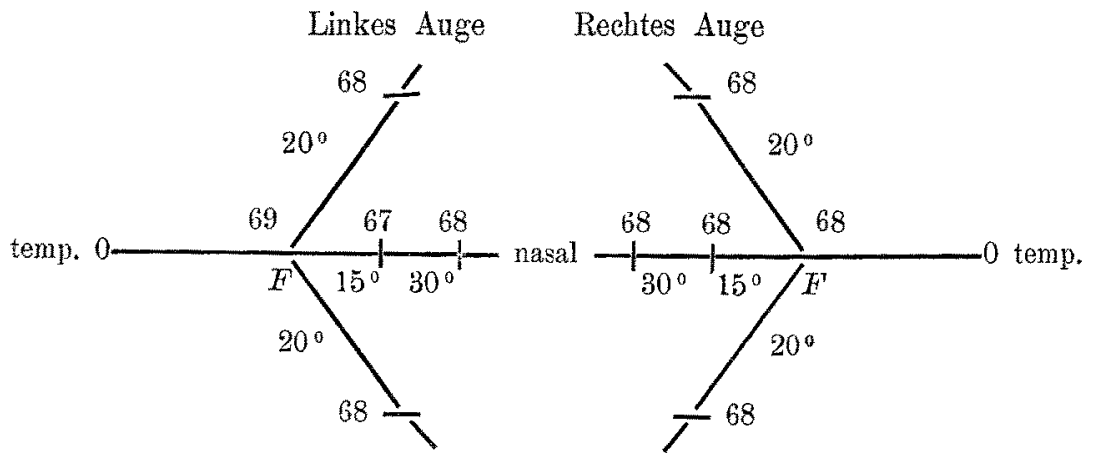

In Empindlichkeitseinheiten ausgedriickt sind die Zahlen (67) 331

(68) 625

(69) 644

Allgemeinuntersuchung: Kleiner schmächtiger, abgemagerter Mann. Auffallende Blässe der Haut und Schleimhant und leichte gelbliche Verfảrbung der Gesichtshaut. Emplysem. Cor.: Klappender II. Pulm.-T. Urin frei. Puls 64.

Grobe Kraft mangelhaft, rechts gleich links. Sehnervenreflexe sämtlich gesteigert. Kein Fussklonus, kein Babinski, keine Ataxie, kein Romberg.

Sensibilität und Hautreflexe intakt.

Gehirnnerven sonst ohne Befund. Comealreflexe beiderseits hochgradig herabgesetzt.

Nach Probefrühstïck (in dex medizinischen Klinik) Fehlen der $\mathrm{HCl}$ (Diagnose: sehr verdächtig auf Carcinoma ventriculi). 
Hämoglobingehalt (Gowers) $100 \%$.

Röntgenbild des Kopfes ohne Besonderheiten.

Serumdiagnose negativ (Prof. Klingmüller).

Lumbalpunktion: Druck $365 \mathrm{~mm}$. Flüssigkeit klar. Line Vermehrung der Globuline, starke Vermebrung der Albumine. Keine Lymphocytose.

Blutdruek: Riva-Rocei $130 \mathrm{~mm}$ Hg.

Patient machte zunächst eine Schmierkur durch, welche keine Änderung der Symptome zur Folge liatte. Während einer zweimonatlichen klinischen Beobachtung treten im Anschluss an eine zweite Lumbalpunktion (Druck $230 \mathrm{~mm}$, mässige Vermelurung der Albumine, mässig viele Lymphocyten im zentrifugierten Sediment) starke Kopfschmerzen und heftiges Erbrechen anf, welche längere Zeit anhielten. Die Sehschärfe nahm ab: $\left.{ }^{\circ}\right|_{20}$ beiderseits (langsam) mit $+3,0 \mathrm{D}$ bei der Entlassung, der Endwert der Empfindlichkeitssteigerung des Stäbelenapparates sank auf 210 sowohl zentral wie $20^{\prime}$ und $40^{\circ}$ peripher in den aasalen Gesichtsfeldhälften nach 1 stündigen Dunkelaufenthalt.

Das Gesichtsfeld zeigte ein langsam fortschreitendes Kleinerwerden der noch relativ funktionierenden Partien der temporalen Hälften. Durch die letzten Aufnahmen vor der Entlassung wurde anch ein Übergreifen auf die
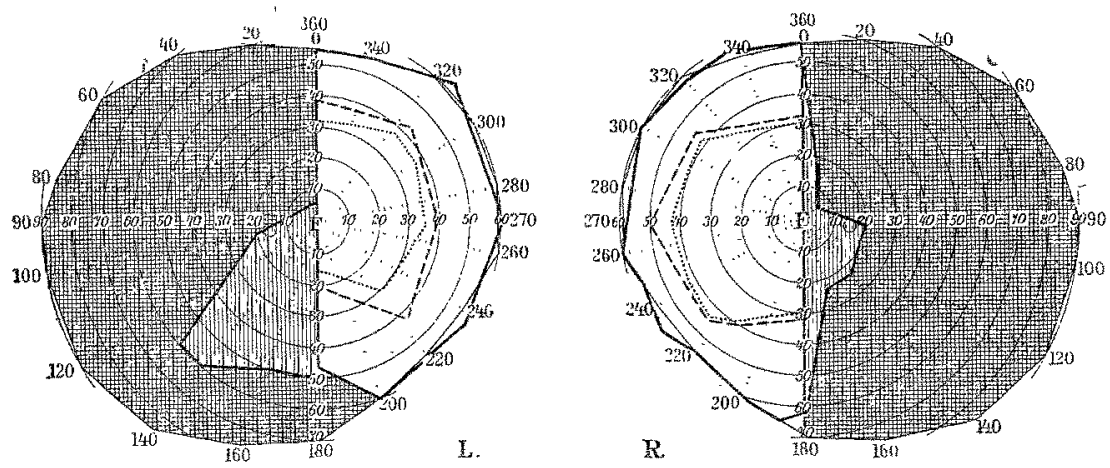

Fig. 4.

nasalen Hälften festgestellt, insofern als die horizontale Trennungslinie aut' dem linken Auge unten von $45^{\circ}$ an nach der nasalen Seite als Begrenzung eines absoluten Defektes abbog. Im übrigen aber waren die nasalen Gesichtsfeldhälften rollkommen normal.

Die Untersuchung auf bemianopische Pupillenstarre ergab nach ${ }^{3} / 4$ stundigem Dunkelaufenthalt links halbseitige Starre, wenn das Licht von temporal, dagegen eine prompte Reaktion, wenn das Licht von nasalwärts ins Ange fiel. Auf dem rechten Auge trat nur vereinzelt eine Verengerung ein, wenn die nasal gelegene Lampe aufleuchtete, niemais aber, wenn die der temporalen Seite eingeschaltet worde.

Niemals die geringsten hemeralopischen Beschwerden. 
Reflexcharakter d. Adaptationsvorgänge, insbes. đ. Dunkeladaptation usw. 241

Epikrise: Dass es sich in dem mitgeteilten Fall ebenfalls um einen chronischen Prozess am Chiasma handelt, geht mit Sicherheit aus der Optikusatrophie und dem Gesichtsfeldbefund hervor. Auch in diesem Fall waren die Augenveränderungen das einzige Symptom, welches auf ein organisches cerebrales Leiden hinwies. Schwieriger aber ist es in diesem Fall, sich eine einigermassen begründete Vorstellung über die Art des zugrunde liegenden anatomischen Prozesses zu machen. Am wahrscheinlichsten erscheint mir besonders im Hinblick auf die erhebliche Steigerung des Lumbaldruckes die Annahme eines das Chiasma infiltrierenden Tumors zu sein, vielleicht ausgehend von der Hypophyse, der gleichzeitig die Umgebung in einen entzündlichen Reizzustand (starke Vermehrung der Albumine) versetzt hat. Eine Lues ist wohl auszuschliessen.

Sehr auffallend ist der Befund, dass schon bei Beginn der Beobachtung in den scheinbar normalen beiden nasalen Gesichtsfeldhalften (vollkommen normale Grenzen für Weiss und Farben) eine ganz hochgradige Beeinträchtigung der Funktion des Dämmerungssehens und zwar ziemlich gleichmässig an den verschiedenen Stellen (horizontal, schräg oben und unten) nachweisbar war. Im weiteren Verlauf zeigte dann das Übergreifen des Ausfalls auf die nasalen Hälften, dass in der Tat auch die ungekreuzten Fasern in Mitleidenschaft gezogen waren.

3. H. M., 39 Jabre, Fahrradhändler.

Fräher angeblich guter Visus beiderseits bis zum 24. Okt. 1909. War damals mit Motorrad des Nachts in voller Fahrt gegen zwei Kälber auf der Chaussee angerannt. Über nähere Eiazelleiten nach diesem Unfall vermag Patient nichts anzugelen. Er ist mit seinem Motorrad allein wieder zurückgefahren. Aus dem Umstand, dass er für den in Frage kommenden Weg unter gewöhnlichen Verhältnissen 20 Minuten mit seinem Rade braucht und er in der betreffenden Nacht zwei Stunden fortgeblieben war, geht hervor, dass er längere Zeit bewusstlos dagelegen hat. Nach dem Unfall bestand Unbesinnlichkeit. Äusserlich waren keine Symptome einer Schädelbasisfraktur vorhanden. Einige Tage später Doppeltsehen. Einige Woelhen darauf bemerkte er beim Versuch, eine in sein reehtes Auge geflogene Fliege wieder zil entfernen, dass er auf dem linken Auge schlecht salı. Angeblich soll das linke Auge früher das bessere gewesen sein. Seitdem hat die Sehsehärfe links angeblich immer mebr noch abgenommen. Sieht im Dunkeln besser als am Tage. Sonst immer gesund. Lues wird entschieden negiert.

Status praes. Pupillen: Rechts weiter als links $(8: 7 \mathrm{~mm})$, Reaktion prompt. Lichtreaktion links weniger ausgiebig als rechts.

Lidspalten: Links weiter als rechts $(12: 9 \mathrm{~mm})$. Auf Kokain erfolgt beiderseits eine gleichmässige Erweiterung der Pupillen und der Lidspalten. 
Augenbewegungen: Der linke Bulbus bleibt beim Blick nach oben, nach innen und nach unten zuriek, Kein Nystagmus.

Ophthalmosk.: Beiderseits totale Abblassung der Papillen, am ausgesprochensten temporal, L. $>$ R., bei normalen Grenzen und Gefässen. Peripherie ohne Befund.

Visus: R. mit $-0,5 D S=0.18$ :

$L_{2}={ }_{1}^{1} 0_{0}^{*}$

Aceommodation olne Befund.

Gesichtsfeld s. Schema.
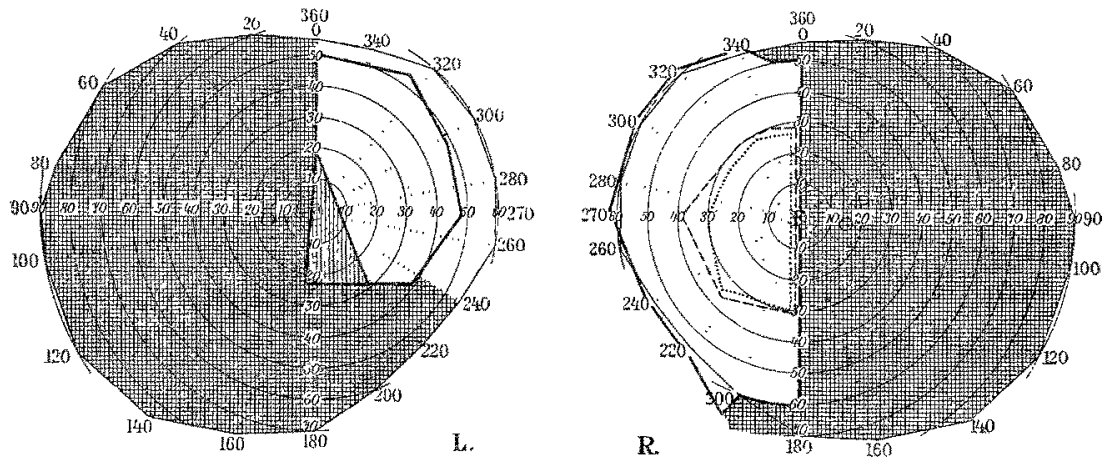

Fig. 5.

Dunkeladaptation des rechten duges:

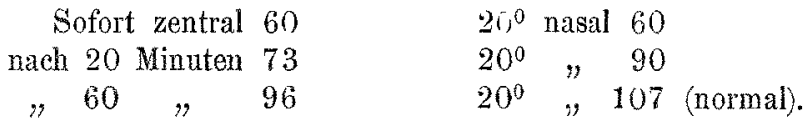

Allgemeinuntersuchung ergibt, abgesehen von einer Hypästhesie und Hypalgesie des ganzen linken Trigeminus, besonders des II. Astes, normale Verhältnisse.

Lumbalpunktion: Sofort $315 \mathrm{~mm}$ Druck nach $5 \mathrm{ccm} 210 \mathrm{~mm}$ "

Flüssigkeit klar. Eiweissgehalt fast normal (Opalescenz mit leichter: Flockenbildung). Keine Vermehrung der Lymphocyten.

Serumdiagnose negativ (Prof. Klingmüller). turciea.

Das Röntgenbild des Schädels zeigt eine Verbreiterung der Sella

Epikrise: Nach dem objektiven Befunde und der Anamnese kann die Diagnose in diesem Falle nur schwanken zwischen einer traumatischen Längsdurchtrennung des Chiasma und einem Tumor in der Gegend des Chiasma. Mit der ersten wahrscheinlichsten Annahme lassen sich ungezwungen die partielle Oculomotorius- und Trigeminusschädigung derjenigen Kopthälfte vereingen, auf welcher auch die Schädigung der optischen Leitungsbahn am ausgesprochensten ist. Für eine der* 
artig schwere Knochen- und Hirnläsion scheint aber die anamnestische Angabe, dass der Patient den Rückweg wieder" allein auf seinem Motorrad zurückgelegt hat, nicht eine genïgend ausreichende Grundlage zu geben. Anderseits dürfte die starke Steigerung des Lumbaldruckes zum mindesten etwas ungewöhnlich bei einer einfachen Schädelbasisfraktur sein, wenn wir nicht gleichzeitig die Annahme machen wollen, dass in einer callösen Wucherung das raumverengernde Moment in der Schädelhöhle gegeben sei. Die Diagnose "Tumor in der Gegend des Chiasma" würde sich, abgesehen von der Steigerung des Lumbaldruckes auf den (wenn anch in seiner Wertigung zweifelhaften) Befund einer Verbreiterung der Sella turcica und auf den progredienten Verlauf der Sehstörung stïtzen. Schwieriger lassen sich mit dieser Annahme aber die partiellen Störungen im $\mathrm{Be}$. reich des III. und VII. Hirnnerven unter völliger Schonung des VI. erklären.

Wir müssen daher die Diagnose in suspenso lassen. Jedenfalls köunen wir aber mit grösster Wahrscheinlichkeit entzündliche Veränderungen ausschliessen. Anamnese und objektiver Befund sprechen - allgemein gesagt - für einen anatomischen Prozess, welcher in erster Linie mechanisch (Zerreissung oder Kompression) auf die basale optische Bahn in der Gegend des Chiasma einwirkt.

Um so bemerkenswerter ist daher der Befund des Fehlens einer Störung der Dunkeladaptation in der sonst normalen Gesichtsfeldhälfte des rechten Auges, ebenso dass auch die Dunkeladaptation beim Blick geradeaus normal ist, trotzdem die Sehschärfe herabgesetzt ist.

Bemerkenswert ist ferner die Angabe des Patienten, dass er im Halbdunkeln besser sähe als im Hellen, dass er geblendet würde, wenn er aus dem Dunkeln ins Helle tritt, und dass er zunächst nichts erkennen könne. In der Beziehung der Hell- und Dunkeladaptation. zejgt der vorliegende Fall eine gewisse Ähnlichkeit mit dem Befund bei absoluter Farbenblindheit, und scheint daher ebenfalls dafiur zu sprechen, dass durch mechanische Schädigungen die Zapfenfunktion wesentlich eher beeinträchtigt wird als die Stäbchenfunlktion.

4. Den vierten Fall habe ich bereits in einer andern Arbeit mitgeteilt. Da der Patient jedoch inzwischen ad exitum gekommen ist, glaube ich berechtigt zu sein, ihn unter Anfügung des weiteren Verlaufes, des Befundes der Sektion und der mikroskopischen Untersuchung noch einmal mitzuteilen. 
O. N., 49 Jahre, Sattler:

30. IX. 1908. Vor 8 Jahren Lues. Seit 1 Jahr Anfalle von starken linksseitigen Kopfsehmerzen, besonders im Hinterkopf mit Anschwellung der Adern in der linken Schläfe. Seit $1 / 2$ Jahr Abnahme des Sehvermögens auf beiden Augen. Bei geringen Anstrengungen starkes Herzklopfen, Schwäche in den Beinen, besonders links. Aunalme des Gedächtnisses. Kein Potus. Seit 4 Jahren verheiratet, 1 Kind tot, 1 Frühgeburt.

Status praes.: Pupillen links weiter als rechts $(4,5: 2,5 \mathrm{~mm}$ Ritcken gegen Fenster). Lichtreaktion links träge und wenig ausgiebig, rechts prompt. Konvergenzreaktion beiderseits vorhanden.

Augenbewegungen frei. Schwidche der Konvergenz.

Ophthalmoskopisch: L. Atroplia n. opt. Grenzen leicht verwaschen. Gefässe verengt.

R. Neuritis optici. Papille rötlichgrau-weiss. Beiderseits Sklerose der Retinalarterien.

Visus: R. $5 / 7-1 / 5$. L. $\% / 10-6 / 7^{*}$

Accommodationsbreite beiderseits nngefähr $3 D$.

Gesichtsfeld s. Schema.
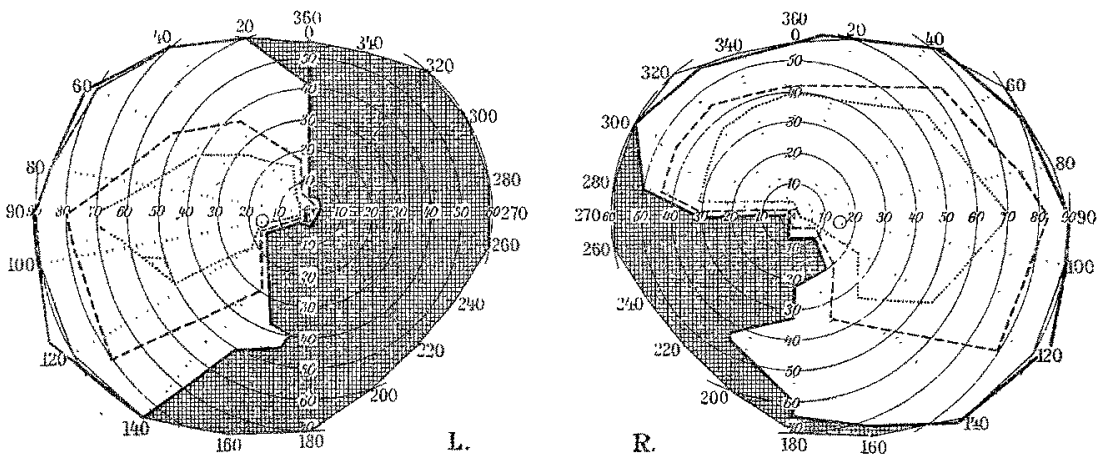

Fig. 6.

Halbseitige Pupillarreaktion: Eine abwechselnde Belichtung der rechten temporalen und nasalen Netzhauthälfte fuhrt auf der teroporalen Hülfte zu keiner, auf der nasalen zn einer prompten Pupillenverengerung.

Wilbrandscher Prismenversuch: Prisma $\left(20^{\circ}\right)$. Basis nach aussen: Es erfolgt keine Einstellangsbewegung. Basis nach innen: Prompte Einstellung.

Wird als Reizobjekt eine elektrisehe Maftglasbirne benntzt, so verschwindet das Licht für den Patienten und die Papille erweitert sich, wenn die Basis des Prisma nach aussen stelt. Steht tie Basis nach innen und wird eine Augeneinstellungsbewegung unterdrickt, so bleibt die Pupillenweite unverändert.

Status nervosus: Grobe Kraft rechts $=$ links, Motilitat, Reflexe und Sensibilität ohne Befund. Keine Blasen-Mastdarmstörungen.

Starke Schlängelung der Arteriae temporales. Geringe Dilatatio cordis. Selr starke Erhöhung, des Blutdruckes. Pulsbeschleunigung. Im Urin Albumen. 
Reflexcharakter d. Adaptationsvorgänge, insbes, d. Dunkeladaptation usw. 245 positiv.

Serumreaktion auf Lues zunächst negativ, bei der Kontrolluntersuchung:

Dureh starke Joddosen bildete sich bei dem Patienten die Neuritis auf dem rechten Auge langsam zariick und machte einer atrophischen Vorfärbung Platz. Gleichzeitig nahn die sklerotische Einseheidung der Netzhautgefässe an Ausdehnung zu. Gesichtsfeld, Sehschärfe und hemianopische Pupillenstare, sowie mangelnde Einstellung beim Prismenversuch blieben unverändert bestehen. Auch eine später vorgenommene Schmierkur hatte keine weitere Änderming des Status im Gefolge.

Vom 18. I. 1909 bis zum 3. II. 1909 wurde Pat. wegen chronischer Nephritis in der medizinischen Klinik behandelt.

Darauf hat er wieder gearbeitet bis Anfang Mai, wo er plötzlich bei der Axbeit zusammenbrach, eine Stunde lang bewusstlos war und, als er dann wieder zu sich gekommen war, eine Lähmung des rechten Arms und Beins aufwies. Die Lähmung des Beins ging nach 1 Stunde wieder zarück, die des Arms hat etwas länger angehalten.

3. VI. Parese des rechten Beins, Lähmung der Beuger des rechten Arms. Steigerung der Sehnenreflexe R, Andeutung von Babinski R., Sensibilität intakt.

Visus: L. $6 / 10-6 / 7$. R. $1 / 7$.

Ophthalmosk.: L. Papille in toto atrophisch, nur in der oberen Hälfte findet sich ein leichter, rötlicher Schimmer. Gefässe stark verengt. Papillengrenzen schärfer.

R. Atrophische Verfärbung der Papille besonders temporal und in der oberen Hälfte, Grenzen verwaschen. Gefässe weniger verengt als links. Die Gefässeinscheidungen sind beiderseits nicht mehr so dentlich wie früher, links mehr als rechts.

Gesichtsfeld, Hemianopische Pupillenstarre, Fehlen der reflektorischen Augeneinstellung beim Prismenversuch unverändert wie früher.

3. X. Wird zur Dunkeladaptationsuntersuchung bestellt. Im Allgemeinen Wohlbefinden. Keine Paresen mehr rechts. Im Urin andauernd Eiweiss. Hat bis jetzt Jod weiter genommen, Keine Spur von Hemeralopie.

Visus: R. $\left.5\right|_{4}$.

L. ${ }^{6} / 7$. Utbriger Befund wie früher. (3. VI.)

Untersuchung der Dunkeladaptation am Dunkelperimeter nach 1stündigem Dunkelaufenthalt:

Rechtes Auge:

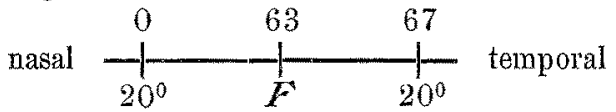

In Empfindlichkeitseinheiten:

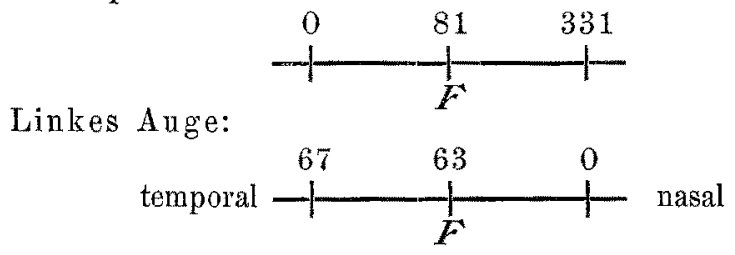


In Empfindlichkeitseinheiten:

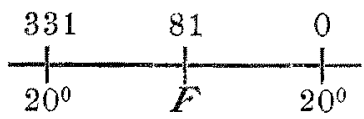

Ablauf der binokularen Empfindlichkeitsunahme:

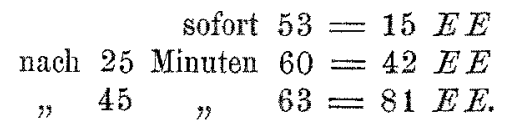

Am 29. X. wurde der Patient bewusstlos in die medizinische Klinik eingeliefert. Vor 3 Tagen Scllaganfall mit linksseitiger Lähmung. Es fand sich eine totale schlaffe linksseitige Lähmung mit Erloschensein der Schmerzempfindung links. Der ophthalmoskopische und der Pupillenbefund war unverändert wie früher.

Am 1. XI. Exitus letalis.

Wesentlicher Sektionsbefund (Geh. Rat Heller). Ansgedehnter frischer lämorrhagischer Herd der rechten Capsula interma. Grosse hämorrhagische Cyste der linken Capsula interna. Verschiebung des Ventrikelseptums nach links, Abplattung dor rechten Hirmwindungen. Leichte Trübung der Arachnoidea. Ganz geringe Mengen leicht blutiger Flüssigkeit im rechten Hinterhorn. Geringe chronische Endarteritis der Basisarterien. Starke Sklerose und Hyperostose des Schädeldaches. Leichte Abplattung beider Sehnerven, stärker links. Bronchopneumonie beider Unterlappen, stärker links. Hyperämie und ödem der übrigen Lunge. Residuen beiderseitiger Pleuritis. Starke Hypertrophie des linken Ventrikels. Geringe fettige Fleckung der Aorta intima. Subseröse Blutung der Milz. Starke Schrumpfung und Granulierung der Nieren. Oystitis mit kleinen Schleimhantblutungen, Trabekularhypertrophie and beginnende Divertikelbildung. Schwielen und Atrophie des rechten Hodens. bahn:

Mikrosk opische Untersuchungderbasalen optischen Leitungs-

Die Stïcke wurden zunächst in Formalin, sodann 2 mal 24 Stunden in dem Orthschen Gemisch gehärtet, darauf durch mehrere Wochen in läufig gewechselte Müllersche Flïssigkeit im Brutofen gelegt und schliesslich ohne Auswässerung in steigendem Alkohol gehärtet. Celloidineinbettung. Serienschnitte.

Ich füge der folgenden Beschreibung eimige Abbildungen bei, aus denen die charakteristischen Veränderungen ersichtlich sind, so dass ich mich hier knrz fassen kann.

Frontalschnitt dureh die Mitte des Chiasma. 1. Weigertscle Eisenhämatoxylinfärbung und Färbung nach v. Gieson. Durch die angelagerte Carotis ist die rechte Hälfte des Chiasma an ihrer äusseren unteren Circumferenz abgeplattet, der Zwischenraum zwischen Nerv und Gefäss ist durch bindegewebige Stränge fast vollkommen ausgefullt. Parallel mit der Grenzlinie finden sich in den peripheren Nervenpartien zahlreiche Bündel von Bindegewebe, zwischen denen Inseln des Parenehyms des Chiasma e1halten geblieben sind. Alle diese bindegewebjgen Elemente sind durchtränkt 
von kleinen Rundzellen. Im oberen äusseren Winkel derselben Seite findet sich ein kleiner Herd mit massenhafter kleinzelliger Infiltration.

Die linke Hälfte des Chiasma ist im ganzen um etwa $1 / 4$ kleiner in allen Dimensionen als die rechte, sie zeigt entsprechend der an ihrer Oberfläche liegenden Arteria cerebri anterior eine Einbuchtung; auch diese Arterie steht durch kleinzellig infiltriertes Bindegewebe mit den Scheiden des Chiasma in inniger Verbindung. Der Nerv selbst ist an dieser Stelle leiclit nach oben mit seinem lateralen Ende gebogen. Es hat den Anschein, als ob er durch eine Verschiebung des Lagerungsverhältnisses zwischen der Arteria carotis interna und der Arteria cerebri anterior diese Richtungsänderung vorgenommen hat. Jedenfalls selliessen sich diese beiden Arterien innig in ihrem Verlauf der stark atrophischen linken Hälfte des Chiasma an.

Die weichen Hirnhäute in der Umgebung des Chiasma besonders auch im vorderen und hinteren Winkel sind ziemlich gleichmässig durch Rundzellen infiltriert. Ebenso weisen sämtliche Gefüsse im Parenchym des Chiasma in ihren Scheiden eine recht hochgradige kleinzellige Infiltration auf, nur im mittleren Viertel fehlt eine stärkere Gefässentwicklung.

Die kleineren Gefässe der Umgebung des Chiasma haben eine stark verdickte Wandung und ein verkleinertes Lumen; in den grösseren Gefässen besteht eircumscript eine Wucherung der Intima. Um sämtliche Gefässe findet sich eine periarteritische Infiltration.

2. Markscheidenfärbung wach Kulschitzki.

Zwischen den beiden Hälften des Chiasma besteht ein auffallendes Missverbältnis in der Dichtigkeit der Fasern. Die linke Hälfte zeigt eine sehr hochgradige Abnahme der Markscheiden und zwar um so mehr, je weiter es nach dem lateralen Ende geht. Auf der rechten Hälfte findet sich ein circumscripter Defekt entsprechend der Stelle, in welchem sich die neugebildeten Bindegewebsstränge vorfinden. Die kleineren Gefässe in Querschnitt des Chiasma sind von einem hellen Hof umgeben, in denen die Markscheiden zngrunde gegangen sind. Im vorderen und hinteren Chiasmawinkel besteht eine recht hochgradige kleinzelige Infiltration und eine Neubildung eines lockeren Bindegewebes.

Die Carotis interna ist weiter nach vorn zu ausgesprochen endarteriitisch verändert auf beiden Seiten, zeigt stellenweise drusenartige Gebilde auf der Intima und Einrisse in der Elastica. Auch die intrakraniellen Teile der Optici zeigen eine entzündliche Infiltration leichteren Grades und eine leichte Perineuritis.

Mikroskopische Diagnose: Bindegewebige Narbe am rechten äusseren Chiasmawinkel, beträchtliche Schrumpfung der ganzen linken Chiasmahälfte, entzündliche Infiltration in den weichen Hirnhäuten des Chiasma und in der Umgebung der Gefässe, letzteres and ausgesprochen in den beiden lateralen Vierteln des Chiasma, Endarteritis in den kleineren und grösseren Gefässen. Sekundäre $a b$ - und aufsteigende Degeneration der peripher am äusseren Chiasmawinkel vorbeiziehenden Fasern. 


\section{Zusammenfassung.}

In den Fällen 2 und 4 (infiltrierender Tumor cerebri bzw. Lues cerebri) ergab die perimetrische Untersuchung ein völlig normales Verhalten der nicht affizierten Gesichts. feldhälften. Die Grenzen für Weiss und für Farben waren durchaus normal. Wir mussten demnach nach diesem Befund annehmen, dass die zugehörigen Nervenfasern won dem krankhaften Prozess im Chiasma verschont geblieben waren, dass m. a. W. in dem einen Fall die beiden äusseren, in dem andern der vordere and hintere Chiasmawinkel frei von pathologischen Veränderungen war.

Nun zeigt uns aber die Untersuchung der Dunkeladaptation, dass in diesen scheinbarganz normalen Gesichtsfeldpartien eine hochgradige Störung der Stäbchenfunktion und zwar ziemlich gleichmässig an allen Stellen besteht. Dass wir aus diesem einzigen Symptom mit vollem Recht auch auf eine Beeinträchtigung der anscheinend gesunden Teile des Chiasma schliessen dürfen, zeigt uns die anatomische Untersuchung des Falles 4. Die Hauptveränderungen finden wir $z$ war in den beiden äusseren Chiasmawinkeln, besonders ausgesprochen auf der linken Seite in rollkommener Übereinstimmung mit dem Gesichtsfeldbefund. Aber auch in der Mitte des Chiasma, sowohl in den zarten Hirnhäuten der Oberfläche und des vorderen und hinteren Winkels wie im Parenchym in der Umgebung der Gefässe, finden sich kleinzellige Herde als Zeichen einer immer noch bestehenden Entzindung.

Dieser Befund gibt anderseits anch eine ausreichende Erklärung für unsere Beobachtungen bei Optikusaffek tionen, dass entzündliche Prozesse die Stäbchenfunktion in erster Linie schädigen.

In dem Fall 1 (Meningitis chron. serosa) entwickelte sich die Störung der Dunkeladaptation unter unsern Augen. Die zu gleicher Zeit sich einstellende hoch gradige Einengung der nasalen Gesichtsfeldhälften lässt uns hier in Übereinstimmung mit diesem Befund das Bestehen einer das ganze Chiasma umfassenden schweren anatomischen Veränderung, allerdings mit einem Intensitätsmaximum zwischen dem vorderen und hinteren Winkel, annehmen.

A us diesen Fällen ergibt sich demnach, dass die Unter- 
suchung der Dunkeladaptation Störungen der optischen Leitungsbahn im Chiasma durch entzündliche Prozesse schon zu einer Zeit nachweisen kann, wo unsere bis jetzt üblichen Methoden auch nicht die geringste Störung in den betreffenden Gesichtsfeldbezirken erkennen lassen. Die Herabsetzung der Stäbchenfunktion kann also das feinste bis jetzt vorhandene und klinisch leicht nachweisbare Reagens auf eine leichte Beeinträchtigung der optischen Leitung im Chiasma sein.

Auch in diesen 3 Fällen fehlten jegliche hemeralopische Beschwerden.

Demgegenüber weist der Fall 3 (Schädeltrauma? Tumor cerebri?) in der normalen Hälfte des rechten Gesichtsfeldes keine Störung der Dunkeladaptation auf, ebensowenig wie eine solche trotz der Herabsetzung der zentralen Sehschärfe beim Blick geradeaus vorhanden war. Aus den epikritischen Bemerkungen zu diesem Fall geht aber hervor, dass wir aller Wahrscheinlichkeit nach im Gegensatz zu den drei vorhergenannten Fällen keinen entzündlichen, sondern vielmehr einen durch Druck zu einer sekundären einfachen Degeneration in der Sehbahn führenden Prozess als Ursache anzunehmen haben. Von diesem Gesichtspunkt aus dürfte der Fall als eine Bestätigung unserer früheren Befunde über das Verhalten der Dunkeladaptation bei Erkrankungen im Optikus selbst oder in seiner Umgebung zu gelten haben, insofern als auch er zeigt, dass bei Druckschädigung der Sehbahn trotz einer bestehenden Schädigung der Zapfenfunktion eine Störung der Dunkeladaptation und damit der Stäbchenfunktion nicht vorhanden zu sein braucht.

\section{Tractushemianopsien.}

F. E., 60 Jahre, Musiker.

Hat als Jäger noch bis vor einigen Wochen gut geschossen. Vor 3 Wochen bemerkte er des Abends beim Spielen plötzlich einen Schleier vor beiden Augen, dessen Dichte weehselte. Zeitweise bestand auch Doppeltsehen. Seitdem leichte Kopfsehmerzen und Unbesinnlichkeit, Abnahme des Gedächtnisses. Seit mehreren Monaten magenleidend und hochgradige Abmagerung. 7 gesunde Kinder. Potus, Lues negiert.

Status praes.: 8. VII. 09. Visus: R. mit $-1,0 D S=\%$

Astigmatismus.

$$
\text { L. } \text { mit }-1,0 D S=6 / 15 \text {. Kein }
$$

v. Graefe's Archiv für Ophthalmologie. LXXY. 2. 
Pupillen und Lidspalten beiderseits ungleich weit.
Pupillen:
R. 3,0
L. 3,5
Lidspalten:
R. 8,0
L. 9,0

Pupillarreaktion auf Licht (foveal) und Konvergenz beiderseits prompt.

Angenbewegungen frei.

Ophthalmoskopisch völlig normal.

Gesichtsfeld: Homonyme linksseitige Hemiachromatopsie, relativer homonymer linksseitiger Defekt für Weiss in der Umgobung von Farben. Periphere Grenzen für Weiss normal.

Ausgesprochene linksseitige bemianopische Pupillenstarre beiderseits.

Wilbrandscher Prismenversuch mit gefärbten (roten) Prismen: Es erfolgt keine Einstellung, wenn die Basis nach rechts, dagegen eine prompte Einstellung, wenn die Basis nach links gerichtet ist.

Dunkeladaptation am Dunkelperimeter nach dreiviertelstündigem Dunkelaufenthalt, binokular geprüft:

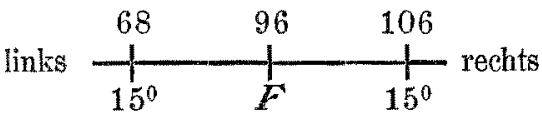

In Empfindlichkeitseinheiten:

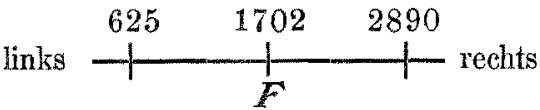

13. VII. Patient gibt an, dass das Sehvermögen sich noch weiter verschlechtert habe. Leidet viel an Kopfschmerzen. Klagt iiber Doppeltsehen. Auf der medizinischen Klinik ist ein Carcinoma ventrieuli festgestellt.

Visus unverändert. Pupille: R. 2,5 mm, L. $3,25 \mathrm{~mm}$. Lidspalten R. $9 \mathrm{~mm}$, L. $10 \mathrm{~mm}$.

Die linke Papille ist leicht gerötet und glasig. Die Grenzen sind unscharf. Gefässe ohne Befund. Keine Prominenz.
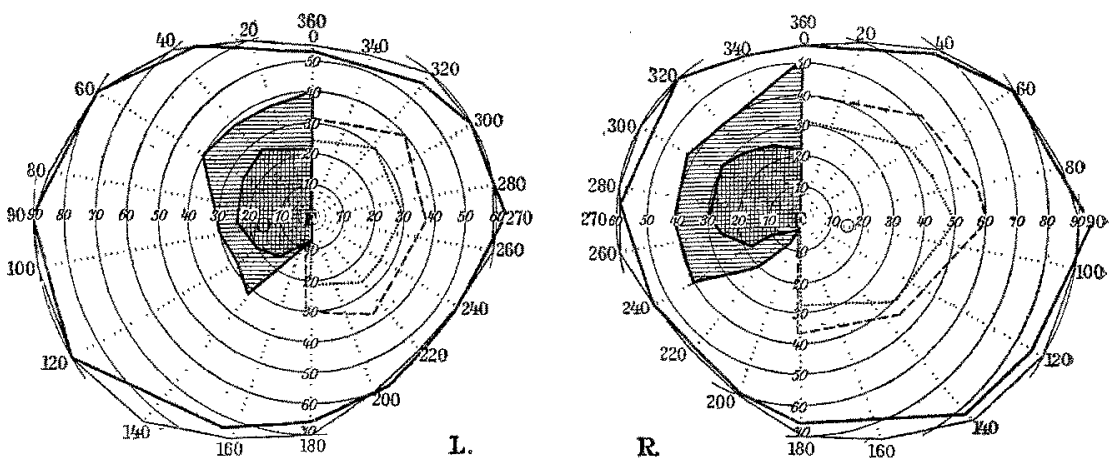

Fig. 7 .

Im Gesichtsfeld ist jetzt an Stelle des relativen homonymen Skotoms für Weiss ein absolutes vorhanden. Der relative homonyme Defekt hat sich ringsherum auf das Doppelte vergrössert. Der Übergang vom abso- 
Iuten in den relativen Defekt ist ein allmählicher, nicht scharf abzugrenzender. Die Trennungslinie geht dureh $F$.

In den unteren linken Quadranten ist für ganz grosse Farbobjekte noch ein gewisses Wahrnehmungsvermögen erhalten.

Die direkte Belichtung der linken Pupille ruft keine so energische und ausgiebige Verengerung wie auf dem rechten Auge hervor.

Augenbewegungen: Leichte nystagmische Zuckungen beim Blick nach rechts. Gleichnamige Doppelbilder beim Blick geradeaus, deren Abstand beim Blick nach rechts zunimmt.

Binokulare Dunkeladaptation nach $3 / 4$ Stunden am Dunkelperimeter (ermüdet sehnell; die Werte der linken Gesichtsfeldhälften sind zuerst festgestellt).

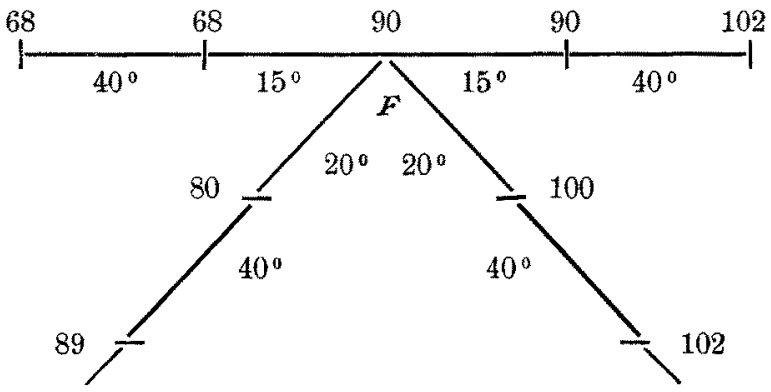

In Empfindlichkeitseinheiten:

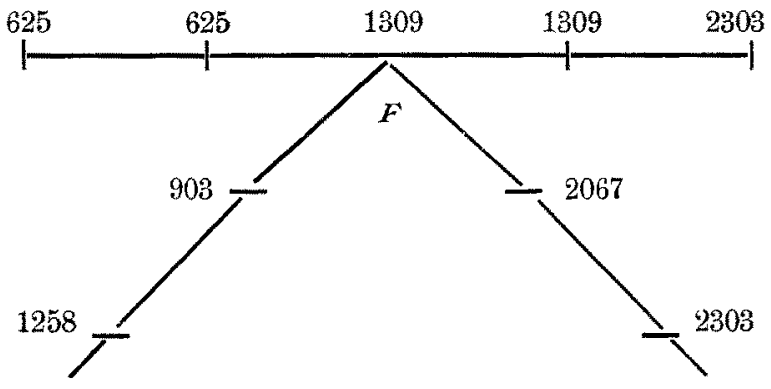

Die Allgemeinuntersuchung in der medizinischen Klinik ergab ausser einem Carcinoma ventriculi und einer hochgradigen Anämie $(40 \%, B b)$ keinen vom normalen abweichenden Befund. Pat. verliess bald die Klinik und starb nach einigen Wochen. Eine Sektion konnte aus äusseren Gründen nicht gemacht werden.

Frau Z., 63 Jahre alt, Telegraphenselkretärstrau.

Bis vor 4 Jahren angeblich immer gesund. Damals im Anschluss an eine Erkältung rechtsseitige Mittelohrentzündung. Vor 2 Jahren „Schlaganfall"; der Mund war nach rechts verzogen, die rechte Körperhälfte war gelähmt (die Muskeln sollen krampfartig zusammengezogen gewesen sein), Pat. hatte rechts ein taubes Gefuhl, in den Fingern der rechten Hand bestand Kriebelgefühl. Ausserdem Schluckbeschwerden, die jedoch bald wieder zurïck- 
gingen. Eine leichte Schwäche und taubes Gefiuhl blieb in der rechten Körperhälfte bestehen.

Vor 14 Tagen trat plötzlich obne irgendwelche cerebralen Begleiterscheinungen Nebelsehen vor beiden Augen auf.

Für Lues keine Anhaltspunkte.

Status: Pupillendifferenz: R. Pup. 2,75 mm,

L. Pup. $3,5 \mathrm{~mm}$ (Rücken gegen Fenster).

Direkte Reaktion auf Licht und Konvergenz beiderseits prompt.

Lidspaltendifferenz: R. Lidspalte $6 \mathrm{~mm}$,

L. Lidspalte $8 \mathrm{~mm}$.

Angenbewegungen frei.

Visus: R. mit $+3 D S=6 / 15$ ?

L. mit $3+3,5 D S=97$.

Ophthalmosk.: Beiderseits Andentung von venöser Stase, sonst o. B.

Gesichtsfeld: Totale homonyme linksseitige relative Hemianopsie für Farben. Die Weissgrenzen sind normal. Die vertikale Trennungslinie für Farben macht um $F$ einen Bogen im Sinne einer typisehen Aussparung.

Untersuchung auf hemianopische Pupillenstarre ergibt binokular wie monokular eine ansgesprochene Herabsetzung der Verengerung bei Belichtung von links, während die Belichtung von rechts eine prompte Verengerung auslöst.

Im Urin fand sich Zucker.

Stat. nervosus: Cornealreflex beiderseits herabgesetzt, R. $>$ L.

Reflexe beiderseits lebhaft, $R .=\mathrm{L}$. Grobe Kraft in der ganzen rechten Körperhälfte herabgesetzt. Geringe diffuse Hypästhesie rechts, feinste Berührungen werden aber wahrgenommen. Keine Ataxie. Sonstiger Befund normal.

Pat. wurde eine Aufnahme in die Klinik geraten.

Nach 5 Tagen begann sich das Farbgesichtsfeld fur rot und blan ( 5 qmm) zu restituieren, die Grenzen uberschritten die vertikale Trennungslinie in einem unregelmässig konzentrischen Bogen, das in der Horizontalen links bis $30^{\circ}$, rechts bis $10^{\circ}$ reichte. In typiseher Weise war ein absoluter Ausfall mit Maculaaussparung noch durch ein 5 qmm grosses grünes und ein $1 \mathrm{~mm}$ grosses rotes Perimeterobjekt nachweisbar.

Die Dunkeladaptationsuntersuchung ergab bei binokularer Prüfung nach $\left.3\right|_{1}$ stïndigem Dunkelaufenthalt:

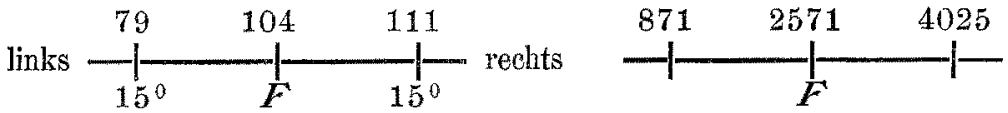

Eine Untersuchung 4 Wochen später ergab: Pat. war inzwischen durch eine antidiabetische Kur sowohl im Urin wie im Blut zuckerfrei geworden (Prof. Wandel).

Visus unverändert. Auf dem rechten Auge hat sich eine leichte Ptosis eingestellt.

Anisokorie: L. Pup. > R. Pup. (besonders deutlich im Halbdunkeln). 
Gesichtsfeld siehe anliegendes Schema.
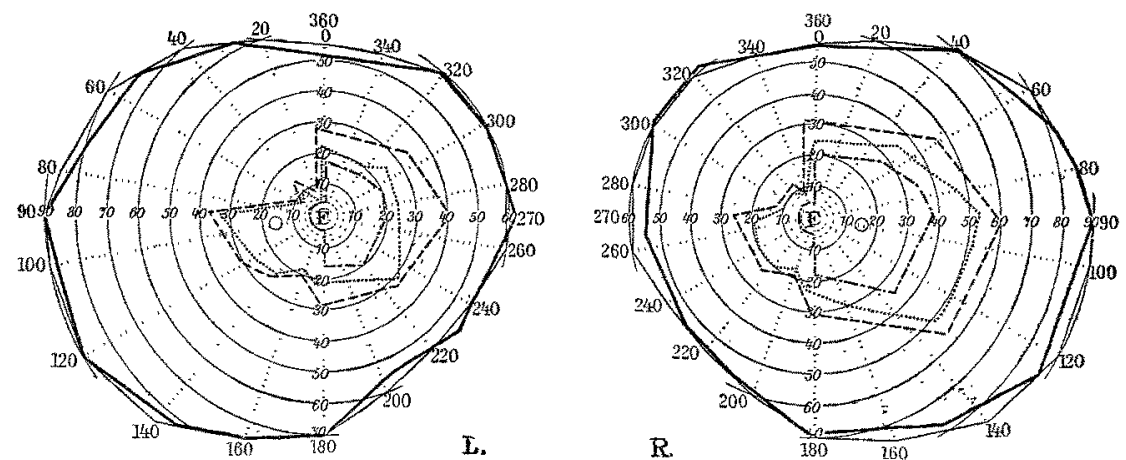

Fig. 8.

Hemianopische Pupillenstare angedentet.

Ophthalmoskopisch wie früher.

Dunkeladaptation: Binokular nach $3 / 4$ stündigem Dunkelaufenthalt

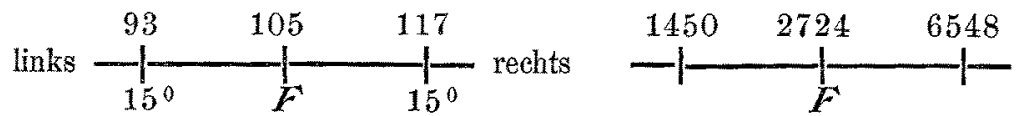

Epikrise: Nach dem obigen Befund ist als Sitz der Läsion der rechte Tractus anzunehmen. Wahrscheinlich sitzt aber der Herd selbst nicht in ihm, sondern im Temporallappen; mit dieser Annahme lässt sich auch die rechtsseitige Ptosis ungezwungen vereinigen. Die Lidspaltendifferenz, welche bei der ersten Untersuchung schon festgestellt war, wird hier in erster Linie wohl auf die Parese des Oculomotorius zurückzuführen sein. Auch in diesem Fall findet sich eine Pupillendifferenz mit der weiteren Pupille auf der Seite des hemianopischen Defektes. - Als Ursache ist wahrscheinlich im Hinblick auf den voraufgegangenen Schlaganfall eine Blutung oder Erweichung anzusprechen.

Ich lasse jetzt zwei Fälle von Tractushemianopsie folgen, die ich bereits in einer friheren Arbeit mitgeteilt habe.

Frau Stahmer, 33 Jahre.

Bei der Patientin wurde Ende 1908 eine homonyme linksseitige Hemianopsie festgestellt, welche durch die bestehende partielle Optikusatrophie, ferner durch das Vorhandensein einer linksseitigen hemianopischen Pupillenstarre, durch die vorhandene Pupillen- und Lidspaltendifferenz mit der weiteren Pupille und Lidspalte auf der Seite der Hemianopsie als Tractushemianopsie anzusprechen war. Wegen des besonderen differenten Verhaltens in dem Grade der Beeinträchtigung auf beiden Seiten hatte ich damals einen Sitz dicht am Chiasma angenommen. 
4. IX. 1909. Aufnahme in die Klinik. Die Kopfschmerzen sind fast rollkommen verschwunden. Das Sehvermögen hat inzwischen langsam aber stetig weiter abgenommen.

Stat. praes.: Pupillen beicerseits mydriatisch. Anisokorie: L. $>$ R.

Reaktion auf Licht links deutlich vorhanden, rechts nur angedeutet.

Lidspalten: Links weiter ais rechts, beiderseits Klaffen. Graefesches Phänomen.

Visus: L. F.-Z. in $2 \mathrm{~m}$,

R. Handbewegungen temporal.

Ophthalmosk. Papillen beiderseits in toto weisslich atrophisch, beiderseits temporal ausgesprochener. Grenzen und Gefässe o. B.

Gesichtsfeld: L. Ausfall der linken Halfte. Die vertikale Trennungslinie macht um $F$ eine Ausbuchtung ron $3-4^{\circ}$. Auf der nasalen Hälfte mittlere konzentrisehe Einschränkung. Farben werden nur unmittelbar um $F$ walurgenommen.

R. Im mittleren temporalen Gesichtsfeldbezirk werden noch gröbere Bewegungen wahrgenommen. Farbensinn erloschen.

Binokulare Dunkeladaptation nach 1 Stunde am Dunkelperimeter:

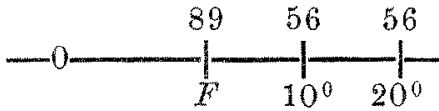

In Empfindlichkeitseinheiten:

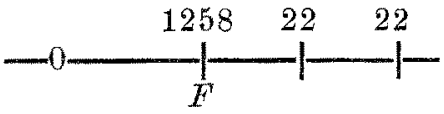

Status nervosus. Patell. - Refl. beiderseits leblaft R. $>$ L., ebenso Achillesreftexe. Kein Klonus, kein Babinski, keine Ataxie. Herabsetzung der groben Kraft der rechten Seite. L. oberer Banchdeckenreflex fehlt. Sonst ohne Befund.

Serumdiagnose auf Lues negativ.

Lumbalpunktion: Druck $200 \mathrm{~mm}$, Spur Albumine, keine Globuline, keine Pleocytose.

Therapie: Energisehe Sehmierkur. Jod in grossen Dosen.

Nach Beendigung derselben keine Änderung im objektiven Befund. Daher Zittmannkur.

Besserung des Visus: L. anf $1 / 10^{*}$ R. auf F.Z. vorm Auge.

L. andanernd hemianopische Starre bei linksseitiger und prompte Reaktion bei rechtsseitiger Beljchtung.

Sonst Status idem.

Unsere ursprüngliche Annahme, dass der Sitz der Affektion im rechten Tractus in der unmittelbaren Nähe des Chiasma anzunehmen war, ist durch den Verlauf bestätigt. Der Prozess griff weiter auf den äusseren rechten Chiasmawinkel über und führte zu einer hochgradigen Funktionsstörung im rechten Auge. Dass er dann auch über den hinteren. Winkel auf den Tractus der andern Seite über- 
Refexcharalter d. Adaptationsworgänge, insbes. d. Dunkeladaptation usw. 255

gegriffen hat, zeigt der Befund auf dem linken Auge. In anderer Beziehung erweist dieser Fall wiederum, dass gegen eine cerebrale Lues selbst eine energische Schmierkur ziemlich wirkungslos sein und erst durch eine angefïgte Zittmannkur eine wesentliche Besserung erzielt werden kann.

Frau Dohm, 50 Jahre.

Bei der Patientin bestand im Juli 1908 eine homonyme rechtsseitige Hemianopsie, absolut in beiden oberen Quadranten, relativ für weisse $O b-$ jekte in den unteren Quadranten. Farben wurden hier nicht wahrgenommen. Die vertikale Trennungslinie machte um $F$ eine Ausbuchtung für ${ }^{2}$ Weiss und Farben. In den beiden unteren rechten Hälften ging sie im Meridian 160 bis zum 50. Parallelkreis nach rechts homolog hinaus (Förstersches Schema). L. Gesichtsfeldhälfte normal. Es bestand ferner eine hemianopische rechtsseitige Pupillenstarre, hemianopisches rechtsseitiges Fehlen der reflektorischen Augeneinstellungsbewegungen (Wil brand), Differenz in der Pupillen- und Lidspaltenweite mit der weiteren Papille und Lidspalte auf der Seite del Hemianopsie. Die Sehschärfe war beiderseits normal. Während der mehrmonatlichen Beobachtung hat sich eine atrophische Verfärbung der Papillen entwickelt.

Status vom 5. II. 09.

Abgesehen von dem Fortbestehen der Kopfschmerzen befindet sich Patientin wohl.

Pupillen:
R. $6 \mathrm{~mm}$
Lidspalten
R. $10 \mathrm{~mm}$
L. $9 \mathrm{~mm}$.

Deutliche rechtsseitige hemianopische Pupillenstarre.

Prismenversuch: Einstellung fehlt, wenn Basis links.

Gesichtsfeld: Wie fruher. Ebenso der ophthalmoskopische Befund. perimeter:

Dunkeladaptation nach $3 / 4$ stïndigem Dunkelaufenthalt am Dunkel-

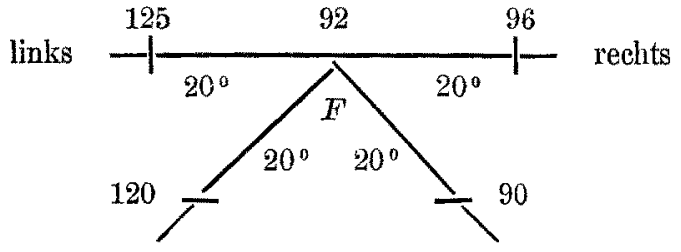

In Empfindliehkeitseinheiten:

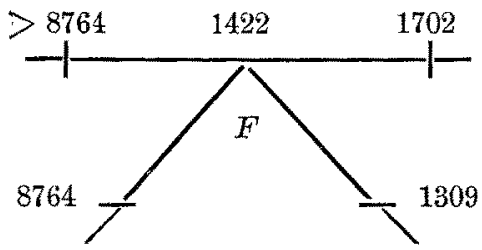

Bei mehrfachen Nachuntersuchungen blieb der Befund unverändert, $a b$ gesehen von einer weiteren Zunahme der atrophischen Verfürbung der Papillen. Der rechte Optikus wurde fast in toto abgeblasst. 
M. L., 33 Jahre, Maler.

Früher immer gesund. Am 8. März angeblich durch einen Unglïcks. fall Lenchtgasvergiftung, lag damals 4 Tage in medizinischer Klinik. Am 29. März klagt er über einen eingenommenen Kopf, musste sich angeblich ins Bett legen, stand dann des Nachmittags wieder auf and ging fort. Das Nähere ist ihm unbekannt. Erst 24 Stunden später warde er bewusstlos in einem abgelegenen Schuppen seines Arbeitsplatzes aufgefunden. Die rechte Gesichtshälfte war angeseliwollen, das rechte Ange blutunterlaufen und über dem rechten Auge eine blutende Stelle sichtbar, die dureh das Hinfallen beim Eintreten der Bewusstseinsstörung, nach Angabe der Frau, entstanden sein musste. Patient wurde zunächst 8 Tage lang von seinem Hausarzt im Hause behandelt. Die Bewusstlosigkeit verschwand bald, Patient wusste aber über Einzelheiten, welche dem Unfall vorhergegangen waren, nicht das geringste anzugeben, weiss anch nicht, wie er in den sonst von ihm kaum bentitzten Scluppen gekommen ist. Die Sohwellung im Gesicht versehwand, die Wunde über der Stirn heilte rasch.

Patient wurde dann wegen einer halbseitigen Extremitätenlähmung in die Klinik verlegt. Klagte bei seiner Aufnahme über leftige Kopfsehmerzen.

Es bestand bei ihm eine totale linksseitige sehlaffe Hemiplegie. Die Kopfbewegungen waren frei, der Facialis in den beiden nuteren Asten paretisch, während der Stimast intakt war. Die Zunge wich stark nach links ab. Das Gaumensegel wurde gerade gehoben. Ausserdem fand sich eine linksseitige Abducensparese, Fehlen des linken Comealreflexes. Sensibilität sonst völlig intakt. Die Reflexe waren links etwas schwächer als rechts, links fand sich das Babinskische Phänomen.

Serumdiagnose negativ.

Lumbalpunktion: Druck $140 \mathrm{~mm}$. Flüssigkeit klar, , keine Eiweissvermehrung, keine Pleocytose.

Angenuntersuchung am 13. V.

Ausgesprochene Anisokorie und Differenz der Lidspaltenweiten:

L. Pupille $5 \mathrm{~mm} \quad$ L. Lidspalte $91 / 2 \mathrm{~mm}$.

R. , $4 \mathrm{~mm}$ (Differenz im Halbdunkeln noch deutlicher). R. Lidspalte $8 \mathrm{~mm}$.

Pupillarreaktion auf Licht beiderseits prompt, links jedoch deutlich weniger ausgiebig als rechts. Konvergenzreaktion beiderseits gleich gut.

Visus: $\left.\begin{array}{rl}\text { R. }-3,5 D S=6 / 7 \\ \text { L. }-4,5 D S=6 / 7\end{array}\right\}$ binokular $6 / 5^{*}$

Augenbewegungen: In den Endstellungen, zeitweise auch beim Blick nach oben, leichter Nystagmus. Beim Blick nach links erreicht der linke Bulbus nicht den äusseren Lidwinkel.

Ophthalmosk: Optici beiderseits hyperämisch, Grenzen leicht verwaschen. $\mathrm{R} .>\mathrm{L}$.

Gesichtsfeld: Komplette absolnte homonyme linksseitige Hemianopsie mit Aussparung der Macula beiderseits von $2^{\circ}$.

Untersuchung auf halbseitige Papillarreaktion: Binokular gepruft ausgesprochene linksseitige hemianopische Starre. Bei Belichtung der rechten 
Netzhauthälften werden die Pupillen deutlich weiter, bei Belichtung der linken Hälften prompt enger.

Monokular: $R$. ausgesprochene linksseitige hemianopische Lichtstarre. Links tritt die Verengerung bei rechtsseitiger Belichtung weniger deutlich auf. Der Untersehied in der Reaktion beider Hälften ist aber einwandfrei festzustellen.

Prismenphänomen: Prismen 14\% Basis L. prompte Einstellung. Basis R. keine Einstellung.

Dunkeladaptation nach $3 / 4$ stündigem Dunkelaufenthalt binokular:

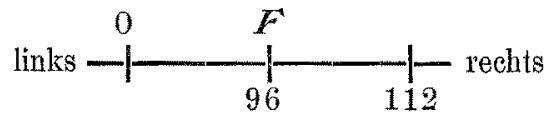

In Empfindlichkeitseinheiten:

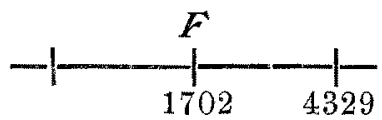

Keine Hemeralopie.

Eine Röntgenuntersuchung des Schädels ergab einen dichten bohnengrossen Sebatten in der Gegend zwischen rechtem Felsen- und Hinterhauptsbein. Bei genauerer Untersuchung fand sich, dass an der Steile der Verletzung über dem rechten Auge im Knochen ein kreisrunder. Defekt vorhanden war. Die Narbe war ebenfalls ziemlich kreisrund und von Erbsengrösse. Damit war als Ursache der sämtlichen Symptome eine Schussverletzung nachgewiesen.

Im weiteren Verlauf stellte sich zunächst im linken Bein eine gewisse Beweglichkeit wieder hor, die Facialisparese wurde geringer. Es kam dann langsam zu einer Steigerung der Reflexe auf der liniken Seite. Eine elektrische Untersuchung ergab normale Verhältnisse. Schliesslich begann anch im linken Arm und in den Fingern neben einer sich einstellenden Kontraktur eine geringe Beweglichkeit zurickzukelren. Der absolute linksseitige hemianopische Defekt blieb dagegen unverändert, ebenso die Pupillenund Lidspaltendifferenz und die hemianopische Pupillenstarre.

Die Schädigung der optischen Bahn ist demnach als eine totale Durchtrennung und als einziges direktes Herdsymptom anzusprechen. Durch unsere klinischen Befunde ist als Sitz der Schädigung der zwischen dem Chiasma (exclus.) und dem Corp. geniculatum laterale (inclus.) gelegene Teil der Sehbahn anzusprechen. Der übrige klinische Befund bestätigt diese Beobachtung aufs beste. Das Zusammentreffen einer intracerebral bedingten Facialisparese mit einer Lähmung des Hypoglossus und der Pyramidenbahn weist mit Sicherbeit auf eine Affektion im Knie der inneren Kapsel hin, denn nur an dieser Stelle liegen die zugehörigen zentralen Fasersysteme zusammen. Das völlige Verschontbleiben der sensiblen Leitungsbahnen sagt uns, dass der hintere Schenkel der inneren Kapsel von der Läsion 
freigeblieben ist, oder mit andern Worten, dass die intracerebralen optischen Bahnen in dem hinteren Schenkel der inneren Kapsel und der Gratioletschen Sehstrahlung nicht gelitten haben können. Ein einziger annähernd senkrecht stehender Herd kann die sämtlichen Symptome erklären, da das Knie der inneren Kapsel und das zentrale Ende des Tractus optici bzw. die Gegend des Corp. geniculatum laterale in einer nicht allzu grossen Entfernung übereinander gelegen sind.

\section{Zusammenfassung.}

In ähnlicher Weise, wie die verschiedenen Fälle ron Chiasmaerkrankung, zeigen also diese Tractusaffektionen eine mehr oder weniger hochgradige Herabsetzung der Dunkeladaptation bzw. der Stäbchenfunktion in denjenigen Partien der affizierten Gesichtsfeldhälften, in welchen sich die Funktionendes Zapfenapparates wiederhergestellthaben.

Dass in den völlig ausser Funktion gesetzten Gesichtsfeldteilen auch das Dämmerungssehen vollkommen aufgehoben ist, bedarf keiner besonderen Erklärung.

Von Interesse ist die Beobachtung, dass die perizentrale Dunkeladaptation entweder uberhaupt nicht oder in einer kaum mit absoluter Sicherheit nachweisbaren Weise gelitten hat.

Auch in diesen Fällen waren keine besonderen hemera. lopischen Beschwerden zu beobachten.

In allen Fällen fand sich eine ausgesprochene Anisokorie und eine Differenz in der Weite der Lidspalten; die weitere Pupille und Lidspalte war dabei immer auf der Seite der Hemianopsie. Die drei neuen Fälle bestätigen also meine früheren Befunde und die Auffassung, dass dem Symptom der Anisokorie und Lidspaltendifferenz (im obigen Sinne) eine Bedeutung für die Diagnose einer Tractus. hemianopsie zukommt.

\section{Intracerebral za lokalisierende Hemianopsien.}

R. G., 44 Jahre, Dreher.

Im 1. Lebensjahr Einsetzen einer Kyphoskoliose. Später Skrofulose. 1898 linksseitige Facialislähmung. 1900 voribergehend Doppeltsehen. Seit einiger Zeit schlechtes Sehen. Lues negiert. Hat 2 gesunde Kinder, Frau hat einmal abortiert.

Stat. praes.: Lidspalten $\mathrm{R} .=\mathrm{L}$.

Pupillen: Anisokorie, L. $5 \mathrm{~mm}$, R. $3 \mathrm{~mm}$. 
Reflexcharakter d. Adaptationsvorgänge, insbes. d. Dunkeladaptation usw. 259

L. Pupille ist total starr. R. Pupille ist lichtstare, auf Konvergenz nur träge Verengerung (unvollkommene totale Starre).

Visus: R. $-3,0 D S=6 / 7$.

$$
\text { L. }-1,0 . D S=6 / 10-6 / 7 \text {. }
$$

Accommodationsbreite: R. ungefähr $3 \mathrm{D}$.
L.
$2 D$.

Ophthalmosk: Normal. Augenbewegungen frei.

Gesichtsfeld: Inkomplette absolute homonyme rechtsseitige Hemianopsie (siehe Schema).
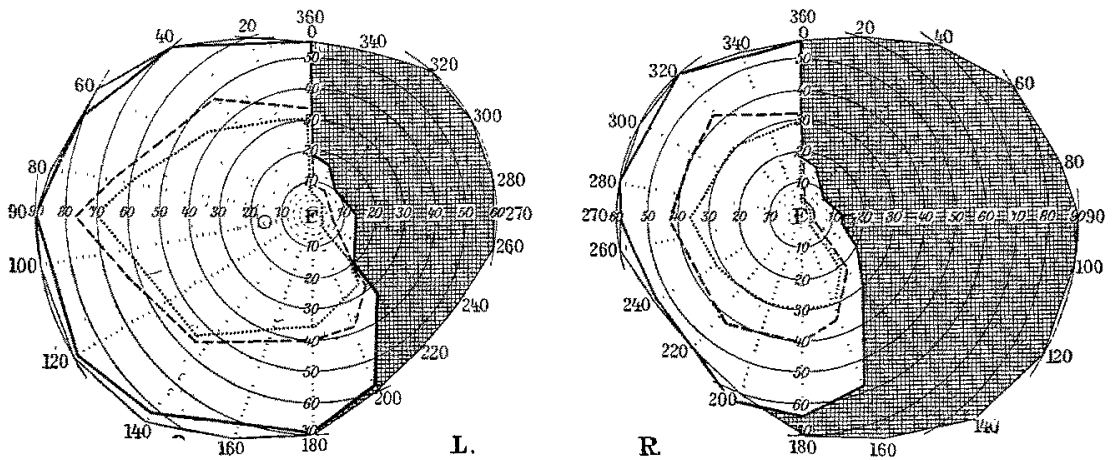

Fig. 9.

Dunkeladaptation am Dunkelperimeter nach $3 / 4$ stiindigem Dunkelaufenthalt binokular.

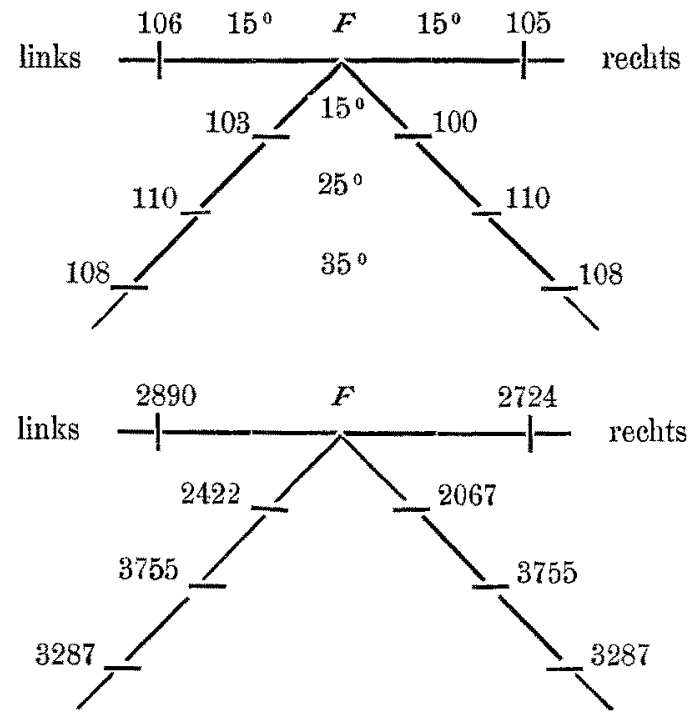

Untersuchung auf halbseitige Pupillenstarre nicht ausführbar (s. 0. .).

Allgemeinstatus ergibt, abgesehen von einer Kyphose, einer leichten Arteriosklerose und einer chronischen Nephritis, normalen Befund. 
Wir dirfen wohl nicht fehl gehen, wenn wir in diesem Fall eine Blutung im linken Hinterhauptslappen auf der Basis der chronischen Nephritis und der Arteriosklerose annehmen.

W. P., 43 Jahre, Kaufmann.

Pat. war früher immer gesund.

Vor 4 Wochen im Anschluss an eine Erkältung plötalicher Verlust des Vermögens zu rechnen, lesen und zu schreiben. Die Sprache war erschwert, er sagte verkehrte Buchstaben und Worte, „es kam immer etwas anderes heraus, als was er sagen wollte". Pat. konnte seinen Namen nicht mehr schreiben. Keine motorischen Reiz oder Ausfallserscheinungen, Gang soll damals unsicher gewesen sein. Keine Bewusstseinsstörung. Etwas Schwindel. Keine Kopfschmerzen, kein Erbrechen. Hat früher viel getrunken.

Befund der psychiatrischen Klinik: Kräftig gebanter Mann. Sohädel nirgends druck- oder klopfempfindlich. L. Facialis wird besser innerviert als der $\mathrm{R}$.

Sprache ist langsam, etwas nasal, zuweilen hesitierend, stolpernd; ausgesprochene aphatische-, Schreib- und Lesestörungen. Schlechte Merkfähigkeit, Zunge wird gerade herausgestreckt, zittert leicht. Gaumenbögen werden gleichmässig gehoben. Rachenreflex gesteigert. Leichter Tremor manunm. Grobe Kraft R. = L. Keine Ataxie. Reflexe der oberen Fxtremitäten etwas lebhaft. Patellar-Achillesreflex beiderseits gesteigert. Andeutung von Fussclonus. Hautreflexe o. B. Gang sicher. Sensibilität o. B. Sklerose der Arterien.

Lumbalpunktion: Druck über $620 \mathrm{~mm}$, Nissl 3 . Keine Globulinreaktion. Keine Lymphocytose.

Serumreaktion (Blut und Liquor): negativ.

Ophthalmolog. Untersuchung 4 Wochen später:

Pupillen: Rechts eine Spur weiter als links, reagieren prompt auf Licht und Konvergenz.

Lidspalten: $\mathrm{R} .=\mathrm{L}$.

Augenbewegungen: frei. Accommodation entsprechend.

Ophthalmosk: Tenen beiderseits etwas stärker gefiullt. R. Optikus leicht unscharf begrenzt. Sonst normal.

Visus: R. $-1,0 D S=" 1 \% 0^{\circ}$

$$
\text { L. }-1,0 D S=6 \% \text {. }
$$

Gesichtsfeld: Inkomplette relative homonyme rechtsseitige Hemianopsie (siehe Schema).

Auf dem rechten Auge findet sich in den periphersten Teilen der temporalen Halfte ein absoluter Ausfall. Das mittlere Drittel dieser Hälfte zeigt in einem um $F$ leicht konzentrisch gebogenen Streifen eine Aufhebung der Farbempfindung and der feineren Weissempfindung, während grösøere weisse Objekte hier noch erkannt werden. Für Farben besteht eine noch weitergehende konzentrische Einengung auf der temporalen Hälfte.

Auf dem linken Auge finden sich dieselben Verhälnisse, wur fehlt hier der absolute Defekt in der Peripherie. 
Untersuchung auf hemianopische Pupillenstarre ergab eine beiderseits gleich prompte und anhaltende Reaktion.
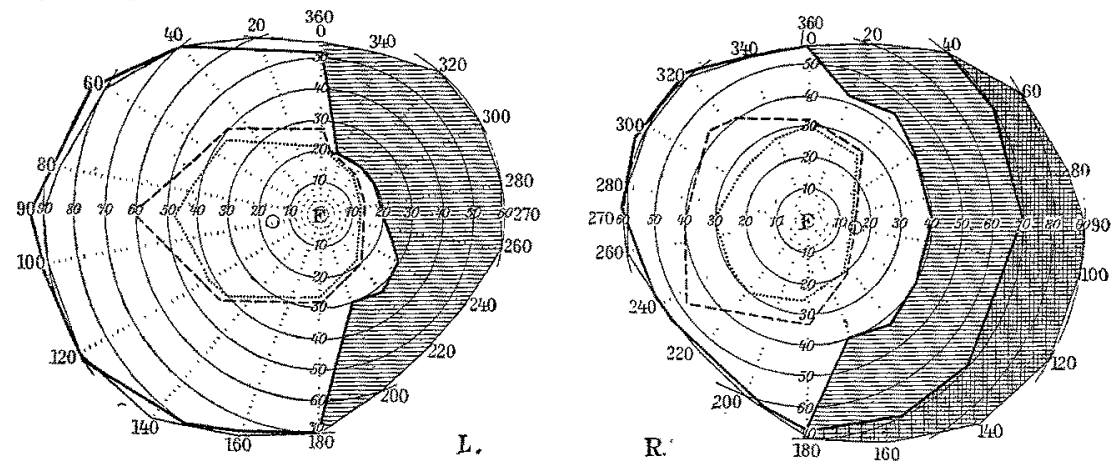

Fig. 10.

Die vergleichende Untersuchung der Dunkeladaptation beider Netzhauthälften ergab keinen Unterschied. (Binokulare Untersuchung nach $3 / 4$ stïndigem Dunkelaufenthalt.)

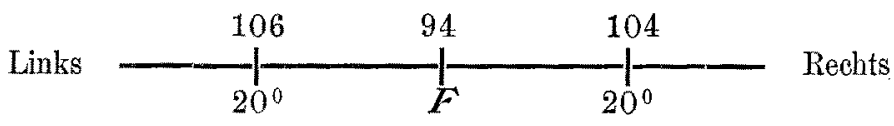

Es bestanden keine Orientierungsstörungen und keine optischen Hallucinationen.

Im weiteren Verlauf besserten sich die sensorisch und motorisch aphatischen Störungen, die Alexie und die Agraphie verschwand fast vollkommen. Im Gesichtsfeld wurden die Grenzen des relativen Defektes beiderseits kleiner und die Farbgrenzen etwas weiter auf den rechten Gesichtsfeldhälften.

Die mehrfach wiederholte vergleichende Untersuchung der Dunkeladaptation beider Netzhauthälften ergab immer einen völlig gleichen Betrag des Schwellenwertes beiderseits. Auch nach einer ${ }_{4} /$ jährigen Beobachtung war keine Verfärbung der Optici im Sinne einer Atrophie zu konstatieren.

Das bemerkenswerte in diesem Fall liegt in der Inkongruenz der Qualität der beiderseitigen Gesichtsfeldstörungen. Der absolute periphere Defekt auf dem rechten Auge betrifft lediglich diejenigen Bezirke, welche auf der homonymen nasalen Seite des andern Auges fehlen. Wir haben also hier den wenn auch nicht ganz reinen Fall vor uns, in welchem eine Störung der zentralen optischen Bahn oder der Rindenprojektion lediglich auf dem einen Auge einen grösseren Ausfall hervorruft, weil die entsprechenden Bahnen im andern Auge nicht vorhanden sind, ein Fall, den Wilbrand theoretisch schon als möglich hingestellt hat. 
II. Hemi-

1. Chiasma-

\begin{tabular}{|c|c|c|c|c|}
\hline Fall & Namen & $\begin{array}{l}\text { Zentraler Visus und } \\
\text { Verhalten der verti- } \\
\text { kalenTremungslinie }\end{array}$ & Ophthalmoskop. & $\begin{array}{l}\text { Gesichts } \\
\text { affizierte }\end{array}$ \\
\hline $\begin{array}{c}1 \\
\text { bi- } \\
\text { temp. }\end{array}$ & E. B. & $\begin{array}{l}\text { (Korrig.) } 6 / 10-6 / 7 \text {. } \\
\text { Trennungslinie } \\
\text { durch } F \text {. }\end{array}$ & $\begin{array}{l}\text { Bds. partielle Op- } \\
\text { tikusatrophie. }\end{array}$ & $\begin{array}{l}\text { Bds. Ausfall d. Farb-, } \\
\text { später arch fast to. } \\
\text { taler Ausfall der } \\
\text { Weissempfindung. }\end{array}$ \\
\hline $\begin{array}{c}2 \\
\text { bi- } \\
\text { temp. }\end{array}$ & H. Th. & $\begin{array}{l}\text { (Korrig.) bds. }=6 / 15 . \\
\text { Trennungslinie } \\
\text { durch } F \text {. }\end{array}$ & $\begin{array}{l}\text { Bds. partielle op- } \\
\text { tikusatrophie. }\end{array}$ & Fast totaler Ausfall. \\
\hline $\begin{array}{l}3 \\
\text { bi- } \\
\text { temp. } \\
4 \\
\text { binasal }\end{array}$ & $\begin{array}{l}\text { H. M. } \\
\text { O. N. }\end{array}$ & $\begin{array}{l}\text { P. (korrig.) } 5 / 18, \mathrm{~L} \text {. } \\
1 / \text { sa, Trennungsinie } \\
R \text {, durch } F \text {. } \\
6 / 7-8 / 5, \text { Ausbuchtung } \\
\text { (unregelmüssig bei } \\
F \text { ). }\end{array}$ & $\begin{array}{l}\text { Bds. totale Ab- } \\
\text { blassung, beson- } \\
\text { ders temporal. } \\
\text { Bds. neuritische } \\
\text { Atrophie. }\end{array}$ & $\begin{array}{l}\text { Absoluter Ausfall. } \\
\text { L. nasal absoluter De- } \\
\text { fekt. } \\
\text { P. nasal sektorenför- } \\
\text { miger Defekt. }\end{array}$ \\
\hline
\end{tabular}

2. Tractus-

\begin{tabular}{|c|c|c|c|c|}
\hline 1 & F. E. & $\begin{array}{l}\text { Korrig. } 6 / 10-6 / 15, \\
\text { Trennungslinie } \\
\text { durch } F \text {. }\end{array}$ & Normal. & $\begin{array}{c}\text { Linksseitige Hemia- } \\
\text { chromatopsie, rela- } \\
\text { tiver Defektf. Weiss } \\
\text { wm } F \text {. Peripher o. B. }\end{array}$ \\
\hline 2 & $\mathrm{Z}$. & $\begin{array}{l}\text { Korrig. R. }{ }^{6} / 15, \text { L. }{ }^{6} / 7 \\
\text { typ. Ausspartung. }\end{array}$ & $\begin{array}{l}\text { Andeutung ron } \\
\text { venöser Stase; } \\
\text { sonst o. B. }\end{array}$ & $\begin{array}{l}\text { Linksseitige Hemia- } \\
\text { chromatopsie, später } \\
\text { inkomplette relative } \\
\text { linksseitige Farben. } \\
\text { hemianopsie. }\end{array}$ \\
\hline 3 & St. & $\begin{array}{l}\text { L. F. }-Z \text {, in } 2 \mathrm{~m} \text {. } \\
\text { R. Handbewegungen. } \\
\text { L. Aussparung. }\end{array}$ & Atrophie bds. & $\begin{array}{l}\text { Linksseitigerabsolu- } \\
\text { ter Ausfall. }\end{array}$ \\
\hline 4 & D. & $\begin{array}{l}6 / \% \text { typische Ausspa } \\
\text { rung. }\end{array}$ & $\begin{array}{l}\text { Partielle A trophie } \\
\text { R. }>\text { L. }\end{array}$ & $\begin{array}{l}\text { Inkompletter rechts- } \\
\text { seitiger Ausfall. }\end{array}$ \\
\hline 5 & M. L. & $\begin{array}{l}\text { 6/s, typische Ausspa- } \\
\text { rung. }\end{array}$ & $\begin{array}{l}\text { Myop. Fundus- } \\
\text { veränderungen. }\end{array}$ & $\begin{array}{l}\text { Absoluter linksseiti- } \\
\text { ger Ausfall. }\end{array}$ \\
\hline \multicolumn{5}{|c|}{ 3. Intracerebrale (supranukleäre) } \\
\hline 1 & P. G. & Korrig. $=6 / 10-8 / \pi$. & Normal. & $\begin{array}{l}\text { Inkompletter links- } \\
\text { seitiger Defekt. }\end{array}$ \\
\hline 2 & W. P. & Korrig. $=6 / x 0-6 / 7$. & $\begin{array}{l}\text { Etwas stärkereve- } \\
\text { nöse Fullung; } \\
\text { sonst normal. }\end{array}$ & $\begin{array}{l}\text { Inkompletter relati- } \\
\text { ver rechtsseitiger } \\
\text { Defekt. }\end{array}$ \\
\hline
\end{tabular}

Die Diagnose kann nicht auf grössere Schwierigkeiten stossen. Alle Symptome weisen auf eine Affektion des linken Temporallappens hin, auch die Einwirkung auf die optische Bahn erklärt sich unge- 
Reflexcharakter d. Adaptationsworgänge, insbes. d. Dunkeladaptation usw. 263

anopsien.

erkrankungen.

\begin{tabular}{|c|c|c|c|c|}
\hline $\begin{array}{l}\text { feld } \\
\text { norm. Hälften }\end{array}$ & $\begin{array}{c}\mathrm{Du} \\
\text { in den gestörten } \\
\text { Hälften }\end{array}$ & $\begin{array}{l}\text { mkeladaptation } \\
\text { in den nor- } \\
\text { malen Hälften }\end{array}$ & zentral & Diagnose \\
\hline $\begin{array}{l}\text { Zunehmende } \\
\text { konzentrische } \\
\text { Einschränkg. }\end{array}$ & $\begin{array}{c}\text { Bds. } 67=331 E E, \\
\text { später }=0\end{array}$ & $\begin{array}{l}104(106)= \\
2571(2870) \mathrm{NE}, \\
\text { später } \\
73=718 \mathrm{EE} .\end{array}$ & $\begin{array}{l}85=1037 E E, \\
\text { später } \\
66=210, \\
69=644 E E\end{array}$ & $\begin{array}{l}\text { Meningitis chron. } \\
\text { serosa. }\end{array}$ \\
\hline Normal. & 0 & $\begin{array}{c}67=331 \mathrm{EE}, \\
(68=625 \mathrm{EE}) .\end{array}$ & $\begin{array}{l}68 \text { bzw. } 69= \\
625 \text { bzw. } 644 \\
E E\end{array}$ & Tumor cerebri. \\
\hline $\begin{array}{l}\text { R. normal. } \\
\text { I. relativ. Rest } \\
\text { nasal oben. }\end{array}$ & 0 & $\begin{array}{l}\text { R. } 107=3059 \\
E E .\end{array}$ & $\begin{array}{l}\mathrm{R} .96 \\
E E\end{array}$ & $\begin{array}{l}\text { Zerreissung des } \\
\text { Chiasma? Tu- } \\
\text { mor cerebri? }\end{array}$ \\
\hline Fast normal. & $\begin{array}{l}\text { In den Partien } \\
\text { desGesichtsfeld- } \\
\text { defektes }=0\end{array}$ & $\begin{array}{l}67=331 \quad E E \\
\text { bds. }\end{array}$ & $\begin{array}{l}\mathrm{Bds}, \quad 63=81 \\
E E .\end{array}$ & $\begin{array}{l}\text { Lues cerebri, } \mathrm{Ar} \text { - } \\
\text { teriosklerose. }\end{array}$ \\
\hline
\end{tabular}

affektionen.

\begin{tabular}{|c|c|c|c|c|}
\hline Normal. & $68=625 E E$. & $\frac{106}{E E .}=2890$ & $96=1702$ & $\begin{array}{l}\text { Carcinommetasta- } \\
\text { seim Tractus op- } \\
\text { ticus? }\end{array}$ \\
\hline Normal. & $\begin{array}{l}79=871 E E, \\
\text { später } 93=1450 .\end{array}$ & $\begin{array}{l}111-4025 \\
E E, \text { später } \\
117=6548 \\
E Z .\end{array}$ & $\left\{\begin{array}{l}105=2571 \\
E E\end{array}\right.$ & $\begin{array}{l}\text { Diabetes mellitus. } \\
\text { Neuritisch. Pro- } \\
\text { zess im Tractus } \\
\text { opticus? }\end{array}$ \\
\hline $\begin{array}{l}\text { L. konzentr: } \\
\text { Einschränlkg. } \\
\text { R. fast totaler } \\
\text { Ausfall. }\end{array}$ & $\begin{array}{l}\mathrm{R}=0 . \\
\mathrm{L}=56=22 \mathrm{EE} .\end{array}$ & & $89=1258$ & Lues cerebri. \\
\hline Normal. & $\begin{array}{c}90=1309(96 \\
=1702 \mathrm{EE}) .\end{array}$ & $\underset{E E .}{125=}>8764$ & $92=1422$ & $\begin{array}{l}\text { Hämorrhag. (Em- } \\
\text { bolie) im linken } \\
\text { Tractus opticus. }\end{array}$ \\
\hline Normal. & 0 & $112=4329$ & $96=1702$ & Sehädeltrauma. \\
\hline
\end{tabular}

Affektionen der Sehbahn.

\begin{tabular}{|c|c|c|c|c|}
\hline Normal. & $\begin{array}{l}\text { In den erhaltenen } \\
\text { Bezirken } 110= \\
3755 \mathrm{EE} .\end{array}$ & $\frac{110}{E E .}=3755$ & & $\begin{array}{l}\text { Hämorrhagia ce- } \\
\text { rebri. (I. K.) }\end{array}$ \\
\hline Normal. & $\begin{array}{l}\text { In denerhaltenen } \\
\text { Bezirken } 104= \\
2571 \mathrm{EE} \text {. }\end{array}$ & $\begin{array}{l}106=2890 \\
E E .\end{array}$ & $94=1555 \mathrm{EE}$ & Tumor cerebri. \\
\hline
\end{tabular}

zwungen durch die Nachbarschaft der Gratioletschen Strahlung. Aller Wahrscheinlichkeit nach handelt es sich um einen langsam wachsenden Tumor, in dem eine Blutung eingetreten war. 
Aus diesen beiden Fällen geht hervor, dass der Schwellenwert der perizentralen Netzhautbezirke bei intracerebral bedingten $\mathrm{He}$ mianopsien nach dreiviertelstindiger Dunkeladaptation vollkommen den normalen Werten entspricht. Ich habe in bezug auf diese Frage noch einige meiner an anderer Stelle mitgeteilten Fälle von absolutem homonym-hemianopischen Gesichtsfeldausfall infolge von intercerebral zu lokalisierenden Prozessen untersucht und habe diese Beobachtung vollkommen bestätigt gefunden. Da sich diese Fälle aber in keiner Weise geändert haben, so glaube ich auf eine nochmalige Mitteilung derselben verzichten und mich mit der einfachen Registrierung dieses überall gleichen und mit den beiden oben mitgeteilten Fällen übereinstimmenden Befundes begnügen zu dürfen.

\section{Zusammenfassung.}

Die (perizentrale) Dunkeladaptation (Stäbchenfunktion) beim Blick geradeaus ist sowohl bei intracerebral wie bei basal bedingten Hemianopsien in keinerW eisebeeinträchtigt. Ebenso ist sie in den nicht affizierten Gesichtsfeldhälften vollkommen normal. In bezug auf diese Verhältnisse besteht also kein Unterschied $z$ wischen den Tractus-und den intracerebralen Hemianopsien.

Dagegen ist das Verhalten der parazentralen Dunkel. adaptation in den Fällen ron inkompletten hemianopischen Störungen für beide Arten ein durchaus entgegengesetztes. Bei intracerebral bzw. supranukleär gelegenen Herden der Sehbahn finden wir in denjenigen Gesichtsfeldpartien, in welchen (selbstverständlich auf der Seite der hemianopischen Störung) die Zapfenfunktion entweder ganz oder zum Teil erhalten geblieben ist, ein normales Verhalten der Stabchentätigkeit, der Dunkeladaptation. Es besteht kein Unterschied in dem Schwellenwert $\mathrm{zwischen}$ diesen Teilen und den äquiexcentrisch gelegenen Bezirken der asdern gesunden Netzhauthälften. Bei Tractushemianopsien finden sich dagegen mehr oder weniger grosse Differenzen zwischen beiden Hälften.

In derartigen Fällen von relativen homonymen Hemianopsien, in welchen die Untersuchung der hemianopischen Pupillenstarre und der Wilbrandsche Prismenversuch aus naheliegenden Gründen versagen kann und in denen sich 
auch keine klinisch nachweisbare Optikusatrophie wegen der relativen Geringfügigkeit der anatomischen Läsion zu entwickeln braucht, kann demnach die Untersuchung der halbseitigen Störung der Dunkeladaptationvon einerwesent. lichen Bedeutung werden, insofern als das Fehlen jeglicher Störung auf den relativ beeinträchtigten Gesichtsfeld. hälften für einen supranukleären Sitz, das Vorhandensein derartiger Störungen für einen basalen bzw. nukleären Sitz der Läsion spricht.

In der Literatur finden sich bis jetzt keine Untersuchungen, welche den eben angeführten analog sind. Zwar nehmen Wilbrand und Saenger an, dass sich bei allen peripher vom Corpus geniculatum laterale gelegenen Herden der optischen Bahn Adaptationsstörungen nachweisen lassen. Eine genauere Prüfung ihrer Angaben zeigt aber, dass sie unter Adaptation nicht die Dunkeladaptation verstehen, welche in unsern oben mitgeteilten Fällen lediglich der Gegenstand der Untersuchungen war. Denn nach ihnen sehen derartige Patienten an trüben Tagen besser, die fixierten Gegenstände verschwinden allzu leicht, die Patienten „zeigen den Symptomkomplex der nerrösen Asthenopie“. Gleichzeitig berichten sie über zwei Fälle von Tractushemianopsie, in denen eine hoch- bzw. mittelgradige konzentrische Einengung als Zeichen einer Störung der Adaptation auf den nicht von der Hemianopsie betroffenen Gesichtsfeldhälften vorhanden war. Aus allem geht also hervor, dass sie die Adaptationsstörungen des Tagesapparates meinen. In meinen Füllen von Tractus- und Chiasmahemianopsie konnte ich allerdings eine derartige konzentrische Einschränkung auf den normalen Gesichtsfeldhälften nicht nachweisen. Nichtsdestoweniger behält die Ansicht Wilbrands, dass die Adaptation im allgemeinen durch ein höheres im Corpus geniculatum laterale gelegenes Zentrum geregelt wird, ihre hohe theoretische Bedeutung. Für den Stäbchenapparat wenigstens glaube ich, wie auch die weiteren Ausführungen ergeben werden, eine derartige zentrale Steuerung als Bestätigung dieser allgemeinen Wilbrand schen Theorie nachgewiesen zu haben.

In der soeben erschienenen Arbeit Stargardts wird in der Schlusszusammenfassung erwähnt, dass sich Störungen der Dunkeladaptation auch bei "Hemianopsien" (ohne Angabe, ob basal oder intracerebral bedingt) finden. Für diese Behauptung fehlt aber in der betr. Arbeit die Anführung beweisender Fälle. 


\section{Physiologische Untersnchungen.}

Die Beeinflussbarkeit der Empfindlichkeitszunahme bei der Dunkeladaptation eines Auges durch gleichzeitige kontinuierliche Belichtung des andern Auges.

Unsere Beobachtungen an pathologischen Fällen haben ergeben, dass eine hochgradige Störung des Dunkelapparates der Netzhaut-(Stäbchen bzw. ihrer zentralen Verbindungsfasern) bestehen kann, ohne dass der Hellapparat (Zapfen) eine irgend wie nachweisbare Beeinträchtigung seiner Funktion aufweist und umgekehrt. Wir baben uns daher die Frage vorzulegen, ob lediglich eine geringere Widerstandsfähigkeit der Stäbchenfasern in den optischen Leitungsbahnen die Ursache dieser Inkongruenz ist, oder $a b$ besondere physiologische Eigentiumlichkeiten dieses Apparates dabei mitsprechen. Dass die verschiedenartigen Fasersysteme der basalen optischen Leitungsbahn eine verschieden grosse Widerstandsfähigkeit gegen pathologische Einflïsse darbieten können, ist bekannt. Ich habe nur nötig daran zu erinnern, dass z. B. bei Stauungspapille die visuelle Funktion völlig erloschen sein kann, ohne dass die Pupillarreaktion auf licht aufgehoben ist. Dass derartige Unterschiede aber bei den beiden visuellen Systemen nicht oder nicht in erster Linie anzuschuldigen sind, beweist die $A b$ hängigkeit des Ausfalls bzw. der Herabsetzung der Stäbchenfunktion von dem Sitz der anatomischen Läsion: Die Herabsetzung findet sich nur bei basalen und peripheren Veränderungen der optischen Leitungsbahn, sie fehlt bei intracerebralen (supranukleären) Prozessen. In demselben Sinne sprechen umgekehrt die Ausfallserscheinungen von seiten des Zapfenapparates: Bei basilärem Sitz kann trotz einer vorhandenen Optikusatrophie und einer hochgradigen Störung des Dämmerungssehens die Funktion des Tagesapparates völlig normal sein, während bei supranukleären Affelktionen gerade der Tagesapparat eine Schädigung aufweist, und im Dämmerungssehen normale Verhältnisse vorliegen können. Schon aus diesen Überlegungen geht hervor, dass als Ursache der Inkongruenz in der Funktionsstörung der Stäbchen und Zapfen besondere physiologische Eigentïmlichkeiten anzunehmen sind.

Es ist nun naheliegend, in der dem Dämmerungssehen schliesslich zugrunde liegenden Sehpurpurbildung eine Ursache dafür zu suchen. Da ich in dieser Zusammenstellung prinzipiell alle die Fälle ausgeschaltet habe, in welchen durch retinale Prozesse die Sehpurpurneubildung gestört werden konnte, so ist die Frage naheliegend, ob für meine Fälle nicht eine Schädigung irgendwelcher von 
irgendeinem Zentrum im Gehirn ausgehenden, zentrifugalen die Sehpurpurbildung hervorrufenden und regelnden Fasern anzunehmen ist. Oder mit andern Worten, ob wir derartige die Sehpurpurregeneration regulierenden Zentren und Fasern anzunehmen haben.

Bei meinen nachfolgenden Untersuchungen über diese Frage ging ich von der Annahme aus, dass auch für die Fasern des Stäbchenapparates eine Semidecussatio im Chiasma besteht, und dass sich das Lagerungsverhältnis der einzelnen Fasern beider homonymen Netzhauthälften in den beiden letzten Dritteln des Tractus und in den weiter zentral gelegenen Bahnen in derselben Weise gestaltet, wie es für den Faserapparat der Zapfen nachgewiesen ist: die von identischen Netzhautpunkten beider Augen kommenden Fasern legen sich aneinander und zeigen im Durchschnitt der Leitungsbahn dieselbe räumliche Anordnung zueinander, wie ihre zugehörigen Ursprungselemente in der Netzhaut. Ein gewisser Beweis für die erste Annahme liegt in dem quantitativen Überwiegen der gekreuzten Fasern über die ungekreuzten. In der Netzhautperipherie finden sich vorwiegend Stäbchen und zwar um so überwiegender an Zahl, je peripherer die betr. Netzhautstelle gelegen ist. Da die gekreuzten Fasern im wesentlichen durch das Hinzutreten der von den ganz peripher gelegenen Netzhautelementen stammenden Fasern, für welche im andern Auge ein korrespondierender Bezirk fehlt, das Übergewicht erbalten, so ergibt sich daraus, dass auch für die Stäbchenfasern eine Semidecussatio im Chiasma vorhanden sein muss. Anderseits zeigen unsere Fälle von Tractushemianopsie, in welchen eine partielle Schädigung der betreffenden homonymen Gesichtsfeldhälften bestand, dass auch die Dunkeladaptation in diesem Bezirk gestört war, während sie in den normalen Gesichtsfeldbezirken derselben Hälften durchaus unbeeinträchtigt geblieben war. Unsere Annahme erfährt dadurch also eine genügende Begründung.

Strahlen nun diese so geordneten Stäbchenfasern in ein supponiertes subcerebrales Zentrum ein, so werden die von zwei identischen Netzhautpunkten kommenden Fasern entweder in eine oder in zwei in unmittelbarer Nachbarschaft nebeneinander gelegene Ganglienzellen einmünden. Haben diese dann weiter einen bestimmenden Einfluss auf die Regeneration des Sehpurpurs, so ist zu erwarten, dass durch eine gegenseitige Beeinflussung dieser Ganglienzellen die Belichtung eines Auges auf die gleichzeitige Dunkeladaptation des andern Auges einen hemmenden Einfluss ausübt. Denn aus den Piperschen Untersuchungs- 
ergebnissen, dass die wesentliche Empfindlichkeitszunahme der Stäbchen erst eintritt, nachdem die Belichtung längere Zeit aufgehoben war, geht hervor, dass jede Belichtung einen hemmenden Einfluss auf die Sehpurpurbildung und damit auf die Stäbchentätigkeit ausïbt (s. u.).

Wem wir daher nachweisen können, dass durch eine konstante Belichtung des einen Auges tatsächlich eine auffallende Herabsetzung der Empfindlichkeitszunahme im andern dunkeladaptierenden eintritt, so ist meines Erachtens damit ein Beweis für die Annahme einer nervösen Regulierung gegeben. Die Regeneration des Sehpurpurs bzw. die Stäbchenfunktion ist dadurch ihres rein retinalen Charakters enthoben und in Abhängigkeit von irgendeinem höheren nervösen Zentrum gebracht.

Über die Frage dergegenseitigen BeeinflussbarkeitbeiderA ugen in bezug auf die Adaptation haben nun bereits Charpentier und Treitel Untersuchungen angestellt, in denen sie die Abhängigkeit der Adaptation von der Differenz des Zustandes, in dem sich beide Augen vor Beginn der Untersuchung befanden, prïften. Bei dem Fehlen einer exakten zahlenmässig arbeitenden Methode darf ich mich wohl mit der Erwähnung dieser in ihrem Ergebnis abweichenden Untersuchungen begnügen. Piper hat dann zuerst einige messende Untersuchungen in demselben Sinne rorgenommen. Er schützte das eine Auge durch einen geeigneten Verband vor der Belichtung, während er das zweite Auge sich dadurch in dem Zustand einer ziemlich hochgradigen Helladaptation erhalten liess, dass er dasselbe in den Zeiten zwischen den Schwellenbestimmungen durch das von einer weissen Kartonfläche reflektierte Licht einer Bogenlampe belichtete. Alle 5 bis 6 Minuten wurden je 2 Schwellenbestimmungen gemacht: einmal isoliert die des Dunkelanges, zweitens bei binokularer Beobachtung. Aus Untersuchungen an sich selbst und auch bei mehrfacher Wiederholung an andern ergab sich, dass die Kurve des Anstiegs der Empfindlichkeit des dunkeladaptierten trotz Belichtung des andern Auges vollkommen gleich war derjenigen, welche bei doppelseitiger Dunkeladaptation und einseitiger Schwellenuntersuchung gewonnen war.

Ich habe diese ron Piper selbst nur kurz gestreiften Untersuchungen ausführlicher erwähnt, da meine Befunde von seinen Untersuchungsresultaten durchaus abweichen, und da sich meines Erachtens diese Differenz unserer Befunde durch die Verschiedenartigkeit unserer Versuchsanordnung leicht erklärt.

Nach Piper hat dann Révész sich eingehender mit der Frage der Beeinflussung der Lichtempfindlichkeit eines Anges durch gleich- 
zeitige Lichtreizung des andern Auges befasst. Révész hat seine Untersuchungen stets begonnen, wenn (nach gleichmässiger Dunkeladaptation beider Augen) das Maximum des steilen Intervalls der Adaptationskurve überschritten war, also nach einem Dunkelaufenthalt von 45 Minuten und mehr. Erst dann setzte er mit einer mehrfach abgestuften Belichtung des einen Auges ein und untersuchte, ob sich der Schwellenwert des andern weiter dunkeladaptierenden Auges veränderte. Er bestimmte dabei zuerst immer binokular die Schwelle, worauf er unmittelbar eine Schwellenbestimmung bei gleichzeitiger Lichtreizung des andern Auges anschloss. Er kommt zu dem Schluss, dass die nach Dunkeladaptation auf einem Ange erreichten Schwellenwerte durch gleichzeitig, d. h. während der Schwellenbestimmung einwirkende Lichtreize im andern Auge nicht in einer gesetzmässigen Weise verändert werden.

So bemerkenswert diese Befunde in bezug auf die Übertragung des Fechnerschen paradoxen Versuches auf die Verhältnisse der Stäbchenfunktion auch sind, insofern sie die Ungültigkeit desselben für das Dämmerungssehen meines Erachtens zu beweisen scheinen, so wenig beweiskräftig dürften sie aber für die Frage sein, ob die Dunkeladaptationsfähigkeit des einen Auges von der Belichtung des andern Auges abhängig ist. Nach den heutigen physiologischen Anschauungen ist die Empfindlichkeit der Netzhaut bei der Dunkeladaptation abhängig von dem Sehpurpurgehalt der Stäbchen. Hat sich nun unter einer ausgiebigen Dunkeladaptation ein gewisses grösseres Quantum von Sehpurpur im Auge angesammelt - einer Substanz, welche vorzugsweise wenn nicht ausschliesslich durch direkte Einwirkung des Lichtes wieder zerstört wird -, so dürfte auch eine maximale Belichtung des einen Auges keine Zerstörung bzw. Bleichung desselben im zweiten nicht belichteten Auge bewirken. Meines Erachtens geht aus diesen Untersuchungen nur hervor, das eine Bleichung des schon angesammelten Sehpurpurs und damit ein Steigen des Schwellenwertes der Stäbchenempfindlichkeit des Auges nicht durch zentrale Einflïsse hervorgerufen werden kann.

Wollen wir untersuchen, ob die Funktion der Dunkeladaptation des einen Auges abhängig ist von dem Reizzustand des andern, so müssen wir unbedingt während der Periode der Sehpurpurbildung und -anhäufung unsere Untersuchungen anstellen. Dabei ist auf die von Piper gemachte Erfahrung besonders zu achten, dass der Verlauf des Anstiegs der Empfindlichkeit abhängig ist von dem Reizzustand, in welchem sich das betr. Auge vor Beginn des 
Dunkelaufenthaltes befunden hat. Wenn wir bei Belichtung des einen Auges das zweite sich dunkeladaptieren lassen, so darf auf keinen Fall während des Fortnehmens und des Wiederanbringens des lichtschützenden Verbandes und weiter durch die Schwellenbestimmung (welches alles naturgemäss im Dunkeln nach Abstellung der Belichtung des einen Auges zu geschehen hat) längere oder auch nur kürzere Zeit verstreichen, in welcher beide Augen obne eine gegenseitige hemmende Beeinflussung in ganz normaler Weise dunkeladaptieren können. Das während dieser Zeit der binokularen Verdunklung in dem zu untersuchenden Auge gewonnene Plus an Sehpurpur wird, wie die Révész'schen Untersuchungen einwandfrei ergeben, auch durch eine maximale Belichtung des zweiten Auges nicht verringert. Es darf daher njcht wundernehmen, dass bei einer solcher Versuchsanordnung irgendeine grössere Beeinflussung nicht nachgewiesen werden konnte.

Ich habe deswegen bei meinen Untersuchungen ein konstantes Reizlicht vor dem einen Auge angebracht, dieses dann lichtdicht nach aussen verschlossen und das auf seine Dunkeladaptation zu untersuchende Auge frei gelassen. So wurde ich aut keine Weise bei den Schwellenbestimmungen behindert. Die Lichtquelle, welche vor das eine Ange vorgebunden wurde, bestand in einer kleinen Glühbirne, die in einem runden, schachtelähnlichen und lichtdicht nach allen bis auf die dem Auge zugekehrte Seite abschliessenden Gehäuse angebracht war. Die dem Auge zugekehrte Öffnung kann durch eine Blende beliebig vergrössert oder verkleinert werden, sie ist durch eine Milchglasscheibe bedeckt. Durch einen in den Stromkreis eingeschlossenen Rheostaten war ich ausserdem in der Lage, die Intensität des Reizlichtes beliebig zu variieren. Die Entfernung der hinter der Blende befindlichen Milchglasscheibe vom Auge ist so gross, dass selbst intensivere Helligkeiten keine übermässige und dem Auge unangenehme Hitze entwickeln, dennoch ist es vorteilhaft, durch ein geeignetes Wattepolster die Entfernung des Gehäuses von dem Auge zu vergrössern. Das Gehäuse muss nun mittels eines durch schwarze Stoffe noch besonders lichtdicht gesicherten Verbandes so vor dem Auge angebracht werden, dass das Lid sich ohne jede Behinderung bewegen kann. Der Patient ist aufzufordern, die beiden Augen andauernd geöffnet zu halten.

Meine sämtlichen Untersuchungen sind des Nachmittags oder des Abends gemacht, in keinem Falle bestand also vor dem Beginne des Dunkelaufenthaltes eine maximale Helladaptation, wie sie 
bei den von Piper aufgestellten Normalkurven als Ausgangspunkt diente.

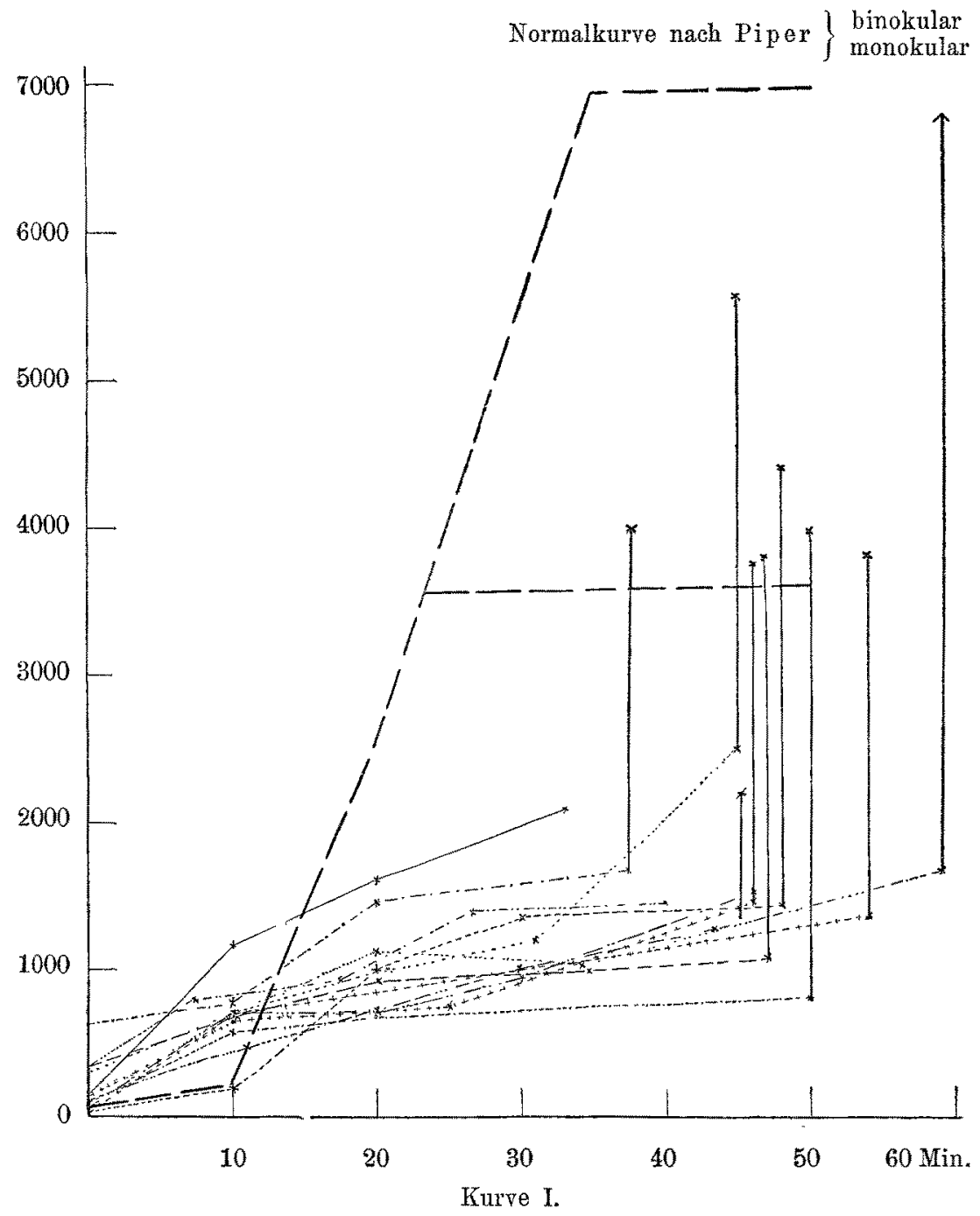

Anstieg der Empfindlichkeit des Stäbchenapparates des einen Auges bei Dunkelaufenthalt und gleichzeitiger Belichtung des andern Auges.

Die Empfindlichkeitswerte der parazentralen Netzhautpartien (nach einem Dunkelaufenthalt von ungefähr $40-60 \mathrm{Min}$.) sind durch eine senkrechte Linie mit den Empfindlichkeitswerten der nasalen Netzhaut perip herie desselben Auges verbunden, welcher im belichteten andern Auge keine korrespondierende Stelle entspricht.

Nach dem Vorgange Pipers babe ich die Empfindlichkeitszunahme des einen Auges während der Dunkeladaptation in Kurvenform aufgezeichnet und die Befunde bei den verschiedenen Unter- 
suchten zusammengestellt. Zum Vergleich habe ich die Pipersche Normalkurve bei monokularer und binokularer Dunkeladaptation mit hineingezeichnet.

Aus meinen Kurven geht nun zunächst hervor, dass der Empfindlichkeitsanstieg während der ersten Minuten des Dunkelaufenthaltes schneller vor sich geht, als wie sie die Pipersche Normalkurve zeigt. Zu erklären dürfte diese Differenz durch den. Unterschied in

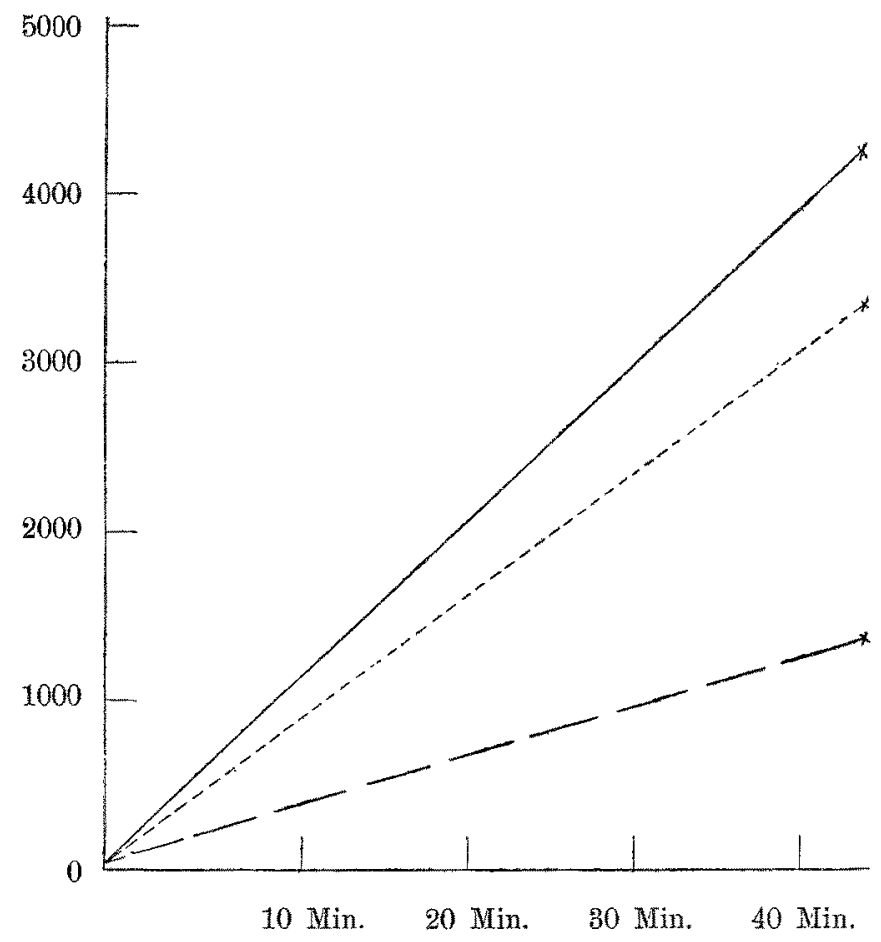

Kurve II.

Mittelwerte des nach 45 Minnten erreichten Empfindlichkeitsmaximums der Kurve I. _— Empfindlichkeitswerte der nasalen Netzhantperipherie des unbelichteten Auges. - - Empfindlichkeitswerte der parazentralen Bezirke desselben Auges. - Normalkurve nach Piper.

der Grösse der Helladaptation vor Beginn des Dunkelaufenthaltes sein, welche, wie oben erwähnt, bei Piper maximal, bei meinen Untersuchungen jedoch relativ niedrig war.

Im weiteren Verlauf der Kurven meiner Untersuchungen fehlt dann jede gröbere Knickung, wie sie die Normalkurve bei Beginn und nach Beendigung des plötzlichen steilen Empfindlichkeitsanstiegs aufweist. 
Reflexcharakter d. Adaptationsvorgínge, insbes. d. Dunkeladaptation usw. 273

Diese normalerweise plötzliche und sehr erhebliche Empfindlichkeitszunahme fällt also fort, wenn das andere Ange gleichzeitig dauernd belichtet wird. Die Zunahme erfolgt nur langsam und ziemlich gleichmässig, wie es die Kurven in ihrem relativ gerade ansteigenden Verlauf zeigen.

Wenn wir die Empfindlichkeiten vergleichen, welche sich ergeben nach Beendigung des steilen Anstiegs der Normalkurve, also nach einem Dunkelaufenthalt von 45 Minuten, so sehen wir, dass durch gleichzeitige kontinuierliche Belichtung des andern Auges die Empfindlichkeit um etwa die Hälfte geringer ist als unter normalen Verhältnissen bei binokolarer Dunkeladaptation und monokularer Schwellenbestimmung.

Ein Einwand, der diesen Untersuchungen möglicherweise gemacht werden könnte, erfordert noch ein kurzes Eingehen. Man kann annehmen, dass bei der grossen Differenz der jedem einzelnen Auge gebotenen Reizmengen eine gegenseitige Beeinflussung im Sinne des Fechnerschen paradoxen Versuches (allerdings in einer modifizierten Auffassung) eintreten könne. Der überwiegende Reiz, der dem konstant belichteten Auge zufliesst, könnte bei der psychischen Trennung der Eindrücke beider Augen sich in einer Herabsetzung der Perzeptionsfähigkeit derjenigen Elemente des optisehen Bewusstseins äussern, welchen die minimalen Reize des dunkeladaptierenden Auges zufliessen, so dass dadurch deren Schwellenwert steigt. Die Révész'schen Untersuchungen dürften jedoch, wie schon erwähnt, einen solchen Einwurf widerlegen. Trotzdem habe ich bei meinen Untersuchungen auf ihn Rücksicht genommen und die ausschlaggebende Schwellenbestimmung immer nach Abstellung der Belichtung des gereizten Auges vorgenommen. Der Vergleich der auf diese Weise gewonnenen Schwellenwerte mit den bei bleibender Lichtreizung des andern Auges aufgenommenen ergab keine irgendwie in Betracht kommenden Differenzen.

Diese Untersuchungen zeigen also, dass durch gleichzeitige Lichtreizung des einen Auges die Dunkeladaptation bzw. die Stäbchenfunktion des andern Auges eine erhebliche Beeinträchtigung im Sinne einer Hemmung erfährt.

Ich habe dann weitere Untersuchungen darüber angestellt, ob unter denselben genannten Versuchsbedingungen in dem dunkeladaptierenden Auge ein Unterschied in der Empfindlichkeitszunahme besteht zwischen denjenigen Netzhautteilen, welchen im andern Auge 
korrespondierende Teile entsprechen, und den peripheren nasalen Netzhautteilen, welche in der temporalen Hälfte des andern Auges fehlen, Von zwei homonymen Gesichtsfeldhälften hat bekanntlich jeder einzelne Punkt einen identischen im andern Auge bis zu einer Excentrizität von zirka $60^{\circ}$, der darüber hinausliegende Bezirk der temporalen Gesichtsfeldhälfte fehlt in der homonymen nasalen Hälfte des andern Auges (siehe Fig. 11).

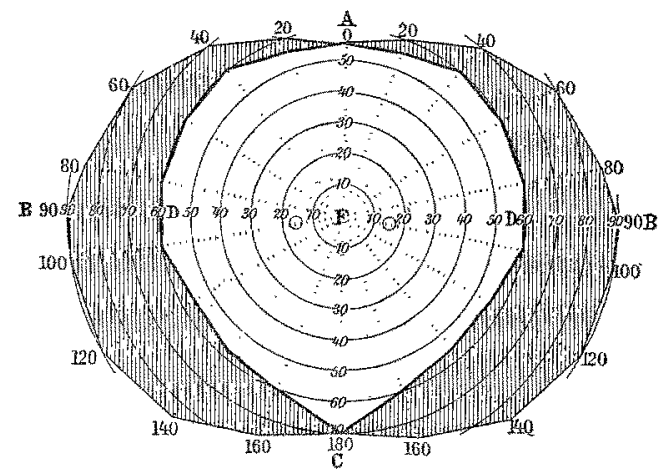

Fig. 11. Binokulares Gesichtsfeld nach Förster.

$A B C$ stellt die temporale Gesichtsfeldhälfte des linken Auges und $A D C$ die homonyme nasale Gesichtsfeldhälfte des rechten Auges dar. Werden beide übereinander gelagert wie in der Figur, so ergibt sich, dass der Beziris $A B C D$ nur in der temporalen Gesichtsfeldhälfte des ilinken Auges vorhanden ist, und dass er in der homonymen nasalen Halfte des andern Auges fehlt. Dementsprechend hat also die nasale Netzbanthälfte in der Peripherie einen Bezirk, für welchen korrespondierende Teile im andern Auge nicht vorhanden sind. Die zentrale Faserverbindung dieses Bezirkes der temporalen Hälfte wird daher ohne eine Anlagerung von Fasem des andern Auges verlaufen, im Gegensatz zu den übrigen von korrespondierenden Netzhautpunkten kommenden Fasern, die von beiden Augen kommend sich im Tractus aneinander legen.

Nachdem ich die Beeinflussbarkeit der Dunkeladaptation des einen Auges durch konstante Belichtung des andern nachgewiesen hatte, war daher die Frage naheliegend, ob sich diese nicht auch an dem einen dunkeladaptierenden Auge durch einen Untersehied in der Empfindlichkeitszunahme dieser beiden verschiedenartigen Netzhautpartien der temporalen Hälfte zeigen würde.

Die Untersuchungen wurden nun in derselben Weise vorgenommen, dass das eine Auge unter einem lichtdichten Verband beleuchtet wurde, während an dem freibleibenden, dunkeladaptierenden andern in verschiedenen Zwischenräumen Schwellenbestimmungen vorgenommen wurden. Nach dreiviertelstündigem oder längeren Dunkelaufenthalt wurde an unserem Adaptationsperimeter nach Feststellung der zentralen Reizschwelle die Schwelle in einer Excentrizität von $30^{\circ}$ und 
Fon $70^{\circ}$ genau bestimmt. Die Art der Untersuchung war dieselbe wie in früher erwähnten Untersuchungen, nur mit dem Unterschied, dass wir hier im allgemeinen auf die Anwendung eines schwach leuchtenden roten Fixationspunktes verzichteten, weil dieser bei derartig genauen Einstellungen sehr leicht durch das Überwiegen seines hochschwelligen zentralen optischen Eindrucks die Aufmerksamkeit von den peripher einwirkenden minimalen Reizen abziehen kann. Aus demselben Grunde habe ich während dieser vergleichenden Schwellenbestimmungen immer auch das vorher belichtete zweite Auge verdunkelt.

Vor Beginn der Untersuchung wurden die betr. Personen jedesmal genau darauf eingeübt, den gedrückten und in eine grössere Excentrizität am Perimeter gebrachten Finger zu fixieren und dabei gleichzeitig die Veränderungen an der Milchglasscheibe des Adaptometers zu beobachten.

In allen Fällen fand ich nun, dass die Empfindlichkeit der peripheren temporalen Gesichtsfeldteile, welche keine Beziehungen zu dem belichteten andern Auge haben, ganz bedeutend diejenige der zentralen und in mittlerer Excentrizität gelegenen übertraf. Die Peripheriewerte erreichen durchaus die normale, bei doppelseitiger Dunkeladaptation und monokularer Untersuchung gefundene Höhe.

Der Unterschied zwischen dem Schwellenwert der ganz excentrischen temporalen und den in mittlerer Excentrizität bzw. zentral gelegenen Partien war den betreffenden Untersuchten so deutlich, dass von jedem einzelnen nach Wiederherstellung der Helladaptation mit absoluter Genauigkeit der jenseits von $60^{\circ}$ nasal von dem untersuchten Auge gelegene Teil des Perimeterbogens als derjenige Bezirk angegeben wurde, bei dessen Fixation während des Dunkelaufenthaltes die Beobachtungsscheibe des Adaptometers am deutlichsten gesehen worden war.

Ich möchte jedoch ausdrücklich betonen, dass die Einstellungen der Schwellen sehr genau gemacht werden müssen. Dabei sind die Untersuchten aufufordern, nur soweit den Kopf nach der nasalen Seite zu drehen, als sie es zur Vermeidung von Ermüdungen bei zu extremer Seitenwendung der Augen für nötig erachten. Die Augenlider müssen nach Möglichkeit auseinander gezogen werden, um die Blendenwirkung des äusseren Lidwinkels auszuschalten, da nach den Untersuchungen Pipers, wie schon erwähnt, der Gesichtswinkel, unter dem beobachtet wird, von grosser Bedeutung für die Empfindlichkeitszunahme ist. Hat man die Schwelle für die tempo- 
rale Gesichtsfeldperipherie $\left(60^{\circ}-70^{\circ}\right)$ genau eingestellt, so kann man abwechselnd diese Partie und dio in mittlerer Excentrizität gelegenen auf die Beobachtungsseheibe einstellen. Man findet dann, dass die Scheibe verschwindet, wenn man mit mittlerer Excentrizität beobachtet, und dass sie sofort wieder aultaucht, wenn man die peripheren Partien einstellt.

Tch habe diese Befunde in die Kurve mit eingetragen und die Empfindlichkeitswerte der Peripherie mit den parazentral gefundenen durch eine Linie verbunden. Diese Befunde sind um so bemerkenswerter, als unter normalen Verbältnissen der Unterschied in der Empfindlichkeit gerade umgekehrt ist, insofern als die Teile mittlerer Excentrizität das Empindlichkeitsmaximum aufweisen (s. 0.).

Aus diesem Befund an einem und demselben Auge geht meines Erachtens einwandsfrei hervor, dass die Stäbchenfunktion bzw. die Regeneration des Sehpurpurs nicht ein reiner retinaler Prozess sein kann, sondern dass sie in einem ganz bestimmten Abhängigkeitsverhältnis zu einem höheren (subcerebralen) Zentrum steht.

Ich habe schliesslich noch eine Reihe von Untersuchungen zur Entscheidung der Frage angestellt, wie sich der durch Dunkeladaptation beider Augen erreichte monokulare Schwellenwert durch das Einschalten einer Belichtung des andern. Auges in bezug auf seinen weiteren Anstieg verbält. Zunächst fand ich in Übereinstimmung mit den Révész'schen Befunden, dass eine Herabsetzung der Empfindlichkeit in keinem Fall eintritt. Im übrigen ist der weitere Anstieg nach Einschalten der Belichtung des andern Auges durchaus von dem Zustand abhängig, in welchem sich in dem betreffenden Augenblick die Dunkeladaptation befand. Hatte sie annähernd das Maximum am Ende des steilen Anstiegs erreicht, so fehlte jeder weitere Anstieg, in den andern Fällen zeigte sich, dass der weitere Anstieg in ganz derselben Weise erfolgte, wie in den Fällen, in welchen die einseitige Belichtung zugleich mit dem Beginn der Dunkeladaptation des andern Auges einsetzte.

Wenn wir uns jetzt fragen, ob auch andere physiologische Tatsachen vorhanden sind, welche für eine funktionelle Abhängigkeit der beiden Netzhäute von einander oder, mit andern Worten, für eine gegenseitige nervöse Beeinflussung durch Vermittlung eines höheren Zentrums sprechen, so bedarf es nur eines Hinweises auf die bekannten Engelmannschen Untersuchungen an Froschaugen über die Pigmentwanderung und die Zapfenverkürzung, welche in 
dem abgedunkelten Ange durch isolierte Lichtreizung des andern eintreten. Nach ihm ist die gegenseitige Beeinflussung durchaus an das Erhaltenbleiben des Gehirns gebunden. Diese Befunde Engelmanns werden allerdings durch Fick angezweifelt, der auch dann eine Pigmentwanderung hat nachweisen können, wenn der Optikus des nicht belichteten Auges durchschnitten war. Bedeutungsvoller scheint mir eine weitere Beobachtung Engelmanns und van Genderen Storts zu sein, nämlich die, dass bei Reizung eines Sehnerven durch Belichtung oder durch chemische Mittel nicht nur in diesem, sondern ebenso in dem Optikus des andern nicht gereizten Auges Aktionsströme als Zeichen einer nervösen Erregung auftreten. Nahmacher hat dann Untersuchungen dariiber angestellt, ob durch Reizung des Optikusquerschnittes mit Kochsalzlösung eine Veränderung der Zapfen hervorgerufen werden kann, und hat dieses einwandsfrei nachweisen können. Er sieht daher in seinen Befunden einen Beweis für das Vorhandensein zentrifugaler Fasern im Optikus. Tatsächlich sind auch bestimmte Fasern im Optikus durch Dogiel und Ramon y Cajal anatomisch nachgewiesen, welche von diesen Forschern als zentrifugale angesprochen werden.

Diese verschiedenartigen und im gleichen Sinne sprechenden Befunde stehen durchaus im Einklang mit meinen Untersuchungen und erfahren durch sie anderseits eine weitere Stütze und Ergänzung.

Die Annahme eines höheren nervösen Zentrums für die Stäbchenfunktion bzw. die Sehpurpurregeneration dürfte damit eine ausreichende Begründung durch physiologische und klinische Untersuchungen haben.

\section{Zur Theorie der Stäbchenfunktion.}

Von grosser Bedeutung für unsere Auffassung der Dunkeladaptation als Funktion des Stäbchenapparates scheinen mir die Untersuchungen von Rabinowitsch zu sein. Derselbe untersuchte den Einfluss, welchen nach einer maximalen binokularen Dunkeladaptation eine kürzer oder länger dauernde, plötzlich einsetzende Belichtung beider Augen auf den erreichten Schwellenwert hat. Aus seinen Befunden geht hervor, dass die Veränderung des Schwellenwerts, der durch die voraufgegangene Dunkeladaptation erreicht war, direkt abhängig ist von der Dauer dieser dazwischengeschalteten Belichtung. Je kürzer dieselbe war, um so weniger änderte sich der Schwellenwert und um so schneller wurde der vor dem Einsetzen der Belichtung vorhandene Wert wieder erreicht. Nach einer be- 
stimmten nicht übermässig langen Dauer der Belichtung war der Zustand erreicht, der vor dem Beginn des Dunkelaufenthaltes überhaupt vorhanden war, d. h. der Verlauf des Wiederanstiegs der Emptindlichkeit war derselbe, als wenn keine längere Dunkeladaptation vorausgegangen wäre.

Aus diesen Befunden, welche ich zum Teil durch Nachuntersuchungen bestätigen kann, geht meines Erachtens hervor, dass sich durch die Belichtung ein Zustand der Retina entwickelt, welcher auf die Stäbchenfunktion bzw. auf die Sehpurpurbildung einen hemmenden Einfluss ausuibt. Die Grösse der Hemmung steht im direkten Verhältnis zu der Dauer der Einwirkung des Lichts. Nach einer gewissen Zeit ist das Maximum des hemmenden Einflusses erreicht. Da auch eine noch weiter getriebene Belichtung keine Änderung des Anstiegs der Empfindlichkeit bei Dunkelaufenthalt hervorzurufen vermag, dürfen wir auch aus dieser Beobachtung mit einiger Berechtigung annehmen, dass die Stäbchenfunktion im Stadium einer ausgiebigen Helladaptation vollkommen ruht. Wie ich schon erwähnte, hat Piper zuerst diesen Gedanken ausgesprochen.

Unsere ganze Vorstellung von der Stäbchentätigkeit, insbesondere ihrer Adaptationsfähigkeit, dürfte sich wesentlich vereinfachen, wenn wir die bis jetzt noch nicht widerlegten Befunde Lodatos einmal als erwiesene Tatsache annehmen, dass durch eine ausgiebige Helladaptation eine Änderung der chemischen Realtion der Netzhaut eintritt, insofern als diese aus einer alkalischen oder neutralen bei Dunkelaufenthalt durch Belichtung in eine saure tiberfuhrt wird. Nun ist es eine bekannte physiologische Tatsache, dass der Sehpurpur am leichtesten durch Säuren zersetzt wird, während Alkalien keine oder nur eine geringe Veränderung hervorrufen. Wenn wir - solange wir nichts anderes an die Stelle zu setzen haben - in dieser sauren Reaktion der Netzhaut eine hemmende Ursache für die Stäbchentätigkeit und die Sehpurpurneubildung annehmen, so werden uns die so plötzlich einsetzenden und gewaltigen Zustandsänderungen der vitalen Tätigkeit der Stäbchen einigermassen verständlich, besonders auch im Hinblick auf die Tatsache, dass die Empfindlichkeitssteigerung zunächst eine geringe ist und dam plötzlich viel stärker wird, trotzdem das Auge während der ganzen Zeit unter den gleichen äusseren Reizbedingungen gestanden hat: Durch eine gute Helladaptation steigt der Säuregehalt der Netzhaut auf ein Maximum und gibt dadurch Verunlassung zu einer maximalen Hemmung der Sehpurpurbildung, welche auch durch weiter andauerde Belichtung nicht mehr gesteigert werden kann. Wenn dann nach dem Beginn des Dunkel- 
aufenthaltes durch den Fortfall einer weiteren Lichtzersetzung der Säuregehalt der Retina langsam abnimmt durch allmähliche Bindung mittels der Alkalescenz des Blutes, so muss damit auch diese Hemmung geringer werden: Wir sehen die Emptindlichkeit für schwache Lichtreize langsam und gleichmässig ansteigen. Schliesslich wird derjenige Punkt erreicht sein, in welchem der ganze Säuregehalt gebunden ist, die Reaktion schlägt um oder sie wird neutral. In diesem Augenblick fällt jeder zentripetal geleitete bemmende Einfluss auf die die Sehpurpurbildung anregende Ganglienzelle fort, was zu einer energischen Produktion von Sehpurpur Veranlassung geben muss: Die Empfindlichkeit der Netzhaut steigt daher ganz plötzlich und gewaltig an. Ebenso rasch wird aber das Stoffwechselgleichgewicht in den Stäbchen bzw. dem Pigmentèpithel hergestellt sein: die Sehpurpurneubildung geschieht von jetzt ab in einem ganz bedeutend verlangsamten Tempo. Der steile Anstieg der Empfindlichkeit erreicht also ein Maximum, von dem, ebenfalls ganz plötzlich, nur ein ganz langsamer weiterer Anstieg erfolgt.

Mit dieser Theorie können wir die auffallenden spezifischen Eigentümlichkeiten der Stäbchentätigkeit in ungezwungener Weise erklären.

\section{Ergebnisse.}

Der Ablauf der Empfindlichkeitszunahme des Stäbchenapparates eines Auges bei Dunkelaufenthalt wird (beim Normalen) durch gleichzeitige kontinuierliche Belichtung des andern Auges stark beeinflusst. Der plötzlich einsetzende steile Anstieg der Empfindlichkeit nach den ersten Minuten des Dunkelaufenthaltes fällt hierbei vollkommen aus. Er vollzieht sich in diesem Fall vielmehr langsam und relativ gleichmässig. Der nach dreiviertelstündigem Dunkelaufenthalt erreichte Endwert der Empfindlichkeit ist dann ungefähr um die Hälfte geringer, als der nach binokularer Dunkeladaptation erreichte und monokular bestimmte Wert.

Unter den genannten Verhältnissen findet sich dabei ein bedeutender Unterschied zwischen dem Schwellenwert der peripheren nasalen Netzhautteile, für welche in der homonymen temporalen Netzhauthälfte des andern belichteten Auges korrespondierende Stellen nicht vorhanden sind, und dem Schwellenwert der übrigen Netzhautbezirke, denen identische Stellen im andern Auge entsprechen. 
Eine Herabsetzung der Empfindlichkeit des Stäbchenapparates ist lediglich in denjenigen Teilen vorhanden, welche durch korrespondierende Punkte in Beziehung zu dem andern belichteten Auge stehen, nicht aber in der nasalen Netzhatperipherie, in denen eine solche Beziehung fehlt und deren Empfindlichkeitszunahme vollkommen normal ist.

Bei Optikusatrophien kann trotz normaler Sehschärfe und eines auch für Farben normalen bzw. annähernd normalen Gesichtsfeldes die Stäbchenfunktion hochgradig gestört sein.

Ebenso kann bei Chiasmaerkrankungen in den nicht affizierten Gesichtsfeldhälften trotz normaler Grenzen für Weiss und Farben die Stäbchenfunktion hochgradig herabgesetzt sein.

Nach dem bis jetzt vorliegenden Material ist die Annahme wohl begründet, dass diese Herabsetzung in beiden Fällen vorzugsweise durch entzündliche und entzündlich degenerative Prozesse hervorgerufen wird, während die durch einfache Kompression deletär einwirkenden weniger die Dunkeladaptation (die Stäbchen) als die Sehschärfe und den Farbensinn (die Zapfen) schädigen.

Bei inkompletten relativen Tractushemianopsien kann in den Gesichtsfeldteilen der erkrankten Hälften, in welchen sich die Zapfenfunktion zum Teil wieder hergestellt hat, die Funktion der Stäbchen mebr oder weniger hochgradig beeinträchtigt sein.

Unter denselben Verhältnissen fehlt dagegen bei intracerebral bedingten inkompletten relatiren Hemianopsien trotz vorhandener Störungen des Farbensinns jede Beeinträchtigung der Dunkeladaptation.

Durch die Untersuchung der Dunkeladaptation sind wir daher im stande, in manchen Fällen eine Störung der basalen optischen Leitungsbahn festzustellen, bevor diese durch unsere andern üblichen Untersuchungsmethoden nachweisbar ist.

Anderseits kann bei inkompletten und relativen homonymen Hemianopsien der Nachweis einer Störung der Dunkeladaptation in den relativ noch funktionstüchtigen Bezirken der relativ ausgefallenen Gesichtsfeldhälften für die An- 
Reflexcharakter d. Adaptationsyorgänge, insbes. d. Dunkeladaptation usw. 281

nahme einer Läsion des Tractus bzw. des Corpus genicul. laterale, im Gegensatz zu intracerebralen Prozessen, verwertet werden und umgekehrt.

Aus den angefuhrten Resultaten der klinischen und physiologischen Untersuchungen ergibt sich der berechtigte Schluss, dass die Stäbchenfunktion bzw. die Regeneration des Sehpurpurs ron einem höheren, mutmasslich zwischen Tractus opticus und der intracerebralen Leitungsbahn gelegenen Zentrum aus geleitet wird. Die Annahme ist wohl begründet, dass die zentripetalen Bahnen der Stäbchen zweier homonymer Netzhauthälften in einem ähnlichen Lagerungsverhältnis wie die Zapfenfasern in ein solches Zentrum einstrahlen, von welchem zentrifugale Bahnen zu den Stäbchen bzw. dem Pigmentepithel zuräckgehen, welche auf die Sekretion des Sehpurpurs regulierend einwirken.

Ein bedeutender Vorzug der Funktionsprüfung der Stäbchen vor der der Zapfen liegt darin, dass wir mit bedeutend grösserer Genauigkeit zahlenmässig die Empfindlichkeit und damit die Funktion desselben feststellen und vergleichen können, als wir es bei der Prüfung der empfindlichsten Funktion des peripheren Zapfenapparates, des Farbensinns, vermögen.

Trotz einer hochgradigen Herabsetzung der Dunkeladaptation, i. e. der Stäbchenfunktion können auch die geringsten hemeralopischen Beschwerden fehlen, anderseits können ausgesprochene hemeralopische Beschwerden vorhanden sein, ohne dass sich die geringste Störung der Stäbchenfunktion vorfindet. Die Hemeralopie dürfte demnach direkt mit einer Erkrankung des Stäbchenapparates nichts zu tun haben und vielmehr auf Störungen der $Z$ apfenfunktion in noch nachauweisender Form zurückzuführen sein.

Den Elementen des Stäbchenapparates kommt eine nennenswerte pupillomotorische Valenz nicht zu.

Die neu mitgeteilten Fälle von Tractushemianopsie weisen sämtlich das Symptom der ausgesprochenen Anisokorie und Lidspaltendifferenz mit der weiteren Pupille und Lidspalte auf der mit der Hemianopsie gleichnamigen Seite auf, während diese bei intracerebralen Hemianopsien fehlt. 
Meine früher mitgeteilte Annahme von dem topisch diagnostischen Wert dieses Symptoms dürfte dadurch eine weitere Stütze erfahren.

\section{Literaturverzeichnis.}

Aubert, Physiologie der Netzhant. Breslau 1865.

Charpentier, Expériences sur la marche de l'adaptation rétinienne. Arch. d'opht. VI. p. 294.

- La sensibilité lumineuse ef l'adaptation. Ibidem p. 196.

- Nouveaux faits sur la sensibilité lumineuse. Ibidem. VII. p. 13.

Engelmann u. van Genderen Stort. Pflügers Arch. $f$ d. gesamte Physiol. Bd. XXXV. S. 458.

Garten, Die Veränderungen der Netzhaut durch Licht. Graefe-Saemisch. Bd. III, 1 .

van Genderen Stort. v. Graefe's Arch, f, Ophth. Bd. XXXII, 2.

Hering, Zur Lehre yom Lichtsinn. Wien 1878.

- Grundzüge der Lehre rom Lichtsinn. Graefe-Saemisch, Handb. d. ges. Augenheilk.

Hess, Untersuchungen über Hemeralopie. Arch. f. Augenheilk. Bd. LII.

Heinrichsdorff, Die Störungen der Adaptation und des Gesichtsfeldes bei Hemeralopie. Arch. f. Ophth. Bd. LX, 3.

Horn, Ober Dunkeladaptation bei Angenhintergrundserkrankungen. Inaug:Dissert. Tübingen 1907.

v. Kries, Die Gesichtsempfindungen. Nagels Handb. d. Physiol. d. Menschen.

Lodato, Contributo alla fisiologia di retinn. Arch. di ottalm. VII.

Loeser, Uber den Einfluss der Dunkeladaptation auf die spezifische Farbensehwelle. Zeitschr. A. Psychol. u. Physiol. der Sinnesorgane. Bd. XXXVI. S. 1.

- Über die Beziehungen zwischen Flächengrösse und Reizwert leuchtender Objelte, Beitr. zur Augenheilk. Festschrift f. Hirschberg.

Lohmann, Untersuchungen über Adaptation und ihre Bedeutung für Erkrankungen des Augenhintergrundes. v. Graefe's Arch. f. Ophth. Bd. LXV, 3.

- Über Helladaptation. Ber. đ. Heidelberger Ophth. Ges. 1906.

Messmer, Über die Dunkeladaptation bei Hemeralopie. Zeitschr. f. Sinnesphysiol. Bd. XLII, 2.

Nahmacher, Uber den Einfuss reflektorischer und zentraler optikusreizung auf die Stellung der Zapfen in der Froschnetzhaut. Pfl hagers Arch. d. ges. Physiol. Bd. LIII.

Nagel, Einige Beobachtungen über die Wirkung des Druckes und des galvanischen Stroms auf das dunkeladaptierte Auge. Zeitschr. f. Psych. u. Physiol. d. Sinnesorg. Bd. XXXIV.

- Handb d. Physiol. d. Menschen. Bd. III. Braunschweig 1905.

- u. Schäfer, Über das Verhalten der Netzhautzapfen bei Dunkeladaptation des Auges. Ebenda Bd. XXXIV.

Nicolai, Über den Gang der Dunkeladaptation und seine Abhängigkeit von der vorausgegangenen Belichtung. Zentralbl. f. Physiol. Bd. XXI.

Piper, Cber Dunkeladaptation. Zeitschr. f. Psychol. u. Physiol. d. Sinnesorg. Bd. XXXI. S. 161.

- Über die Abhängigkeit des Reizwertes lenchtender Objekte von ihrer Flächenbzw. Winkelgrösse, Ibidem. Bd. XXXIl. S. 98.

- Über das Helligkeitsverhältnis monokular und binokular ansgelöster Lichtempindungen. Ibidem. Bd. XXXII. S. 161.

- Über die Funktionen der Stäbchen and Zapfen und über die physiologische Bedenting des Sehpurpurs. Med. Klin. 1905.

- Zur messenden- Untersuchung und zur Theorie der Helldunkeladaptation. Klin. Monatsbl, f' Angenhéilk. Bd. XEY. S. "357. 
Reflexcharalter d. Adaptationsvorgänge, insbes. d. Dunkeladaptation usw. 283

Rabinowitsch, Über den Gang der Schwellenempindlichkeit bei Dunkeladaptation und seine Abhängigkeit von der vorausgegangenen Belichtung. Zeitsehr. f. Augenheilk. Bd. XIX. S. 301.

Révész, Wird die Lichtempfindlichkeit eines Auges durch gleichzeitige Lichtreizung des andern Auges verändert. Zeitschr. f. Psychol. u. Physiol. d. Sinnesorg. Bd. XXXIX.

Schirmer, Über die Adaptation im gesunden und kranken Auge. Verhandl. d. X. intern. med. Kongr. in Berlin. Bd. IV, 2.

Stargardt, Über Störungen der Dunkeladaptation. v. Graefe's Arch. f. Ophth. Bd. LXXIII, 1.

Treitel, Über den Lichtsinn der Netzhautperipherie. v. Graefe's Arch. f. Ophth. Bd. XXXV, 1.

Trendelenburg, Über die Bleichung des Sehpurpurs mit spektralem Licht in ihrer Abhängigkeit von der Wellenlänge. Zentralbl. f. Physiol, 1904.

Wilbrand-Saenger, Die Neurologie des Auges. Bd. III u. IV, 1. Wiesbaden 1904 น. 1909.

Erklärung der Abbildungen auf Taf. VIII u. IX, Fig. 1-4.

Fig. 1. Eisenhämatoxylin-van Gieson-Fürbung nach Weigert.

Narbige Verwachsung des rechten äusseren Chiasmawinkels mit der Carotis interna, Abplattung der Oberfläche, Narbenbildung in den peripheren Partien des Chiasma an dieser Stelle. Abplattung und Umknickung der linken Halfte, deren Oberflache ebenfalls bindegewebige Verwachsungen mit den anliegenden Gefässen aufweist. Kleinzellige Infiltration der weichen Hirnhäute des Chiasma nit stellenweiser Verdickung derselben. Endo- und Periarteriitis der umliegenden Gefässe. Leichte kleinzellige Infiltration im Parenchym des Chiasma, hochgradige um die umliegenden Gefässe.

Fig. 2. Stärkere Vergrösserung. Partie aus dem unteren Teil der rechten Chiasmahälfte. Leichte kleinzellige Infiltration im Parenchym, hochgradige um die Gefisse. Leptomeningitis mit Nenbildung von bindegewebigen, ins Parenchym eintretenden Strängen. Endo- und Periarteriitis.

Fig. 3. Markscheidenfärbung nach Kulschitzki. Schnitt aus der gleichen Höhe wie in Fig. 1.

Fig. 4. Eisenhämatoxylin-van Gieson-Färbung nach Weigert.

Rechter Optikus zwischen Foramen optieum und Chiasma: An der Carotis hochgradige Endarteriitis mit teilweiser Verdoppelnng der Elastica. An einer Stelle ist diese rupturiert: erster Beginn eines Aneurysma. Am Optikus findet sich diffus eine kleinzellige Infiltration, eine Atrophie in den peripheren Bündeln und eine leichte Perineuritis. 


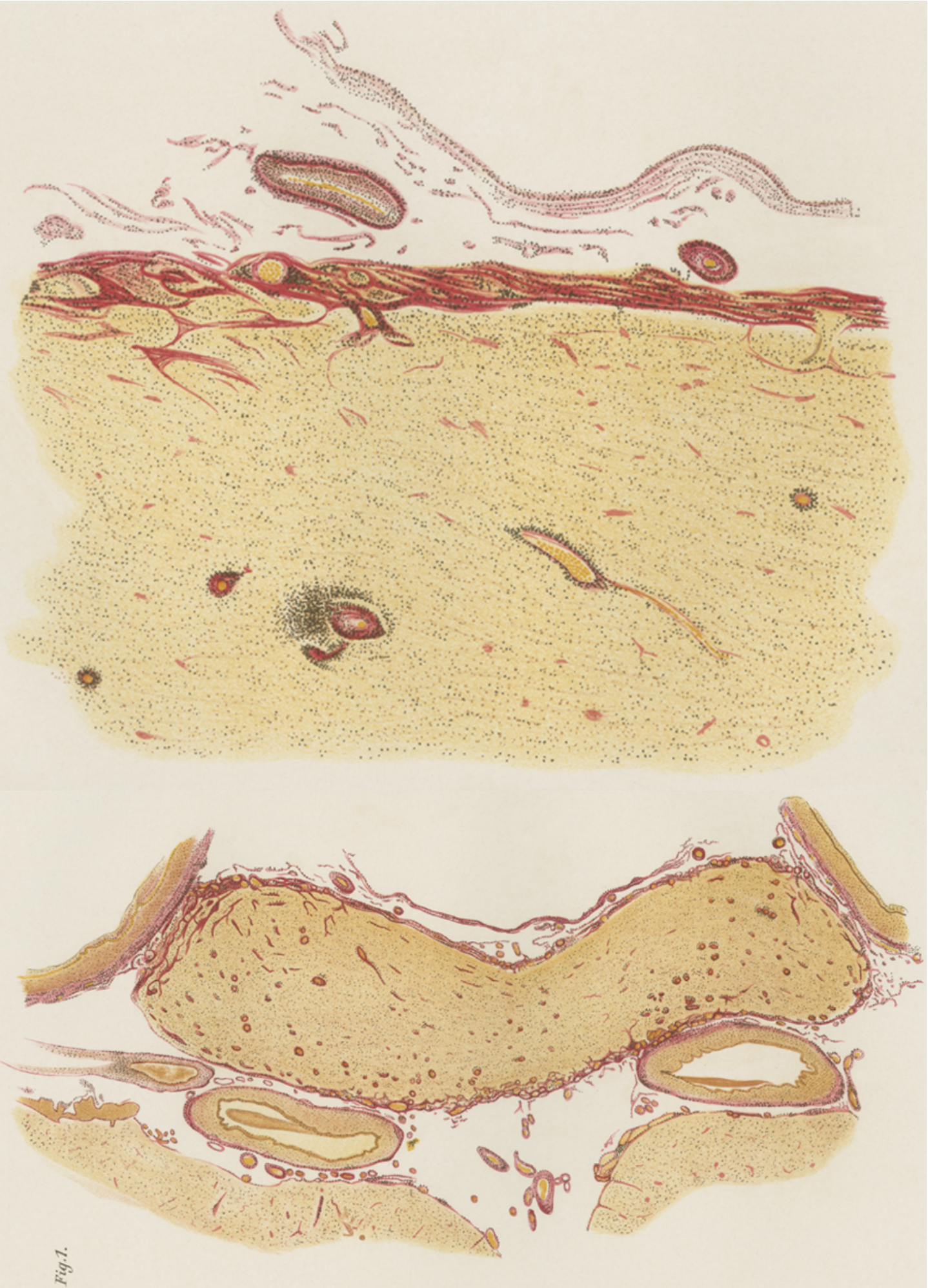


t
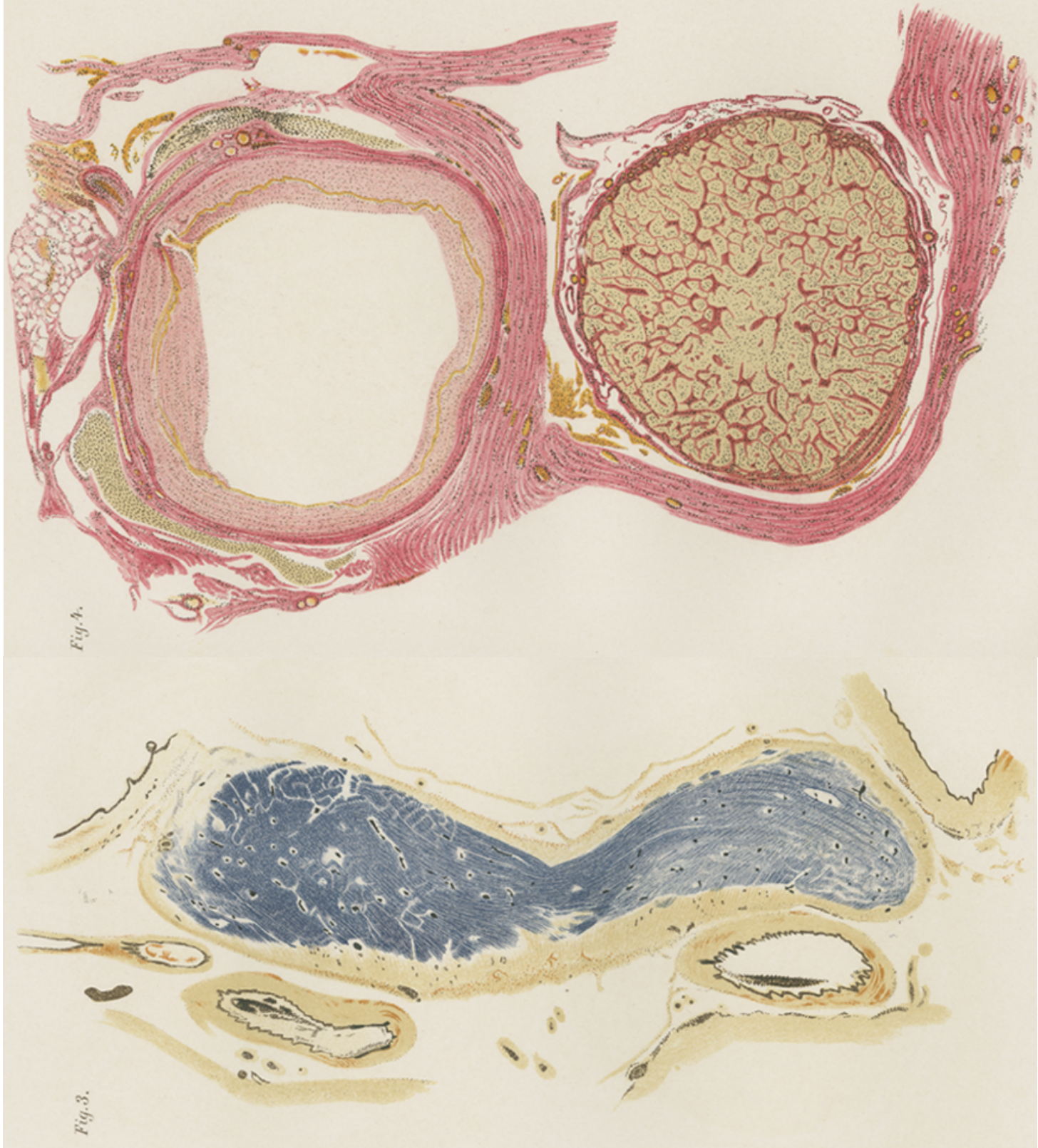